\title{
DISPONIBILIDADE DE ENERGIA E NUTRIENTES PARA A POPULAÇÃO DAS REGIÕES METROPOLITANAS DE RECIFE E SÃO PAULO
}

\author{
CÉLIA REGINA FERRARI FAGANELLO
}

\begin{abstract}
Dissertação apresentada à Escola Superior de Agricultura "Luiz de Queiroz, Universidade de São Paulo, para obtenção do título de Mestre em Ciências, Área de Concentração: Ciência e Tecnologia de Alimentos.
\end{abstract}

\author{
PIRACICABA \\ Estado de São Paulo - Brasil \\ Novembro - 2002
}




\title{
DISPONIBILIDADE DE ENERGIA E NUTRIENTES PARA A POPULAÇÃO DAS REGIÕES METROPOLITANAS DE RECIFE E SÃO PAULO
}

\author{
CÉLIA REGINA FERRARI FAGANELLO \\ Engenheiro Agrônomo
}

Orientadora: Profa. Dra. MARINA VIEIRA DA SILVA

\begin{abstract}
Dissertação apresentada à Escola Superior de Agricultura "Luiz de Queiroz, Universidade de São Paulo, para obtenção do título de Mestre em Ciências, Área de Concentração: Ciência e Tecnologia de Alimentos.
\end{abstract}

\author{
PIRACICABA \\ Estado de São Paulo - Brasil \\ Novembro - 2002
}


Dados Internacionais de Catalogação na Publicação (CIP) DIVISÃO DE BIBLIOTECA E DOCUMENTAÇÃO - ESALQ/USP

Faganello, Célia Regina Ferrari

Disponibilidade de energia e nutrientes para a população das regiões metropolitanas de Recife e São Paulo / Célia Regina Ferrari Faga nello. - - Piracic aba, 2002.

$113 \mathrm{p}$.

Dissertação (mestrado) - - Escola Superior de Agricultura Luiz de Queiroz, 2002.

Bibliografia.

1. Alimentos industrializados 2. Área metropolitana 3. Consumo a limentar 4. Sã o Pa ulo 5. Rec ife 6. Renda fa miliar I. Título

CDD 664

"Permitida a cópia total ou parcial deste documento, desde que citada a fonte - $\mathrm{O}$ autor" 
Ao meu amado pai, José Faganello

Aos meus queridos irmãos Marina, Alexandre e Adriano

À minha mãe, Márcia, que já não se encontra entre nós, mas que deixou seu espectro de luz e amor em nossas vidas

Dedico. 


\section{AGRADECIMENTOS}

À Escola Superior de Agricultura "Luiz de Queiroz", por ser minha escola da vida.

À $\operatorname{Prof}^{\mathrm{a}} \mathrm{Dr}^{\mathrm{a}}$ Marina Vieira da Silva, pela orientação, por tudo que me ensinou, e pela pessoa alegre, positiva e iluminada que é.

Ao Prof. Dr. Rodolfo Hoffmann, pela colaboração nas análises estatísticas.

Ao meu pai e aos meus irmãos Marina, Alexandre e Adriano por me ajudarem sempre, especialmente este último, meu grande companheiro.

À esposa de meu pai, Márcia, pelo amparo nas horas difíceis.

Às minhas queridas tias Elisabeth e Lélia, por torcerem sempre por mim.

À todos os professores e funcionários do Departamento de Agroindústria, Alimentos e Nutrição.

À Banca de Qualificação: Prof ${ }^{a} \operatorname{Dr}^{a}$ Marília Oetterer, Prof ${ }^{a} \operatorname{Dr}^{\mathrm{a}}$ Marta Helena Fillet Spoto e $\operatorname{Prof}^{\mathrm{a}} \mathrm{Dr}^{\mathrm{a}}$ Solange Guidolin Canniatti Brazaca pelas pertinentes sugestões.

A todas as Bibliotecárias pelo auxílio na correção das referências bibliográficas.

À querida amiga Maria Cecília da Silva pela amizade e companheirismo.

Às amigas Daniela Cristina Rosseto Caroba e Michele Sanches pela pronta disponibilidade para ajudar.

À todos que eu não mencionei e que contribuíram para a realização desse sonho, a minha mais profunda gratidão. 


\section{SUMÁRIO}

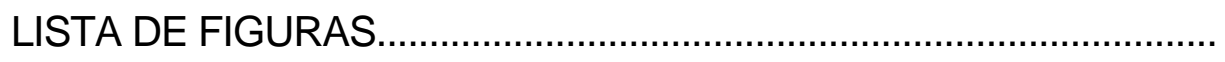

Página

LISTA DE QUADROS.

LISTA DE TABELAS.

$X$

RESUMO

$\mathrm{xi}$

xiii

SUMMARY.

xvi

1 INTRODUÇÃO

2 REVISÃO DE LITERATURA...

3 METODOLOGIA.

3.1 Base de dados.

3.2 Análise dos dados.

32

4 RESULTADOS E DISCUSSÃO.

36

5 CONCLUSÕES.

103

REFERÊNCIAS BIBLIOGRÁFIC AS.

106 


\section{LISTA DE FIGURAS}

Página

1 Variação da disponibilidade de folacina, no domicílio, de acordo com o recebimento familiar per capita, nas regiões metropolitanas

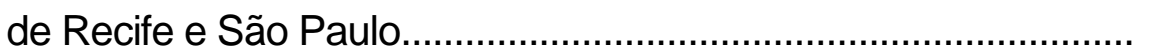

2 Variação da disponibilidade de niacina, no domicílio, de acordo com o recebimento familiar per capita, nas regiões metropolitanas de Recife e São Paulo.

3 Variação da disponibilidade de vitamina $B_{12}$, no domicílio, de acordo com o recebimento familiar per capita, nas regiões metropolitanas de Recife e São Paulo

4 Variação da disponibilidade de vitamina $B_{6}$, no domić́lio, de acordo com o recebimento familiar per capita, nas regiões metropolitanas de Recife e São Paulo

5 Variação da disponibilidade de vitamina $B_{2}$, no domić́lio, de acordo com o recebimento familiar per capita, nas regiões metropolitanas de Recife e São Paulo

6 Variação da disponibilidade de vitamina $B_{1}$, no domicílio, de acordo com o recebimento familiar per capita, nas regiões metropolitanas de Recife e São Paulo

7 Variação da disponibilidade de vitamina $C$, no domicílio, de acordo com o recebimento familiar per capita, nas regiões metropolitanas de Recife e São Paulo 
8 Variação da disponibilidade de vitamina $E$, no domicílio, de acordo com o recebimento familiar per capita, nas regiões metropolitanas de Recife e São Paulo

9 Variação da disponibilidade de vitamina $D$, no domicílio, de acordo com o recebimento familiar per capita, nas regiões metropolitanas de Recife e São Paulo

10 Variação da disponibilidade de retinol, no domicílio, de acordo com o recebimento familiar per capita, nas regiões metropolitanas de Recife e São Paulo.

11 Variação da disponibilidade de vitamina $A$, no domicílio, de acordo com o recebimento familiar per capita, nas regiões metropolitanas de Recife e São Paulo

12 Variação da disponibilidade de fibra, no domicílio, de acordo com o recebimento familiar per capita, nas regiões metropolitanas de Recife e São Paulo.

13 Variação da disponibilidade de colesterol, no domicílio, de acordo com o recebimento familiar per capita, nas regiões metropolitanas de Recife e São Paulo.

14 Variação da disponibilidade de lipídio insaturado, no domicílio, de acordo com o recebimento familiar per capita, nas regiões metropolitanas de Recife e São Paulo.

15 Variação da disponibilidade de lipídio total, no domicílio, de acordo com o recebimento familiar per capita, nas regiões metropolitanas de Recife e São Paulo

16 Variação da disponibilidade de proteína, no domicílio, de acordo com o recebimento familiar per capita, nas regiões metropolitanas de Recife e São Paulo.

17 Variação da disponibilidade de carboidratos, no domicílio, de acordo com o recebimento familiar per capita, nas regiões metropolitanas de Recife e São Paulo 
18 Variação da disponibilidade de energia, no domicílio, de acordo com o recebimento familiar per capita, nas regiões metropolitanas de Recife e São Paulo.

19 Variação da disponibilidade de ácido pantotênico, no domicílio, de acordo com o recebimento familiar per capita, nas regiões metropolitanas de Recife e São Paulo.

20 Variação da disponibilidade de sódio, no domicílio, de acordo com o recebimento familiar per capita, nas regiões metropolitanas de Recife e São Paulo.

21 Variação da disponibilidade de cálcio, no domicílio, de acordo com o recebimento familiar per capita, nas regiões metropolitanas de Recife e São Paulo.

22 Variação da disponibilidade de ferro, no domicílio, de acordo com o recebimento familiar per capita, nas regiões metropolitanas de Recife e São Paulo.

23 Variação da disponibilidade de fósforo, no domicílio, de acordo com o recebimento familiar per capita, nas regiões metropolitanas de Recife e São Paulo.

24 Variação da disponibilidade de zinco, no domicílio, de acordo com o recebimento familiar per capita, nas regiões metropolitanas de Recife e São Paulo.

25 Variação da disponibilidade de selênio, no domicílio, de acordo com o recebimento familiar per capita, nas regiões metropolitanas de Recife e São Paulo.....................................................................

26 Variação da disponibilidade de cobre, no domicílio, de acordo com o recebimento familiar per capita, nas regiões metropolitanas de Recife e São Paulo.

27 Variação da disponibilidade de iodo, no domicílio, de acordo com o recebimento familiar per capita, nas regiões metropolitanas de Recife e São Paulo. 
28 Variação da disponibilidade de potássio, no domicílio, de acordo com o recebimento familiar per capita, nas regiões metropolitanas

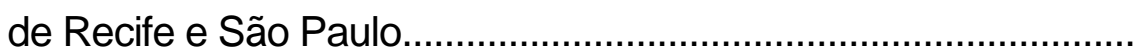

29 Variação da disponibilidade de magnésio, no domicílio, de acordo com o recebimento familiar per capita, nas regiões metropolitanas de Recife e São Paulo...................................................................

30 Variação da disponibilidade de manganês, no domicílio, de acordo com o recebimento familiar per capita, nas regiões metropolitanas de Recife e São Paulo...........................................

31 Proporção de carboidratos, no valor energético total, de acordo com o recebimento familiar per capita e regiões metropolitanas de Recife e São Paulo.

32 Proporção de proteínas, no valor energético total, de acordo com o recebimento familiar per capita e regiões metropolitanas de Recife e São Paulo.

33 Proporção de lipídios, no valor energético total, de acordo com o recebimento familiar per capita e regiões metropolitanas de Recife e São Paulo. 


\section{LISTA DE QUADROS}

Página

1 Categorias de consumo de energia e proteínas de origem animal nos países (média de 1997, 1998 e 1999)......................................

2 Disponibilidade de energia por habitante/dia, de acordo com a fonte de alimento. Brasil: 1985-1995............................................. 7

3 Disponibilidade de proteínas por habitante/dia, de acordo com a fonte de alimento. Brasil: 1985-1995............................................. 8

4 Setores selecionados e domicílios esperados, selecionados e "entrevistados" no total, segundo a área das pesquisas. POF

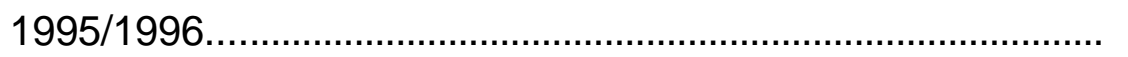

5 Municípios que compõem as regiões metropolitanas integrantes

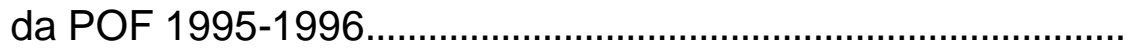

6 Valor da despesa média mensal familiar com a alimentação. POF. 1995/1996.

7 Características econômicas e demográficas das famílias pertencentes æ̀̀ regiões metropolitanas de Recife e São Paulo. $1995 / 1996$ 


\section{LISTA DE TABELAS}

Página

1 Disponibilidade de energia e nutrientes nos domicílios das regiões metropolitanas de São Paulo e Recife, de acordo com o recebimento familiar per capita (em salários mínimos).

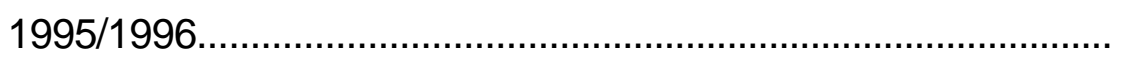

2 Disponibilidade de proteína, nos domicílios, de acordo com a origem (animal e vegetal) e estratos de recebimento familiar. 1995/1996

3 Disponibilidade nos domicílios, das regiões metropolitanas de São Paulo e Recife, de energia e participação dos macronutrientes (proteínas, carboidratos e lipídeos) de acordo com o recebimento familiar per capita. 1995/1996..........................

4 Estimativas dos parâmetros e testes relativos ao modelo de análise da disponibilidade de energia e nutrientes selecionados em função dos recebimentos nas regiões metropolitanas de Recife e São Paulo, 1995/1996

5 Estimativas dos parâmetros e testes relativos ao modelo de análise da disponibilidade de nutrientes (vitaminas hidrossolúveis) selecionados em função dos recebimentos nas regiões metropolitanas de Recife e São Paulo, 1995/1996............ 
6 Estimativas dos parâmetros e testes relativos ao modelo de análise da disponibilidade de nutrientes (minerais) selecionados em função dos recebimentos nas regiões metropolitanas de Recife e São Paulo, 1995/1996.

60

7 Estimativa dos parâmetros relativos ao modelo de análise de regressão da proporção dos macronutrientes (carboidratos, proteínas e lipídios) no valor energético total - VET em função dos recebimentos nas regiões metropolitanas de Recife e São Paulo. 1995/1996.

8 Participação relativa de grupos de alimentos na disponibilidade de energia para indivíduos das regiões metropolitanas de São Paulo e Recife, com rendimento familiar inferior a dois salários mínimos. 1995/1996.

9 Participação relativa de grupos de alimentos na disponibilidade de energia para indivíduos das regiões metropolitanas de São Paulo e Recife, com rendimento familiar entre seis e oito salários mínimos. 1995/1996..

10 Participação relativa de grupos de alimentos na disponibilidade de energia para indivíduos das regiões metropolitanas de São Paulo e Recife, com rendimento familiar superior a trinta salários mínimos. 1995/1996 


\title{
DISPONIBILIDADE DE ENERGIA E NUTRIENTES PARA A POPULAÇÃO DAS REGIÕES METROPOLITANAS DE RECIFE E SÃO PAULO
}

\author{
Autora: CÉLIA REGINA FERRARI FAGANELLO \\ Orientadora: Profa. Dra. MARINA VIEIRA DA SILVA
}

\section{RESUMO}

A interpretação do perfil de consumo alimentar de uma população é tarefa complexa, especialmente quando a sociedade brasileira vem passando por intensos processos, entre outros, a rápida industrialização, acelerada urbanização, a crescente participação da mulher no mercado de trabalho, o desenvolvimento da agroindústria e os planos de ajustes econômicos, o envelhecimento da população, a crescente importância da mídia, modificações dos hábitos e costumes.Também têm sido enfatizados os conhecidos danos para a saúde que podem decorrer do consumo insuficiente de nutrientes ou do consumo excessivo, que invariavelmente condiciona a obesidade. Tendo em vista as lacunas existentes, sobre o consumo alimentar da população, julgou-se pertinente implementar a presente pesquisa tendo entre seus objetivos a análise do conteúdo de energia e nutrientes, disponível nos domicílios das regiões metropolitanas de Recife e São Paulo e a variação dos mesmos de acordo com o recebimento familiar per capita; avaliação da participação relativa dos diferentes grupos de alimentos e, também, dos macronutrientes no valor energético total - VET. Como base de dados, foram utilizadas as informações obtidas pela Pesquisa de Orçamentos Familiares - POF, realizada pelo IBGE, 
durante o período de $1^{\circ}$ de outubro de 1995 a 30 de setembro de 1996 (IBGE, 1998). Para a análise dos dados relativos ao conteúdo disponível de energia e nutrientes, adotou-se o software Virtual Nutri (Philippi et al, 1996).Os recursos do software Statistical Analysis System - SAS (1996),foram utilizados para a elaboração das demais análises. Para analisar como a disponibilidade de energia e os nutrientes selecionados variam com o recebimento familiar per capita nas duas regiões metropolitanas analisadas, utilizou-se o modelo de regressão múltipla. Elaborou-se a análise da participação dos macronutrientes (carboidratos, proteína e lipídeos) no valor total de energia disponível nos domicílios para as famílias de todos os estratos de recebimentos, adotando-se como parâmetros os valores preconizados pela National Academy of Sciences (2002). Verificou-se que para as duas regiões metropolitanas e totalidade dos estratos de recebimento, a participação da proteína animal supera o valor recomendado .Note-se que a participação da proteína que procedem de fontes animais supera $50 \%$, quando se examina os resultados referentes à totalidade dos estratos de recebimentos.Quando se considera a participação dos macronutrientes, verifica-se que o maior valor (31\%), referente aos lipídios no VET é verificado na região metropolitana de São Paulo (famílias com rendimento entre 15 e 20 s.m.). Valor também considerado elevado, foi observado em São Paulo para famílias pertencentes aos estratos de 3 a 5, 20 a 30 e acima de 30 salários mínimos. No tocante a participação dos carboidratos, vale enfatizar que os maiores percentuais (63\% e $62 \%$ ) foram verificados na região metropolitana de Recife. Quando se considerou os três estratos de recebimento (< 2 s.m.; entre 6 e 8 s.m.; e > 30 s.m.) verificou-se que as famílias da região metropolitana de Recife, pertencentes aos referidos estratos dispõe de maior conteúdo de energia no domicílio, que as famílias da região metropolitana de São Paulo.A disponibilidade de fibras se revelou muito inferior ao mínimo recomendado. Situação preocupante também foi observada quando se considerou a disponibilidade no domicílio, do ferro. Verificou-se também que possivelmente os hábitos regionais exerçam forte influência no consumo da 
população. Ilustra esse registro a contribuição do grupo das farinha no VET disponível para as famílias da região metropolitana de Recife (região nordeste do pais) que se revelou superior àquela verificada para São Paulo. A participação das frutas se revelou mais expressiva, para as famílias pertencentes aos estratos mais elevados de renda, das duas regiões consideradas nas análises. Espera-se que os resultados obtidos na presente pesquisa forneçam subsídios para as análises do comportamento do perfil alimentar dos brasileiros das áreas duas urbanas .Acredita-se, também, que os resultados contribuam para sistemas agroalimentares brasileiros e, entre outros procedimentos de intervenção, para a elaboração de programas educativos na área da saúde mais condizente com a melhoria do estado nutricional da população.As indústrias de alimentos e profissionais da área de marketing também poderão se beneficiar dos resultados à medida que esses revelam tendências e preferências dos consumidores. 


\title{
ENERGY AND NUTRIENTS DISPONIBILITY TO THE PEOPLE LIVING IN RECIFE AND SÃO PAULO METROPOLITAN AREAS
}

\author{
Author: CÉLIA REGINA FERRARI FAGANELLO \\ Adviser: Profa. Dra. MARINA VIEIRA DA SILVA
}

\section{SUMMARY}

It is a complex task interpreting the eating habits of a given population, especially when the Brazilian society is passing through great changes, as the fast industrialisation, quick urbanisation growth the increasing of the women's participation at the job market, the agroindustrial development, the economic agreement plans, the population aging-process, the growth of the media importance, those factors result in habit and custom changings. It is also been emphasising the well-known health problems that occur because of the inadequate nutrients consumption or the excess nutrients consumption, which drives the individual to an obese condition. Because of the lack of information on the population eating consumption, I resolve to start the following research to analyze the energy and nutrient contents, available at the tomes in Recife and São Paulo metropolitan regions and the range of the energy and nutrients according on how much each family earns, their per capita income, the evaluation of the relative participation of the different food groups, and also the macronutrients found in the Total Energetic Value - TEV. Based on collected data, it was used the information obtained by the pesquisa de Orçamentos Familiares - POF (Familiar Budget Research) fulfiled by IBGE (Instituto 
Brasileiro de Geografia e Estatística - Brazilian Institute of Geography and Statistics) throughout the period of October $1^{\text {st }}, 1995$ to September $30^{\text {th }}, 1996$ (IBGE,1998). To analyze the data related to the available energy and nutrients contents, it was used the Virtual Nutri software (Philippi et al, 1996). The Statical Analysis Sytem - SAS resources (1996) were used to elaborate the other analyses. To analyze how the energy and nutrient available chosen ranges according the familiar per capita income in both metropolitan regions it was used a multiple regression model. It was elaborated the macronutrients (carbohydrate, protein and fat) participation in the total valour of the available energy found at the homes to the families from every social class, the parametres taken were the foretold by the National Academy of Sciences (2002). It was verified that for both regions and all familiar range income the participation of animal protein surpasses the recommendable valour, in a $50 \%$ scale, when it is taken the whole familiar income range. When one considers the macronutrients participation, one verifies that the major valour $(31 \%)$ is conserning to the fat in the TEV it is found that in São Paulo metropolitan region (families that have about 3000 to 4000 Reais monthly income - being 1 dollar equal to about 3,80 Reais nowadays) another high considered valour was observed in São Paulo within the families who have incomes from 600 Reais to 1000 Reais, the families who income ranges from 4000 Reais to 6000 Reais and the families that have an income higher than 6000 Reais. As far as carbohydrate is concerned it is good to emphasise that the major valours (63\% and $62 \%$ ) were found in Recife metropolitan region. When it was considered the three levels of income (less than 400 Reais; between 1200 Reais and 1600 Reais and more than 6000 Reais) it was verified that the families in Recife metropolitan area in the citied income levels have more energy content at home than theirs counterparts in São Paulo metropolitan areas. The available fibre turned out to be much fewer than the recommendable one. That worrying situation was also observed when one considered the iron available at home. It was observed that probably the regional habits have a strong influence as far as comsuption is 
concerned. The flour in the TEV available to the families shows us the regional habits, because it is higher in Recife metropolitan area than in São Paulo metropolitan area. It was noticed the fruits expressive participation among the families who have the major incomes in both regions. It is expected that the results in this research provide subsidies to the Brazilian eating behaviour in both metropolitan regions. It is believed that the results will help the Brazilian agro-food systems and amongst other intervention proceedings, to elaborate educative programmes on health field aiming the improving the nutritional state of the population. The food industries and the professionals on the marketing area will also be able to get the benefits from the results for they reveal the consumers tendencies and preferences. 


\section{INTRODUÇÃO}

Os processos intensos de industrialização, a acelerada urbanização, a crescente participação da mulher no mercado de trabalho, o desenvolvimento da agroindústria e os planos de ajustes econômicos, o envelhecimento da população, a mídia, hábitos e costumes, entre outros fatores, têm propiciado importantes mudanças, particularmente no consumo alimentar da população brasileira.

De longa data também são conhecidos os danos para a saúde, entre os quais, podem ser destacadas a desnutrição, decorrente do consumo insuficiente de nutrientes e situação oposta, especialmente devido ao consumo excessivo de energia, a obesidade. Recentemente, também, acumulam-se

evidências de que características qualitativas da dieta são igualmente importantes para o estado de saúde, especialmente no que se refere às doenças crônicas, que acometem os indivíduos, com maior freqüência, na fase adulta.

Além do aumento do consumo de alimentos fora da moradia, verifica-se, também, mudanças relativas à disponibilidade de alimentos no domicílio, sendo este último aspecto, o foco de interesse da presente pesquisa. Neste contexto, observa-se uma diminuição da participação dos gastos, das famílias brasileiras, com alimentação e, ainda, é notório que os dispêndios com alimentação são maiores para os grupos pertencentes aos estratos de rendimentos mais baixos.

De uma maneira geral, o que tem sido observado, na maioria dos países em desenvolvimento, é um aumento do consumo de alimentos com elevado conteúdo de gorduras e açúcares e uma diminuição do consumo de alimentos ricos em fibras e carboidratos complexos. 
É evidente a importância da implementação de análises que possibilitem o conhecimento do padrão da alimentação da população brasileira, uma vez que as informações a respeito desse assunto são escassos. Tendo em vista as lacunas existentes, pretende-se com a presente pesquisa analisar a disponibilidade, no domićlio, e a variação dos mesmos de acordo, com o recebimento familiar per capita, das famílias moradoras das regiões metropolitanas de Recife e São Paulo; avaliar a participação relativa dos diferentes grupos de alimentos no valor energético total - VET e, também, a origem da proteína disponível nos domicílios das famílias moradoras das regiões metropolitanas brasileiras. Para tanto foram utilizados os dados da Pesquisa de Orçamentos Familiares - POF, realizada pelo Instituto Brasileiro de Geografia e Estatística - IBGE em 1995/1996.

Espera-se que os resultados obtidos na presente pesquisa forneçam subsídios para as análises do comportamento do perfil alimentar dos brasileiros das áreas urbanas.

Acredita-se que os resultados contribuam para sistemas agroalimentares e, também, para adoção de procedimentos de intervenção, como por exemplo a elaboração de programas alimentares e ainda ações educativas na área da saúde mais condizentes para que se alcance um melhor padrão do estado nutricional da população brasileira.

As indústrias de alimentos e profissionais da área de marketing também poderão se beneficiar dos resultados à medida que esses revelam tendências de consumo das famílias de distintas regiões metropolitanas e estratos de rendimentos. 


\section{REVISÃO DE LITERATURA}

O consumo de alimentos bem como o consumo de outros bens é determinado por fatores econômicos, sociais, culturais e, também, pelas suas inter-relações. Entre os fatores econômicos incluem-se os preços dos alimentos, os preços dos bens complementares e substitutos, o nível da renda da população e sua distribuição, além da quantidade de mercadorias ofertadas. Os fatores sociais são representados pela escolaridade, grau de urbanização da população, condições de higiene, saneamento e moradia, atendimento de profissionais da área de saúde e nutrição, estágio de vida, número de pessoas integrantes das famílias, mudanças na organização familiar, dentre outros. Os fatores culturais são aqueles encontrados nos padrões de conduta intrínsecos a determinados povos, regiões e grupos familiares; são transmitidos de geração a geração e estão sujeitos a diversos tipos de influência, modismos, valores morais e religiosos (Martins, 1998).

Vale registrar que de acordo com Bourges (1988), a conduta alimentar obedece mais a influência dos hábitos e costumes que a da razão ou instintos e depende da disponibilidade, tradições e experiências previas e interações de fatores psicológicos e não psicológicos e o conhecimento profundo sobre a natureza dos hábitos e de como são gerados e evoluem é fundamental para se compreender a conduta alimentar. Ainda de acordo com o referido autor, os hábitos alimentares podem referir-se a: o que se come, quanto, como, quando e onde se come. Nesse contexto inserem-se fatores œmo número de refeições realizadas no dia, seus horários, alimentos de uso mais freqüente, aspectos sensoriais preferidos ou mais prestigiados, composição final da dieta, hábitos de higiene, de compra, armazenamento e manipulação de alimentos, 
aos ritos e tabus ou várias outras combinações desses aspectos. O mesmo autor enfatiza que a aquisição de alimentos é função das necessidades alimentares, do poder aquisitivo da família, da estrutura do mercado local e das motivações que levam æ̀ compras, como hábito s familiares, conhecimentos e habilidades culinárias, tipos de utensílios disponíveis, facilidades para conservar e armazenar os alimentos e o valor que as famílias atribuem a cada alimento. De acordo com o referido autor, entre os valores mais importantes de um alimento estão: o sensorial, o econômico e sua relação com a saúde e com o status social.

O mundo tem passado por uma série de transformações desde a década de 50 , sendo as mais perceptíveis, a globalização e a urbanização. Essas mudanças afetam, entre outros aspectos, a qualidade dos alimentos produzidos e industrializados e também as escolhas dos consumidores, que parecem estar cada vez mais associadas a um novo estilo de vida.

Nota-se, nos países industrializados, uma tendência de se adotar novos hábitos alimentares "gerados" ou estimulados pela indústria de alimentos em resposta æ̀ necessidades que a vida moderna impõe. A escassez de tempo, as longas distâncias entre a casa e o trabalho, situação freqüentemente observada nos grandes centros urbanos, levam a uma crescente demanda por refeições tipo fast-food e ao aumento do consumo de alimentos pré-preparados e aquisição de produtos congelados. Verifica-se assim a redução do tempo envolvido nos "rituais alimentares" desde o preparo até a ingestão e a diminuição do consumo de produtos regionais e com forte tradição cultural. Neste contexto surge um novo padrão de alimentação, o padrão das sociedades industrializadas, tanto em países desenvolvidos como os Estados Unidos e países da Europa, mas também naqueles em desenvolvimento caracterizando, assim o padrão ocidental de alimentação.

Observa-se a evolução do consumo de alimentos industrializados, da alimentação fora do domicílio (em cantinas, restaurantes, fast-foods), a 
preferência pelos supermercados para a compra de alimentos, a busca de praticidade e de economia de tempo (Móron, 1996).

Neste contexto, as preferências alimentares na sociedade moderna parecem condicionadas, também, em parte, pelo substancial volume de publicidade, particularmente a relativa aos alimentos industrializados.

Sampaio (2001), implementou uma análise comparativa do consumo de alimentos entre países da América Latina e da União Européia. De acordo com o referido autor, a fundamental diferença entre o padrão de consumo de alimentos dos países do Primeiro Mundo e dos países da América Latina diz respeito àquantidade de proteínas de origem animal consumida e àquantidade de calorias ingeridas (Quadro 1). Ainda, de acordo com o autor, todos os países integrantes do grupo considerado mais desenvolvido, exceto o México, têm um nível relativamente elevado de consumo de proteínas de origem animal, o que não foi observado para os países da América Latina, com exceção do Uruguai. Esses resultados revelam que os países considerados pelo autor como "do primeiro mundo" consomem de maneira mais elevada que os países da América Latina, produtos como carnes, ovos e leite e seus derivados).

Em sua pesquisa, Sampaio (2001) classificou os países da América Latina em quatro grupos relativamente homogêneos. O Brasil foi inserido no grupo 2, para qual foi verificado consumo médio de energia proveniente de alimentos de origem vegetal (1921,58 kcal/dia/habitante) e animal (353,69 kcal/dia/habitante), totalizando $2275,27 \mathrm{kcal} / \mathrm{dia} / \mathrm{habitante}$. Vale ressaltar que a média geral observada para a América Latina foi de 1928,90 kcal/dia/habitante para alimentos de origem vegetal e $381,09 \mathrm{kcal} / \mathrm{dia} / \mathrm{habitante}$ para alimentos de origem animal (total de 2309,99 kcal/dia/habitante). Esses valores apresentamse inferiores aos observados para os países da União Européia: 1977,00 $\mathrm{kcal} / \mathrm{dia} / \mathrm{habitante}$ para alimentos de origem vegetal; 816,78 kcal/dia/habitante para alimentos de origem animal, e um total de 2793,78/dia/habitante (energia ingerida). O autor ainda verificou um consumo médio superior dos produtos: arroz, batata, óleos vegetais, frutas, carne de frango, pescados, açúcar e 
adoçantes, quando se adota como referência os dados dos países da América Latina. Por outro lado, observou um consumo médio abaixo da média geral dos seguintes alimentos: milho, carne bovina e carne suína.

Com relação às proteínas, Sampaio (2001), verificou um consumo de $27,56 \mathrm{~g} / \mathrm{dia} / \mathrm{habitante}$ de proteínas de origem vegetal e $26,31 \mathrm{~g} / \mathrm{dia} / \mathrm{habitante}$ de proteínas de origem animal para o grupo 2, ao qual pertence o Brasil. Vale ressaltar a média para os países da América Latina de 31,27g/dia/habitante e $27,31 \mathrm{~g} / \mathrm{dia} /$ habitante para alimentos de origem vegetal e animal, respectivamente. Quando o autor analisou a situação dos países da União Européia, verificou que os mesmos, apresentaram um consumo total médio de 93,83g de proteína/habitante/dia sendo $33,50 \mathrm{~g}$ de proteína/habitante/dia proveniente de alimentos de origem vegetal e 60,34g de proteína/habitante/dia oriundos de alimentos de origem animal.

\begin{tabular}{|c|c|c|}
\hline Energia & Proteína de Origem Animal & Países \\
\hline \multirow[t]{2}{*}{$\begin{array}{c}\text { Elevado } \\
\text { Superior a } 2800 \mathrm{kcal}\end{array}$} & Relativamente elevado $(>50 \mathrm{~g})$ & $\begin{array}{c}\text { Países da União Européia, } \\
\text { EUA, Canadá, Argentina e } \\
\text { Uruguai. }\end{array}$ \\
\hline & Relativamente baixo $(<50 \mathrm{~g})$ & Brasil, Chile e México. \\
\hline \multirow[t]{2}{*}{$\begin{array}{c}\text { Intermediário } \\
2400 \text { a } 2800 \text { kcal }\end{array}$} & Relativamente elevado $(>30 \mathrm{~g})$ & $\begin{array}{c}\text { Costa Rica, Panamá e } \\
\text { Paraguai }\end{array}$ \\
\hline & Relativamente baixo $(<30 \mathrm{~g})$ & $\begin{array}{l}\text { Colômbia, Cuba, El Salvador, } \\
\text { Equador, Jamaica, Peru, } \\
\text { Trinidad\&Tobago }\end{array}$ \\
\hline \multirow[t]{2}{*}{$\begin{array}{c}\text { Fraco } \\
\text { Inferior a } 2400 \mathrm{kcal}\end{array}$} & Relativamente elevado $(>15 \mathrm{~g})$ & $\begin{array}{l}\text { Bolívia, Honduras, República } \\
\text { Dominicana, Venezuela, }\end{array}$ \\
\hline & Relativamente baixo $(<15 \mathrm{~g})$ & Haiti, Guatemala e Nicarágua \\
\hline
\end{tabular}

Quadro 1 - Categorias de consumo de energia e proteínas de origem animal nos países (média para os anos de 1997, 1998 e 1999).

Fonte: Sampaio (2001) 
A seguir são apresentados os Quadros 2 e 3 contendo os dados referentes à disponibilidade, para a população brasileira, de energia por habitante/dia e proteínas por habitante/dia, respectivamente. Vale registrar que os cálculos foram elaborados, por Barros (1996), tendo por base o "consumoaparente".

\begin{tabular}{|c|c|c|c|}
\hline \multirow{2}{*}{ Ano } & \multicolumn{2}{|c|}{ Fonte } & \multirow{2}{*}{ Total } \\
\cline { 2 - 3 } & Vegetal & Animal & 2274 \\
\hline 1985 & 1736 & 538 & 2490 \\
\hline 1986 & 1877 & 613 & 2277 \\
\hline 1987 & 1697 & 580 & 2266 \\
\hline 1988 & 1710 & 556 & 2370 \\
\hline 1989 & 1762 & 608 & 2343 \\
\hline 1990 & 1743 & 600 & 2370 \\
\hline 1991 & 1743 & 627 & 2318 \\
\hline 1992 & 1710 & 608 & 2334 \\
\hline 1993 & 1704 & 630 & 2433 \\
\hline 1994 & 1797 & 636 & 2545 \\
\hline 1995 & 1838 & 707 & \\
\hline
\end{tabular}

Quadro 2 - Disponibilidade de energia por habitante/dia, de acordo com a fonte de alimento. Brasil: 1985-1995.

Fonte: Barros (1996) 


\begin{tabular}{|c|c|c|c|c|}
\hline \multirow{2}{*}{ Ano } & \multicolumn{3}{|c|}{ Fonte } & \multirow{2}{*}{ Total } \\
\cline { 2 - 4 } & Vegetal & Animal & $\begin{array}{c}\text { Percentual de } \\
\text { Animal }\end{array}$ & \\
\hline 1985 & 30 & 27 & 48 & 57 \\
\hline 1986 & 31 & 33 & 52 & 64 \\
\hline 1987 & 27 & 32 & 54 & 59 \\
\hline 1988 & 29 & 31 & 52 & 60 \\
\hline 1989 & 28 & 34 & 55 & 62 \\
\hline 1990 & 28 & 34 & 55 & 62 \\
\hline 1991 & 28 & 35 & 56 & 63 \\
\hline 1992 & 29 & 35 & 55 & 64 \\
\hline 1993 & 28 & 36 & 56 & 64 \\
\hline 1994 & 30 & 36 & 55 & 66 \\
\hline 1995 & 31 & 40 & 56 & 71 \\
\hline
\end{tabular}

Quadro 3 - Disponibilidade de proteínas por habitante/dia, de acordo com a fonte de alimento. Brasil: 1985-1995.

Fonte: Barros (1996)

É interessante observar o expressivo aumento da disponibilidade de proteína animal (principalmente no período compreendido ente 1994 e 1995). Note-se também que nos anos em que foram implementados planos de estabilização da economia (1986 o Plano Cruzado e 1994/1995 o Plano Real) houve melhoria no padrão alimentar da população: em 1995, por exemplo, foram consumidos maiores quantidades de energia e proteínas do que a media dos anos anteriores (Barros, 1996).

É importante registrar também que à medida que se intensifica o consumo de alimentos fora do domicílio, ocorre um aumento do número de estabelecimentos e indivíduos (comércio ambulante) que comercializam alimentos. Tal situação demanda a atuação efetiva dos órgãos vinculados à Vigilância Sanitária, no sentido de assegurar à população, acesso aos alimentos adequados, sob o ponto de vista sanitário. Mac Donald \& Griffin (1986), citados por Felipe et al (1995), ressaltam que cerca de $40 \%$ dos surtos de toxinfecções são atribuídos ao consumo de refeições produzidas em larga escala. Neste contexto verifica-se a importância da segurança alimentar, 
especificamente no tocante ao aspecto qualitativo - o food safety, ou seja, a garantia à população de alimentos seguros do ponto qualitativo. Deve-se salientar que os problemas decorrentes do consumo de alimentos contaminados ou deteriorados, assim como a dieta não-balanceada, freqüentemente atingem, de maneira mais drástica, a população de menor renda.

Ressaltam-se, também, os conhecidos efeitos e ou prejuízos decorrentes quer do consumo alimentar insuficiente - deficiências nutricionais -, quer do consumo excessivo - obesidade (Mondini \& Monteiro, 1994). Neste contexto enquadram-se os aspectos quantitativos e qualitativos envolvidos na segurança alimentar, ou seja, os primeiros aspectos, freqüentemente, relacionados, de forma geral, ao suprimento de alimentos para a população (food security) e os segundos, aos atributos nutricionais (food safety).

Espera-se, como postula a Lei de Engel, que o processo de desenvolvimento econômico - social acarrete uma redução da participação da alimentação no gasto total das famílias. No entanto, em algumas regiões do país, e especialmente para famílias de menor renda, o gasto com a alimentação é ainda o de maior proporção no orçamento familiar (Menezes et al, 2002).

Castro \& Magalhães (1998), ao analisarem a evolução da estrutura do gasto familiar, tendo como base os dados das Pesquisas de Orçamentos Familiares - POFs, dos anos de 1987/88 e 1995/96, mostraram uma redução da participação dos gastos com alimentação para o total das áreas pesquisadas, e para o conjunto das famílias, de $25,3 \%$ para $23,6 \%$ entre os anos de $87 / 88$ e 95/96. Os autores destacam que, entretanto, quando se considera as famílias mais pobres de Fortaleza, por exemplo, cerca de $49,2 \%$ dos gastos com consumo eram destinados aos alimentos, ou seja, praticamente metade das despesas de consumo das famílias estavam comprometidas com alimentação. Quando se examina as informações para a região metropolitana de São Paulo, uma família pertencente ao estrato mais pobre, destina $32,4 \%$ do seu gasto de consumo com os alimentos. Ainda de acordo com os referidos autores, na 
medida em que os gastos com alimentação ainda são um item fundamental no orçamento das famílias pertencentes aos menores estratos de renda, principalmente nas regiões mais pobres do país, estudos sobre a demanda assumem importância no sentido de orientar a formulação de políticas públicas voltadas para a melhoria da segurança alimentar e das condições de saúde e nutrição da população.

Menezes et al (2002), analisaram os microdados da POF 1995/1996, verificando as despesas com 41 produtos alimentares, que constituem versão reduzida da cesta normativa proposta em 1989, pela Comissão Econômica para a América Latina e o Caribe - CEPAL, que engloba 280 itens alimentares. $O$ exame dos microdados da POF apontou 236,053 aquisições, envolvendo esses alimentos, considerando 16060 famílias investigadas. Os autores ressaltam que entre os referidos registros, são contabilizadas 785 famílias que não efetuaram nenhum gasto com alimentos, das quais 15 não tiveram despesas de consumo e 11 declararam renda nula. Foi observado também que há 952 registros de desembolso, sendo 868.176 de gastos com itens de consumo, dos quais 388.526 são aquisições envolvendo alimentos e bebidas. Os autores chamaram a atenção para o fato dos registros relativos às aquisições alimentares mostrarem a importância das despesas com os referidos produtos no orçamento das famílias.

É importante registrar que quando se pondera as unidades de consumo (famílias) pesquisadas, pelos fatores de expansão da amostra, o universo investigado pela POF 1995/1996 representa 12,5 milhões de famílias $(46,4$ milhões de pessoas), residentes nos onze principais centros urbanos do país.

Menezes et al (2002) ressaltam que os gastos com consumo das famílias metropolitanas atingiram, em 1996, $R \$ 149$,4 bilhões, dos quais $R \$ 16,1$ bilhões foram alimentos que integram a cesta ${ }^{1}$.

\footnotetext{
${ }^{1}$ Valores referentes a setembro de 1996, para o período compreendido entre primeiro de outubro de 1995 e 30 de setembro de 1996.
} 
Nota-se, portanto, que os gastos com a cesta representam $10,8 \%$ do orçamento familiar. Vale salientar que a participação dos registros desses alimentos no total dos registros de consumo alcança $27,2 \%$, ou seja, são produtos repetidamente adquiridos pelas famílias.

Ao analisar a participação dos gastos com a cesta no dispêndio familiar de acordo com estratos de renda (em salários mínimos), fica evidente a importância (representam cerca de $25 \%$ das despesas de consumo) dos alimentos para as famílias com menor rendimento.

Segundo Menezes et al (2002), quando se considera a participação dos gastos com a cesta no total do dispêndio alimentar (incluindo bebidas e alimentação fora do domicílio), os alimentos representam, para a média das classes de renda e no total das áreas, cerca de $50 \%$. As despesas totais com os alimentos da cesta variam, de acordo com os autores, de $30,9 \%$ a $65,8 \%$ do total da despesa com alimento, para famílias com renda mensal superior a 30 salários mínimos e para o grupo com rendimentos até dois salários mínimos, respectivamente.

Monteiro (2002), ao elaborar análises sobre a situação alimentar da população brasileira, destaca que "a fome e a desnutrição são hoje no Brasil bem menores que há dez anos e imensamente menores que há 20 ou 30 anos". Ainda de acordo com o referido autor é pouco provável que exista no país, "cerca de 30 milhões de pessoas que não tenham o que comer". Os números, de acordo com o autor, provavelmente reflitam a parcela da população com falta de renda, mas não a população sem acesso aos alimentos.

A fome, ainda segundo Monteiro (2002), existe sempre de forma paralela àmiséria, mas nem sempre a miséria se traduz pela ocorrência de fome. Deve se considerar a produção para autoconsumo, os programas públicos como a merenda escolar, e ainda as redes privadas de filantropia.

Ainda de acordo com Monteiro (2002), famílias com uma renda extremamente baixa, que residem em região urbana considerada mais rica, raramente sofrem de desnutrição. No entanto, a família com as mesmas 
características econômicas, vivendo numa região rural muito pobre, estará ameaçada pela possibilidade de não ter o que comer. Os municípios pobres "não têm como custear programas assistenciais, não conseguem construir e manter uma rede que impeça que a família pobre caia na desnutrição".

É interessante destacar que nas últimas décadas, ocorreram mudanças na paisagem rural de algumas regiões do Estado de São Paulo, em decorrência, especialmente, da expansão dos assentamentos rurais. Particularmente, na região do Pontal do Paranapanema, onde havia pastagens extensivas, florescem pequenas propriedades rurais, sítios, nos quais a presença do homem é marcante e onde prolifera a agricultura familiar.

A agricultura familiar é praticada em $85 \%$ dos estabelecimentos agropecuários do Brasil por 4,14 milhões de famílias, proporcionando ocupação para 13,8 milhões de trabalhadores, o que representa $77 \%$ de todo o trabalho do meio rural brasileiro (ITESP, 2000).

Tendo em vista a performance, a agricultura familiar é considerada um setor estratégico para a manutenção e geração de emprego, para a redistribuição de renda, para a segurança alimentar do país e para o desenvolvimento sustentável (ITESP, 2000).

A produção para autoconsumo,tem papel essencial no sistema de produção, pois é "ele que garante a estabilidade do produtor frente aos resultados oscilantes das culturas comerciais". Note-se também que tem um papel de reserva de segurança para períodos difíceis, além de produzir eventuais excedentes, æ̀̀ vezes muito expressivos para o mercado local (ITESP, 2000).

Reconhece-se, portanto que a produção para autoconsumo, ou seja, aqueles produtos que o assentamento obtém no seu próprio lote e utiliza na alimentação de sua família, assume posição central para a construção da segurança alimentar (food security), especialmente quando se considera os assentamentos. 
Andrade (2002) mostrou que o Instituto de Terras do Estado de São Paulo - ITESP ${ }^{2}$, desenvolveu pesquisa entre 1999 e 2000, envolvendo 8.828 famílias distribuídas em 137 assentamentos no Estado de São Paulo. Vale registrar que do referido total de famílias, 4.747 concentravam-se no Pontal do Paranapanema, em 83 assentamentos. O objetivo central do estudo foi verificar o impacto da produção de alimentos para o autoconsumo, atribuindo-lhe valor econômico que permitisse avaliar sua importância, possibilitando, entre outros aspectos, garantir a segurança alimentar das famílias. Entre os principais resultados merece destaque a observação relativa àprodução de autoconsumo, que integra a paisagem bastante diversificada próxima àmoradia, com plantas frutíferas, ervas medicinais, animais domésticos e aves.

Foi observado, de acordo com o referido autor, que em geral, as mulheres assumem um papel de maior dimensão nas atividades de autoconsumo, uma vez que "são elas as responsáveis, no dia a dia, pelo preparo das refeições". A pesquisa, implementada pelo ITESP, mostrou também que, em maior ou menor grau, a produção para o autoconsumo estava presente em praticamente todos os lotes. Alimentos como mandioca, milho, arroz e feijão são os mais constantes, constituindo a base da alimentação das famílias nos assentamentos.

Ainda de acordo com Andrade (2002), merece destaque também a melhoria do padrão de vida e saúde decorrente da diversificação da produção para autoconsumo. A rotina diária de consumo de vitaminas e proteínas, invariavelmente inacessível, tornou-se efetiva com a disponibilidade de frutas, hortaliças, carne de porco e aves e também ovos. Enfatiza-se, também, que o consumo abundante de leite e queijos foi viável a partir da produção decorrente,

\footnotetext{
2 O programa ITESP - Apoio àprodução familiar (subprograma Segurança Alimentar) inclui a distribuição de sementes (horta), matrizes (aves e suínos) e mudas (pomar caseiro) às famílias assentadas que, uma vez beneficiadas, devem redistribuir o benefício às outras famílias e/ou comunidade por meio do repasse de produtos à merenda escolar ou de matrizes a outros produtos inicia ntes. Busca-se com este programa, iniciado em 1998, atingir todos os lotes, estimulando a diversificação da produção para autoconsumo, reconhecidamente importante ao desenvolvimento das famílias.
} 
notadamente, da substituição da pecuária de corte patronal pela pecuária de leite de caráter familiar.

Não sobram dúvidas de que os alimentos beneficiam as famílias, em especial as crianças e ainda, que a produção de autoconsumo representa concretamente maior segurança para os produtores, pois é permitido æ̀ famílias a disponibilidade de vários tipos de alimentos e o enfrentamento de eventuais adversidades.

De acordo com os resultados da pesquisa do ITESP, no estado de São Paulo, o consumo médio per capita de alimentos provenientes do próprio lote é de 419,85 kg/ano - 1,15 kg/dia, representando um valor monetário de $\mathrm{R} \$$ 402,12. De acordo com Andrade (2002), quando se considera o número de médio de cinco pessoas por família, o consumo médio atinge $2.099,25 \mathrm{~kg}$ de alimentos por familia/ano, com valor de $R \$ 2.010,62$ - ou $R \$ 167,55$ mensais. Vale lembrar que o salário mínimo na época da obtenção de dados totalizava $\mathrm{R} \$ 136,00$ mensais.

Delgado (2002) elegeu a análise do consumo e autoconsumo de alimentos, como temas centrais de pesquisa implementada, tendo por base amostra de 6.253 domicílios, sendo 3.000 na Região Sul e 3253 na Região Nordeste, onde residia pelo menos um aposentado ou pensionista rural. A amostra foi extraída de um universo de quatro milhões de domicílios rurais. $O$ autor revela que, para a classe mais pobre da amostra, aquela composta pelas famílias que têm exclusivamente a aposentadoria como fonte de renda familiar (22\% dos domicílios no Nordeste e $11 \%$ no Sul) e apenas uma aposentadoria (ou pensão) por domicílio, é presumível admitir que as referidas famílias gastem tudo o que ganham em alimentação, nada ou quase nada thes sobrando para despesas de consumo e, obviamente, nada de excedente. Ainda de acordo com Delgado (2002), tanto no Sul, quanto no Nordeste, os gastos com alimentação eram, em média, de $R \$ 124,00$, valor praticamente idêntico ao salário mínimo da época. 
Quando se considera o grupo mais representativo (classe modal = famílias que ganham de um até dois salários mínimos de renda domiciliar) a situação é claramente de suficiência em relação à despesa média de consumo no Nordeste, mas ainda não configura o atendimento ao padrão médio de consumo do domicílios da Região Sul.

A partir do terceiro estrato $(2,01$ a 3,0; 3,01 a 5,0; 5,01 a 10 e acima de 10 salários mínimos), de acordo com o referido autor, é possível observar, no Sul e no Nordeste os domicílios que apresentam claramente excedente. Nesses casos há uma gama de estratégias e relações familiares em que, geralmente, as pessoas do domicílio têm acesso a outras fontes de renda e notadamente aos estabelecimentos rurais familiares, que thes garantem autoconsumo, postos de trabalho e produção agrícola como "peças importantes da sua estratégia de sobrevivência". Os resultados obtidos por Delgado (2002) revelam que 65\% dos domicílios no Sul e 38\% no Nordeste apresentam rendimentos domiciliares superiores a dois salários mínimos, sendo possível identificar, nesse estrato, as famílias que efetivamente ultrapassam a linha de pobreza (1/2 salário mínimo per capita), revelando capacidade de gerar e/ou produzir algum tipo de excedente, em geral integrado por meios de subsistência alimentar.

Vale registrar que na presente pesquisa, as análises, tendo por base os dados da Pesquisa de Orçamentos Familiares - POF, de 1995/1996, não foi considerada a disponibilidade de alimentos, provenientes da produção para autoconsumo. A POF - 1995/1996 não obteve dados relativos ao autoconsumo e ainda, foi implementada, com exclusividade, em regiões metropolitanas do país.

No que diz respeito à crescente participação da mulher no mercado de trabalho pode-se dizer que este fato tem contribuído para a incorporação de novos hábitos como a alimentação fora do domicílio ou consumo de alimentos semi-prontos e congelados uma vez que as distâncias entre a casa e o local de trabalho nas grandes cidades, não permite o fácil deslocamento até o domicílio ou o preparo de refeições mais elaboradas. 
Outro aspecto que vale destacar é a questão do padrão da nutrição infantil. O trabalho da mulher, fora de casa, contribui para um aumento da renda o que pode melhorar o padrão nutricional da criança, por permitir a aquisição de uma variedade maior de alimentos. Por outro lado, a falta de tempo para acompanhar a alimentação dos filhos pode levar à aquisição de hábitos alimentares inadequados pela prole.

Bertasso (2000), estudando o efeito da inserção da mulher no mercado de trabalho sobre o consumo alimentar, verificou uma tendência de consumo domiciliar de alimentos, definidos pelo autor como "modernos", em famílias com mulheres que trabalhando fora do domicílio. Observou ainda que nessas famílias há uma freqüência maior e em maior quantidade de consumo alimentar fora do domicilio, com destaque para as opções que envolvem alimentos considerados menos saudáveis.

No Brasil, o Plano Real provocou a estabilização da moeda. A redução da taxa de inflação teve um impacto positivo na renda dos trabalhadores em geral, levando a uma ligeira diminuição na desigualdade da distribuição de renda. Algumas mudanças positivas ocorreram em virtude do referido plano como, por exemplo, a estabilização do preço e, também, da venda de alimentos e o aumento da venda de alimentos em supermercados.

Segundo Bertasso (2000), a renda é o principal condicionante da demanda. $O$ consumo de alimentos tende a crescer com o aumento da renda principalmente quando esse crescimento é acompanhado de uma diminuição na desigualdade de distribuição de renda, pois a elasticidade-renda do dispêndio é maior para níveis de rendimentos mais baixos. Analisando o efeito da renda sobre o consumo alimentar dos brasileiros, o referido autor verificou que a freqüência de compra de alimentos é diretamente proporcional ao rendimento e que incrementos no mesmo elevam o consumo. Ainda de acordo com o autor, o rendimento condiciona a adoção da "alimentação moderna" (exemplos como refrigerantes, enlatados e conservas, alimentos preparados e a alimentação fora do domicílio) em comparação com a adesão pela "alimentação 
tradicional" (alimentos tipicamente brasileiros que exijam um certo grau de elaboração antes do consumo, tais como cereais, leguminosas e oleaginosas, alimentos frescos, leite e derivados).

Segundo Galeazzi, citado por Bleil (1998), toda vez que há aumento da renda de um grupo, seu padrão de consumo tende a ficar mais próximo ao do segmento mais rico, mesmo quando nenhum outro hábito se altera. Com a estabilização da moeda os brasileiros de todas as classes sociais passaram a planejar melhor as compras e a consumir uma variedade maior de alimentos, porém isso não significa que houve uma melhora na qualidade da dieta. Alguns produtos como cereal matinal, creme de leite e refrigerantes tiveram aumento de consumo, registrado especialmente entre famílias pertencentes as classes sociais de menor renda.

Tem merecido expressivo destaque nas publicações compiladas pela Organização Mundial de Saúde a associação estreita entre características qualitativas da dieta e ocorrências de enfermidades crônico-degenerativas, como as doenças cardiovasculares, o diabetes mellitus não insulino dependente, diferentes tipos de câncer e até mesmo a obesidade (OMS, 1998).

Drewnowski \& Popkin (1991), ao elaborar uma revisão de literatura sobre a transição nutricional global, ressaltam que embora dietas ricas em gordura principalmente advindas de carne, leite e derivados - fossem restritas æ̀s nações industrializadas, esse panorama está mudando e evidências têm mostrado que a transição nutricional tem ocorrido nos países em desenvolvimento, onde mais recentemente, uma parcela maior da população também passou a ter acesso a esse tipo de dieta. Os mesmos autores citam um estudo da Food and Agriculture Organization - FAO, realizado em 1962, envolvendo 85 nações que mostrava a relação linear entre produto interno bruto elevado e alto consumo de energia proveniente de açúcares e gorduras de origem animal e vegetal. Também elevado se revelava o consumo de proteína animal e baixo consumo de energia proveniente de carboidratos complexos. Praticamente três décadas mais tarde, os autores realizaram um estudo enfatizando a análise dos dados 
da FAO relativos ao período compreendido entre 1962 e 1990. Por meio de elaboração de análise de regressão obtiveram resultados que demonstraram uma relação linear entre consumo elevado de proteína e gordura e aumento da renda, reproduzindo os resultados obtidos e registrados no estudo da FAO, realizado no início da década de 60. Com as análises implementadas em 1990 os referidos autores observaram a ocorrência de profundas mudanças tais como o aumento da proporção de energia proveniente de gorduras vegetais entre a população das nações ricas e pobres. Portanto, uma situação que independe da renda da população. Dietas ricas em carne, leite e derivados revelaram vinculo com o consumo de indivíduos pertencentes aos estratos elevados de rendimentos.

Pesquisa realizada pelo então Instituto Nacional de Alimentação e Nutrição-INAN, em 1996 e citada por Bleil (1998), demostrava que apesar de ser a base da dieta nacional, o consumo do arroz e do feijão diminuiu 30\% entre os anos do período referente ao final das décadas de 70 e 80 .

Ainda, segundo a referida pesquisa, dados das indústrias de alimentos mostram que as vendas de salsicha e presunto aumentaram $50 \%$, entre os anos de 1996 e 1998 e que o refrigerante é um dos dez produtos alimentares mais consumidos, integrando a rotina de consumo da população brasileira,. Somente na cidade do Rio de Janeiro, o consumo do refrigerante aumentou $268 \%$ nos últimos 20 anos.

Outras mudanças constatadas na alimentação da população brasileira podem ser registradas, entre os anos de 1994 e 1995, como é o caso do crescimento de $70 \%$, em apenas dois anos, do consumo doméstico de hambúrgueres, pratos prontos, aves e carnes congeladas e ainda, a substituição da macarronada pelo macarrão instantâneo (marca comercial Miojo) e aumento de $140 \%$ do consumo de sopa pronta ("sopão"), apenas considerando as aquisições dos grupos com rendimentos mais baixos. Verificou-se também uma queda do consumo de feijão de $11,8 \mathrm{~kg}$ para $9,9 \mathrm{~kg}$ per capita (Bleil, 1998; Hoffmann, 1995). 
Bertasso (2000) analisa o efeito da faixa etária sobre o padrão de consumo alimentar, propondo a divisão em dois tipos. O primeiro diz respeito æ̀ necessidades nutricionais que diferem entre as diversas faixas etárias e 0 segundo está relacionado æ̀ diferenças de hábitos que pessoas de gerações diferentes apresentam. O autor cita dados do Instituto Brasileiro de Geografia e Estatística - IBGE (1997) que apontam para o processo de envelhecimento da população brasileira como um provável condicionante de mudanças no padrão de consumo alimentar. Prevê-se que a população brasileira crescerá 3,22 vezes até o ano de 2025, o segmento acima de 65 anos aumentará 8,9 vezes, e o grupo com idade acima de 80 anos, 15,6 vezes. Com isso a proporção de idosos passará de um patamar inferior a $6 \%$, verificado em 1980 , para $14 \%$, no ano de 2025. Desse modo, em menos de 50 anos o Brasil deverá ocupar o sexto lugar, no cenário mundial, com 31,8 milhões de idosos (Campos, et al, 2000).

Em suas análises, Bertasso (2000) observou uma certa homogeneidade no padrão de consumo alimentar das pessoas pertencentes a três grupos de famílias: famílias integradas por crianças e indivíduos com idade até 20 anos, famílias com jovens entre 21 e 30 anos e famílias com pessoas de 51 anos ou mais. $O$ autor concluiu que as pessoas que integram o primeiro e o terceiro grupos apresentaram menor freqüência de consumo fora do domicílio; que o nível de consumo per capita das pessoas do terceiro grupo é maior quando comparado ao primeiro; que as pessoas do terceiro grupo "privilegiam mais o consumo de alimentos tradicionais"; que as pessoas do primeiro grupo não discriminam alimentos "tradicionais e modernos" e que as pessoas do segundo grupo apresentam um maior nível de consumo alimentar fora do domicílio privilegiando mais alimentos de consumo rápido como lanches, salgadinhos, sucos, entre outros. Ainda de acordo com o referido autor, o envelhecimento da população acabará mesclando o consumo de alimentos tradicionais e modernos sem que ocorra total substituição dos primeiros ainda que haja um aumento progressivo do segundo grupo. 
Os dados relativos ao padrão alimentar da população brasileira são escassos, mas as informações disponíveis revelam que nos últimos vinte anos, a população brasileira passou a consumir maior quantidade de alimentos de origem animal, enquanto grãos e cereais passaram a ser ingeridos em menor quantidade. Em algumas regiões do país o consumo de gordura se revelou acima da recomendação máxima (30\% da energia total). Nota-se também que a proporção de adultos obesos aumentou em mais de $50 \%$, desde a realização, no início da década de 70, do Estudo Nacional da Despesa Familiar-ENDEF (Mondini \& Monteiro, 1994).

Drewnowski \& Popkin (1991), elaborando uma revisão de literatura sobre a transição nutricional global ressaltam que 0 aumento da renda e das populações vivendo em áreas urbanas têm levado æ̀ mudanças nos hábitos alimentares da sociedade. Os autores enfatizam que, de maneira geral, dietas ricas em carboidratos complexos e fibras têm dado lugar æ̀̀ mais variadas dietas com elevadas proporções de gorduras (inclusive saturadas) e açúcares. Essas mudanças na estrutura da dieta são acompanhadas por mudanças demográficas associadas à elevada expectativa de vida e redução dos índices de fertilidade. De forma concomitante, têm ocorrido mudanças na prevalência, entre a população, das doenças que passam dos grupos identificados como infecciosas e deficiências nutricionais, para a classe de associadas ao coração, câncer, obesidade (principalmente infantil) e diabetes não-insulino-dependente. Ainda segundo os referidos autores, para alguns profissionais da área de saúde, os efeitos adversos da transição nutricional, desarticulada de efetivos programas de orientação para o consumo, constitui uma das conseqüências negativas do crescimento econômico. Em alguns casos, a "ocidentalização" dos hábitos alimentares tem uma responsabilidade à parte, lembrando que alimentos importados, e o aumento do consumo de gordura animal e açúcares são associados ao aumento dos índices globais de obesidade e doenças crônico-degenerativas. Drewnowski \& Popkin (1991), ressaltam também o paradoxo das tendências alimentares salientando que enquanto as nações ricas 
industrializadas da América do Norte e da União Européia que investem substancial parcela de recursos econômicos tentando convencer a população a substituir a dieta contendo elevado conteúdo de gorduras pelas ricas em grãos, vegetais e frutas, as nações em desenvolvimento utilizam o crescimento da renda para substituir suas dietas tradicionais ricas em fibras pelas dietas ricas em gorduras e açúcares. Os autores enfatizam ainda que no final da década de 90, um dos grandes dilemas dos profissionais que atuam na área de nutrição e saúde é saber como conciliar o crescimento econômico e a prevenção, concomitantemente, dos efeitos indesejáveis da transição nutricional.

Vale ressaltar que em resposta æ̀ tendências alimentares, reveladas pela população, os países têm estabelecido programas nacionais de nutrição na tentativa de restabelecer a adequação nutricional das dietas e ofertas de alimentos e promover a prevenção de doenças-crônico-degenerativas. As estratégias adotadas envolvem intervenções no sentido de diminuir o consumo de gordura (total e saturada), de sódio e colesterol e elevar o de carboidratos complexos, fibras, frutas e vegetais (OMS, 1998).

Pesquisas atuais têm estimulado o surgimento de novos parâmetros para a avaliação da participação de lipídeos, proteínas e carboidratos no valor energético total da dieta (VET). Estudos intervencionais e epidemiológicos demostram que a baixa ingestão de gordura e a elevada ingestão de carboidratos reduzem a concentração plasmática de colesterol HDL e aumentam a de colesterol total e triacilgliceróis, potencializando os riscos de doença cardíaca coronária - DCC. Por outro lado, muitos estudos intervencionais mostram que a elevada ingestão de gordura eleva o consumo de energia total, causando ganho de peso. Esses estudos mostram ainda, que a combinação desses dois fatores pode ser prejudicial aos indivíduos suscetíveis à obesidade, intensificando as conseqüências metabólicas e, particularmente, os riscos de DCC. Além disso, dietas ricas em gordura, em geral, possuem elevados níveis de ácidos graxos saturados que podem aumentar as concentrações de colesterol LDL favorecendo os riscos de DCC. 
Com base no possível risco de DCC que as dietas pobres em gordura e a elevada ingestão energética podem oferecer, levando, consequentemente, a obesidade e, com base na ingestão de dietas ricas em gorduras, foi estimado pela National Academy of Sciences (2002), Acceptable macronutrients of distribution ranges - AMDR - por exemplo, para adultos, na faixa de $20-35 \%$ para gordura e, para carboidrato, em torno de $45-65 \%$ do total da energia, respectivamente. Com o consumo de gordura e carboidrato, respeitando essas faixas, o risco para a obesidade, assim como o risco para DCC e diabetes, podem ser minimizados. Além disso, os intervalos preconizados permitem a ingestão suficiente de nutrientes essenciais enquanto mantém a de ácidos graxos saturados em níveis moderados (National Academy of Sciences, 2002).

Evidências sugerem que crianças possuem uma taxa de oxidação de gordura maior em relação aos adultos e que o consumo de dietas pobres em gordura pode acarretar baixa ingestão de certos micronutrientes. Vale destacar que a alta ingestão de gordura pode elevar os riscos de DCC e obesidade. A gordura dietética fornece energia, importante para crianças de menor idade, cuja ingestão de alimentos é reduzida, especialmente durante a transição de uma dieta rica em leite para uma dieta mista. Consequentemente, nesta etapa, ocorre uma transição da alta ingestão de gordura (55\% de energia para crianças com idade entre 0 a 6 anos e $40 \%$ para crianças de 7 a 12 meses) para uma recomendação de consumo menor. Além disso, estima-se que a AMDR da ingestão de gordura é aproximadamente 30 a $40 \%$ de energia para crianças com idade entre 1 a 3 anos e 25 a 35\% de energia para indivíduos de 4 a 18 anos. A AMDR para carboidratos é a mesma para adultos ( 45 a $65 \%$ de energia). As taxas de ingestão de gordura incluem ingestão de gordura saturada que deve ser consumida em níveis tão baixos quanto possível (National Academy of Sciences, 2002).

Não há evidências de que a AMDR para proteína deva ser abaixo dos valores preconizados pela Recomended Dietary Allowances - RDA, (cerca de $10 \%$ do total de energia) para adultos. Para complementar as AMDRs de 
gordura (20 a 35\% de energia) e carboidrato ( 45 a $65 \%$ de energia) para adultos, a ingestão protéica, para assegurar uma dieta nutricionalmente adequada, pode ser situada entre 10 e $35 \%$ do valor energético total. Para crianças e adolescentes, a RDA é aproximadamente 5 e 10\% de energia, respectivamente. Para complementar a AMDR de gordura (30 a 40\% de energia) e carboidrato ( 45 a $65 \%$ de energia) para crianças e para os adolescentes (25 a 35\% de energia oriunda das gorduras e 45 a $65 \%$ de energia proveniente dos carboidratos), a ingestão protéica pode alcançar de 5 a $20 \%$ para crianças e 10 a $30 \%$ para adolescentes (National Academy of Sciences, 2002).

Não sobram dúvidas que a avaliação do padrão de consumo de alimentos de uma população é informação básica para a formulação do direcionamento, entre outros, de políticas em áreas como a saúde, agricultura, tecnologia de alimentos, comércio exterior. No entanto, é importante salientar que as informações sobre consumo alimentar da população brasileira são, ainda hoje, reduzidas. O país dispõe somente de um levantamento de consumo de alimentos, em nível nacional (IBGE, 1978) realizado em meados da década de 70. Além disso, há a disponibilidade de dados obtidos por duas Pesquisas de Orçamentos Familiares - realizadas nas décadas de 80 (POF 1987/1988) e 90 (POF 1995/1996).

Face ao exposto, julgou-se pertinente realizar a presente pesquisa, tendo por base os dados da mais recente Pesquisa de Orçamentos Familiares (1995/1996), implementada pelo Instituto Brasileiro de Geografia e Estatística IBGE (1998). 


\section{METODOLOGIA}

\subsection{Base de dados}

Como base de dados, foram utilizadas as informações registradas pela Pesquisa de Orçamentos Familiares - POF, realizada pelo IBGE, durante o período de 1ํ de outubro de 1995 a 30 de setembro de 1996 (IBGE, 1998).

O objetivo principal da POF foi obter informações sobre a estrutura de orçamentos das famílias, ou seja, sua receita ("o quanto ganham") e "com quais itens é gasta essa receita". Por meio da POF foi possível conhecer os bens consumidos e os serviços utilizados pelas famílias das regiões pesquisadas, bem como a participação de cada bem ou serviço na despesa global familiar. As informações contidas na POF possibilitam a elaboração de análises sobre a evolução dos hábitos de consumo da população brasileira pertencente à onze regiões metropolitanas pesquisadas. Permite também a investigação da alocação de gastos e distribuição dos recebimentos que em seu conjunto compõem os Índices Nacionais de Preços ao Consumidor, com o objetivo de atualiza-lo. Esse índice reflete o padrão médio de consumo da população abrangida pela pesquisa e é produzido pelo IBGE.

As informações sobre os gastos com alimentos e bebidas refletem os hábitos da população e permitem avaliar, de maneira indireta, a adequação nutricional da dieta das mesmas. Pode-se também utilizar essas informações para, como já registrado, "construir" cestas básicas de alimentos por meio das quais é viável o acompanhamento mensal dos preços e, ainda, o estabelecimento da medida de pobreza por meio do método da renda. 
A POF foi realizada por meio da definição de amostragem, ou seja, foi selecionada uma amostra populacional representativa da população como um todo. O plano de amostragem adotado na pesquisa foi praticamente o mesmo utilizado na POF 1986/1987 e compreendeu duas etapas de seleção. $\mathrm{Na}$ primeira etapa realizou-se a estratificação das unidades primárias (setor da base geográfica do Censo Demográfico 1991) e a seleção sistemática com probabilidade proporcional ao tamanho (número de domicílios). A seguinte etapa foi dedicada à seleção aleatória das unidades de segundo estágio (domicílio particular permanente).

De acordo com o IBGE, as informações da pesquisa foram obtidas diretamente nos domicílios particulares (amostra probabilística) selecionados, por meio de entrevistas realizadas junto aos moradores. Os domicílios pertencem æ̀ regiões metropolitanas de: Belém, Fortaleza, Recife, Salvador, Belo Horizonte, Rio de Janeiro, São Paulo, Curitiba, Porto Alegre além de Brasília - DF e município de Goiânia. Nestas importantes áreas urbanas encontram-se $29,85 \%$ da população brasileira, sendo que, se for considerado o perímetro urbano, esse percentual alcança $37,69 \%$.

Durante as entrevistas, os pesquisadores obtiveram, inicialmente, informações sobre o domicílio e seus moradores, para só então serem registradas as despesas e os recebimentos. Alguns dados foram obtidos por meios de questionários recorrendo-se à memória dos entrevistados (como as despesas com a habitação e a aquisição de bens duráveis, informações sobre os rendimentos, recebimentos e as deduções e encargos incidentes sobre os mesmos). Os demais dados, referentes a despesas com alimentos, produtos de higiene e limpeza foram anotados por sete dias consecutivos pelos próprios moradores num sistema de caderneta.

A coleta de campo da POF teve a duração de doze meses, compreendendo o período de $1^{\circ}$ de outubro de 1995 a 30 de setembro de 1996 de maneira a contemplar todas as épocas do ano. Desse modo, foi possível que os resultados refletissem o padrão médio anual de consumo e a variação dos 
gastos e recebimentos. Viabilizou-se, também, a identificação da sazonalidade do consumo, ou seja, obter não só os gastos realizados de forma contínua durante o todo o ano, mas também os gastos efetuados com maior intensidade, por exemplos, devido à diferentes estações do ano, mudanças de preços dos produtos em função de safra e entressafra, datas especiais como férias, início de ano letivo, natal. Todos os dados de "valor" da POF foram registrados na forma de dados "anuais", com data referencial em 15 de setembro de 1996 (corrigidos da data de registro até esse dia pelo Índice Nacional de Preços ao Consumidor - INPC/IBGE, tornando todos os valores de despesas e recebimentos a preços constantes).

Vale ressaltar que as quantidades de produtos foram obtidas de forma direta, ou seja, informadas pelas famílias pesquisadas, diferentemente dos resultados apresentados na publicação respectiva a POF 1987-1988, cuja metodologia consistiu na mensuração indireta do consumo, com base nas despesas informadas por produto e os preços médios obtidos do Sistema Nacional de Índices de Preços ao Consumidor - SNIPC. Embora haja essa diferença de metodologia entre as duas pesquisas, os resultados são comparáveis, pois ensaios realizados com as duas metodologias, utilizando-se dados dos principais produtos da última POF, revelaram a não existência de diferenças estatisticamente significativas.

Para a obtenção das quantidades de alimentos consumidas, o IBGE adotou instrumentos de coleta onde eram registrados diariamente, durante sete dias consecutivos, a descrição detalhada de cada produto, o valor pago, a unidade de medida e a quantidade (em gramas ou mililitros). Todas as unidades foram transformadas em peso, "anualizadas" e expandidas para a população como um todo e finalmente os resultados foram tabulados, adotando-se o registro em quilogramas per capita ano e apresentados por faixa de renda mensal familiar (salário mínimo), de acordo com o produto e agregações de subgrupos e grupos - agregações feitas considerando-se fatores como morfologia e parte pela qual o produto é comercializado. 
Destaca-se que, diferentemente da Pesquisa de Orçamentos Familiares POF 1987-1988, os resultados das quantidades de alimentos e bebidas adquiridos para consumo domiciliar são apresentados por área pesquisada e também por faixa de renda mensal familiar (em salários mínimos), o que possibilita uma maior complexidade na sua exploração.

O Quadro 4 mostra o número de setores selecionados e também o número de domicílios esperados, selecionados e "entrevistados" no total, segundo as áreas das pesquisas.

\begin{tabular}{|l|c|c|c|c|}
\hline \multirow{2}{*}{$\begin{array}{c}\text { Áreas da } \\
\text { Pesquisa }\end{array}$} & \multirow{2}{*}{$\begin{array}{c}N^{0} \text { de setores } \\
\text { selecionados }\end{array}$} & \multicolumn{3}{|c|}{ Número de Domicílios } \\
\cline { 3 - 5 } & & Esperados & Selecionados & "Entrevistados" \\
\hline Total & 1456 & 14560 & 19816 & 16014 \\
\hline Belém & 128 & 1280 & 1699 & 1415 \\
\hline Fortaleza & 175 & 1750 & 2398 & 1982 \\
\hline Recife & 174 & 1740 & 2349 & 1891 \\
\hline Salvador & 142 & 1420 & 1983 & 1488 \\
\hline Belo Horizonte & 136 & 1360 & 1840 & 1548 \\
\hline Rio de Janeiro & 144 & 1440 & 2001 & 1623 \\
\hline São Paulo & 124 & 1240 & 1734 & 1352 \\
\hline Curitiba & 105 & 1050 & 1409 & 1095 \\
\hline Porto Alegre & 106 & 1060 & 1424 & 1223 \\
\hline Brasília & 88 & 880 & 1177 & 880 \\
\hline Goiânia & 134 & 1340 & 1802 & 1517 \\
\hline
\end{tabular}

Quadro 4 - Setores selecionados e domicílios esperados, selecionados e "entrevistados" no total, segundo a área das pesquisas. POF 1995/1996.

Fonte: IBGE (1998)

A seguir, no Quadro 5, são mostrados os municípios que integram as regiões metropolitanas pertencentes a amostra da POF 1995/1996. 


\begin{tabular}{|c|c|}
\hline $\begin{array}{c}\text { Regiões } \\
\end{array}$ & Municípios Integrantes \\
\hline Região Metropolitana de Belém & Ananindeua e Belém \\
\hline Região Metropolitana de Fortaleza & $\begin{array}{l}\text { Aquiraz, Caucaia, Euzébio, Fortaleza, Guaiúba, } \\
\text { Maracanaú, Maranguape e Pacatuba. }\end{array}$ \\
\hline Região Metropolitana de Recife & $\begin{array}{l}\text { Abreu e Lima, Cabo, Camaragibe, lgarassu, } \\
\text { Itamaracá, Itapissuma, Jaboatão dos Guararapes, } \\
\text { Moreno, Olinda, Paulista, Recife e São Lourenço } \\
\text { da Mata. }\end{array}$ \\
\hline Região Metropolitana de Salvador & $\begin{array}{l}\text { Camaçari, Candeias, Dias d'Ávila, Itaparica, Lauro } \\
\text { de Freitas, Madre de Deus, Salvador, São } \\
\text { Francisco do Conde, Simões Filho e Vera Cruz. }\end{array}$ \\
\hline Região Metropolitana de Belo Horizonte & $\begin{array}{l}\text { Belo Horizonte, Betim, Brumadinho, Caeté, } \\
\text { Contagem, Esmeraldas, Ibirité, Igarapé, Lagoa } \\
\text { Santa, Mateus Leme, Nova Lima, Pedro Leopoldo, } \\
\text { Raposos, Ribeirão das Neves, Rio Acima, Sabará, } \\
\text { Santa Luzia e Vespasiano. }\end{array}$ \\
\hline Região Metropolitana de Rio de Janeiro & $\begin{array}{l}\text { Duque de Caxias, Itaboraí, Itaguí, Magé, } \\
\text { Mangaratiba, Marica, Nilópolis, Niterói, Nova } \\
\text { Iguaçu, Paracambi, Rio de Janeiro, São Gonçalo e } \\
\text { São João de Meriti. }\end{array}$ \\
\hline Região Metropolitana de São Paulo & $\begin{array}{l}\text { Arujá, Barueri, Biritiba-Mirim, Caieiras, Cajamar, } \\
\text { Carapicuíba, Cotia, Diadema, Embu, Embu- } \\
\text { Guaçu, Ferraz de Vasconselos, Francisco Morato, } \\
\text { Franco da Rocha, Guaracema, Guarulhos, } \\
\text { Itapecirica da Serra, Itapevi, Itaquaquecetuba, } \\
\text { Jandira, Juquitiba, Mairiporã, Mauá, Moji das } \\
\text { Cruzes, Osasco, Pirapora do Bom-Jesus, Poá, } \\
\text { Ribeirão Pires, Rio Grande da Serra, Salesópolis, } \\
\text { Santa Isabel, Santana de Parnaíba, Santo André, } \\
\text { São Bernardo do Campo, São Caetano do Sul, } \\
\text { São Paulo, Suzano, Taboão da Serra e Vargem } \\
\text { Grande Paulista. }\end{array}$ \\
\hline Região Metropolitana de Curitiba & $\begin{array}{l}\text { Almirante Tamandaré, Araucária, Balsa Nova, } \\
\text { Bocaiúva do Sul, Campina Grande do Sul, Campo } \\
\text { Largo, Colombo, Contenda, Curitiba, Mandirituba, } \\
\text { Piraquara, Quatro Barras, Rio Branco do Sul, São } \\
\text { José dos Pinhais, Cerro Azul, Quitandinha e } \\
\text { Tijucas do Sul. }\end{array}$ \\
\hline Região Metropolitana de Porto Alegre & $\begin{array}{l}\text { Alvorada, Cachoeirinha, Campo Bom, Canoas, } \\
\text { Dois Irmãos, Eldorado do Sul, Estância Velha, } \\
\text { Esteio, Glorinha, Gravataí, Guaíba, Ivoti, Nova } \\
\text { Hartz, Novo Hamburgo, Parobé, Portão, Porto } \\
\text { Alegre, São Leopoldo, Sapiranga, Sapucaia do } \\
\text { Sul, Triunfo e Viamão. }\end{array}$ \\
\hline Brasília - DF & Brasília \\
\hline Goiânia & Goiânia. \\
\hline
\end{tabular}

\section{Quadro 5 - Municípios que integram as regiões metropolitanas integrantes da POF 1995-1996.}

Fonte: IBGE (1998) 
É importante ressaltar que devido à dificuldade de se obter informações sobre a quantidade de determinados produtos, principalmente aqueles que são comercializados por unidades de medidas que impossibilitam o conhecimento de seu peso (exemplos: pé, maço, entre outras), os resultados de consumo alimentar domiciliar da POF não refletem a totalidade dos produtos, entretanto abrangem a totalidade de consumo dos produtos mais importantes que representam cerca de $89,08 \%$ do gasto total com alimentos.

Outro fator que merece destaque é o fato de a POF não ter sido concebida com o objetivo de permitir avaliações nutricionais da população, entretanto, as despesas familiares com alimentos bem como o volume comprado dos mesmos possibilitam fazê-lo indiretamente. Quanto a isso Rocha (1999) lembra que a despesa monetária não corresponde necessariamente ao consumo, porém, o consumo monetário é parcela significativa do consumo alimentar em áreas urbanas. Além, disso, a disponibilidade do produto por meio do consumo monetário ou outra forma não significa ingestão efetiva. A POF não investiga a ingestão, nem como os alimentos são repartidos entre os membros da família, ela não é o recurso mais preciso para a elaboração de estudos de avaliação nutricional dos indivíduos que integram as família porém, trata-se da melhor fonte para estudos que enfocam a relação entre perfil socioeconômico e despesa alimentar (Rocha, 1999).

Segundo Silva (1999), a POF é de grande importância para auxiliar tomadas de decisões sobre o combate à fome e à pobreza. $O$ autor ainda cita a importância da POF para diversas áreas de estudo, tais como: avaliação do consumo alimentar domiciliar; avaliação sobre disponibilidade interna de alimentos e estudos de segurança alimentar; identificação de padrões nutricionais; estimativa do consumo pessoal; análises relativas aos padrões e tendências do consumo das famílias; estudos de diferenças regionais; avaliações mercadológicas; estruturas de despesas das famílias; diagnósticos sobre aspectos demográficos e socioeconômicos em geral; composição e 
distribuição da renda das famílias; geração de estruturas de ponderação do Sistema Nacional de Índices de Preços ao Consumidor.

Julgou-se interessante apresentar, a seguir (Quadro 6), os dados relativos à despesas das famílias, integrantes da amostra da POF, quando se considera a alimentação (em trânsito domiciliar e fora dele).

\begin{tabular}{|l|c|c|c|c|c|}
\hline \multirow{2}{*}{$\begin{array}{c}\text { Região } \\
\text { metropolitana }\end{array}$} & \multirow{2}{*}{$\begin{array}{c}\text { Total dos gastos } \\
\text { (em reais) }\end{array}$} & \multicolumn{4}{|c|}{ Valor em reais da despesa mensal familiar de acordo } \\
& & \multicolumn{4}{|c|}{ com o local } \\
\cline { 3 - 6 } & & Valor & percentual & valor & percentual \\
\cline { 3 - 6 } & & 128,43 & 79,25 & 33,63 & 20,75 \\
\hline Goiânia & 162,06 & 203,80 & 74,75 & 68,85 & 25,25 \\
\hline Brasília & 272,65 & 201,89 & 80,99 & 47,38 & 19,01 \\
\hline Belém & 249,27 & 161,17 & 76,05 & 50,76 & 23,95 \\
\hline Fortaleza & 211,93 & 168,31 & 80,37 & 41,12 & 19,63 \\
\hline Recife & 209,43 & 172,17 & 77,05 & 51,27 & 22,946 \\
\hline Salvador & 223,44 & 173,87 & 72,94 & 64,51 & 27,06 \\
\hline Belo Horizonte & 238,38 & 142,88 & 71,36 & 57,34 & 28,64 \\
\hline Rio de Janeiro & 200,22 & 191,97 & 74,45 & 65,89 & 25,55 \\
\hline São Paulo & 257,86 & 188,81 & 78,15 & 52,79 & 21,85 \\
\hline Curitiba & 241,60 & 174,63 & 75,27 & 57,36 & 24,72 \\
\hline Porto Alegre & 231,99 & & &
\end{tabular}

Quadro 6 - Valor da despesa média mensal familiar com a alimentação. POF. 1995/1996.

Fonte: IBGE (1998)

Devido æ̀ dificuldades envolvidas em uma análise que englobe a totalidade das onze regiões metropolitanas integrantes da POF, optou-se, nesta pesquisa, por restringi-la às áreas de Recife e São Paulo. Essas regiões foram escolhidas visando permitir uma comparação regional que tenha como sujeitos regiões (no caso São Paulo e Recife) com grande contingente populacional e bastante díspares, entre outros aspectos, quanto ao índice de distribuição de renda, características culturais e níveis de desenvolvimento econômico vigentes. 
Integram o Quadro 7, os dados relativos às características econômicas das famílias pertencentes às regiões metropolitanas de São Paulo e Recife, selecionadas para integrarem a presente pesquisa.

\begin{tabular}{|l|l|c|c|c|c|}
\hline $\begin{array}{c}\text { Região } \\
\text { Metropolitana }\end{array}$ & $\begin{array}{c}\text { Estrato de } \\
\text { Recebimento } \\
\text { (em salários mínimos) }\end{array}$ & Limite & $\begin{array}{c}\text { Recebimento } \\
\text { Total }\end{array}$ & $\begin{array}{c}\text { Número de } \\
\text { Famílias }\end{array}$ & $\begin{array}{c}\text { Número de } \\
\text { Pessoas }\end{array}$ \\
\hline São Paulo & até 2 & 0 & 156,14 & 296824 & 804357 \\
Recife & até 2 & 0 & 142,21 & 184972 & 659012 \\
\hline São Paulo & Mais de 2 a 3 & 224 & 281,63 & 244246 & 766104 \\
Recife & Mais de 2 a 3 & 224 & 297,70 & 96624 & 380073 \\
\hline São Paulo & Mais de 3 a 5 & 336 & 441,73 & 495329 & 1829251 \\
Recife & Mais de 3 a 5 & 336 & 443,12 & 130097 & 572433 \\
\hline São Paulo & Mais de 5 a 6 & 560 & 613,38 & 289434 & 1066272 \\
Recife & Mais de 5 a 6 & 560 & 614,66 & 40027 & 171078 \\
\hline São Paulo & Mais de 6 a 8 & 672 & 786,50 & 480778 & 1751715 \\
Recife & Mais de 6 a 8 & 672 & 784,53 & 66053 & 299198 \\
\hline São Paulo & Mais de 8 a 10 & 896 & 1018,94 & 336931 & 1363644 \\
Recife & Mais de 8 a 10 & 896 & 1019,75 & 35024 & 150514 \\
\hline São Paulo & Mais de 10 a 15 & 1120 & 1378,56 & 693843 & 2696824 \\
Recife & Mais de 10 a 15 & 1120 & 1387,73 & 56535 & 244163 \\
\hline São Paulo & Mais de 15 a 20 & 1680 & 1955,90 & 407524 & 1661012 \\
Recife & Mais de 15 a 20 & 1680 & 1947,87 & 29830 & 123088 \\
\hline São Paulo & Mais de 20 a 30 & 2240 & 2749,66 & 409422 & 1558111 \\
Recife & Mais de 20 a 30 & 2240 & 2785,91 & 33339 & 131297 \\
\hline São Paulo & mais de 30 & 3360 & 6585,53 & 636838 & 2438730 \\
Recife & mais de 30 & 3360 & 5900,22 & 43437 & 175572 \\
\hline
\end{tabular}

Quadro 7 - Características econômicas e demográficas das famílias pertencentes às regiões metropolitanas de Recife e São Paulo. 1995/1996.

Fonte: IBGE (1998) 


\subsection{Análise dos Dados}

Para a análise dos dados, inicialmente foi realizada a construção de planilhas utilizando o software Microsoft Excel (versão 2000), adotando-se como base de dados as informações disponibilizadas pelo IBGE, por meio da última Pesquisa de Orçamentos Familiares - POF 1995/1996 (IBGE, 1998). As planilhas foram construídas com o objetivo de converter os dados de consumo (anual) alimentar domiciliar per capita, registrados em quilogramas pela POF, em consumo alimentar domiciliar per capita diário (em gramas) por meio da divisão dos valores em quilograma/ano de consumo de cada alimento por 365 dias e multiplicando-se o valor obtido por 1000. Vale registrar que os cálculos do conteúdo disponível de energia e nutrientes, para as famílias das regiões metropolitanas de Recife e São Paulo, foram elaborados para a totalidade dos estratos de recebimentos. Os cálculos foram viabilizados, adotando-se o software Virtual Nutri - Sistema de Análise Nutricional (versão 1.0 for Windows 1996) desenvolvido por pesquisadores da Faculdade de Saúde Pública da Universidade de São Paulo (Philippi et al, 1996). Nesta etapa realizou-se a inclusão de todos os alimentos (com vistas à construção de banco de dados) presentes nas planilhas, para as faixas selecionadas de recebimentos. Cabe ressaltar que nesta etapa do trabalho algumas dificuldades foram identificadas:

- nem todos os alimentos presentes nas planilhas estavam registrados no banco de dados do programa. Em vista disso foi necessário elaborar um amplo levantamento dos alimentos registrados em tabelas de composição de alimentos. Foram consultadas fontes complementares de dados, como exemplos a Tabela de Composição Química dos Alimentos do ENDEF (FIBGE, 1978), Tabela de Composição Química de Alimentos do IBGE (FIBGE, 1981), Tabela de Composição Química dos Alimentos (Franco, 1992) e Tabela Brasileira de Composição de Alimentos (Faculdade de Ciências Farmacêuticas, 2001). Após o levantamento, foi incluído cada novo alimento no arquivo básico de composição nutricional de alimentos integrante do software. Essa iniciativa 
demandou cuidadosa revisão com vistas à não incorporação de informações indevidas no banco de dados;

- a composição nutricional de alguns alimentos não foi encontrada, sendo necessário agrupar alimentos semelhantes, pois a não inclusão dos mesmos no banco de dados levaria a obtenção de um conteúdo total subestimado do consumo alimentar o que poderia prejudicar a análise nutricional. Vale frisar que o padrão alimentar da população tem por base a participação relativa dos diferentes alimentos (ou grupos de alimentos) na dieta. Após o agrupamento dos alimentos, empreendeu-se nova revisão do banco de dados.

Para analisar como a disponibilidade de energia e os nutrientes selecionados variam com o recebimento familiar per capita nas duas regiões metropolitanas analisadas, utilizou-se o modelo de regressão múltipla descrito a seguir. Seja Y o logaritmo da disponibilidade per capita de energia ou nutrientes e seja $X$ o logaritmo do recebimento per capita em cada um dos dez estratos de rendimento familiar. Para captar a diferença entre São Paulo e Recife, define-se uma variável binária $Z$ de maneira que $Z=0$ para Recife e $Z=1$ para São Paulo. O modelo utilizado é:

$$
\begin{aligned}
& Y_{i}=\alpha+\beta X_{i}+\gamma Z_{i}+\delta Z_{i} X_{i}+\mu_{i} \text {, onde: } \\
& i=1,2 \ldots, 20
\end{aligned}
$$

Note-se que para Recife, com $Z=0$, os valores esperados de $Y$ são dados por:

$$
E(Y)=\alpha+\beta X
$$

Para São Paulo, com $Z=1$, os valores esperados de $Y$ são:

$$
E(Y)=\alpha+\gamma+(\beta+\gamma) X
$$


O parâmetro $\gamma$ mostra em quanto o intercepto da reta para São Paulo difere do intercepto da reta para Recife e o parâmetro $\delta$ mostra a diferença na inclusão das duas retas. Para verificar se existe diferença entre as duas retas, ou seja, para verificar se a maneira como a disponibilidade varia de acordo com o rendimento difere nas duas regiões metropolitanas, deve se testar a hipótese da nulidade de que $\gamma=\delta=\gamma=0$. Nesta pesquisa, serão apresentadas tabelas e figuras, visando melhor ilustrar os resultados obtidos.

Julgou-se pertinente também identificar a participação de proteína de alto valor biológico na disponibilidade total de proteína nos domicílios das famílias residentes nas duas regiões metropolitanas selecionadas.

De acordo com Vanucchi et al (1990), a participação de proteína de origem animal deve ser de 35\%, em relação àdisponibilidade protéica total.

Elaborou-se a análise da participação dos macronutrientes (carboidratos, proteína e lipídeos) no valor total de energia disponível nos domicílios das famílias pertencentes a totalidade dos estratos de recebimentos. Adotou-se os parâmetros preconizados pela National Academy of Sciences (2002). Tendo por base a população adulta, são aceitos os seguintes intervalos de participação dos macronutrientes no VET: lipídeos, 20-35\%, carboidratos, 45-65\% e proteínas, $10-35 \%$.

À semelhança das demais avaliações, as análises foram elaboradas utilizando-se o Statistical Analysis Sistem - SAS (1996).

Visando descrever a estrutura do valor energético total - VET disponível, nos domicílios das regiões metropolitanas de Recife e São Paulo, no tocante a participação de proteínas, lipídeos e carboidratos e, também, a comparação entre a situação registrada para as referidas regiões, adotou-se a técnica estatística da regressão múltipla, cujo modelo é apresentado a seguir: 
$\mathrm{Y}=\alpha+\beta \mathrm{X}+\gamma \mathrm{Z}+\delta \mathrm{ZX}+\mathrm{u}$

quando $Z=0$, obtém-se $E(Y)=\alpha+\beta X$

quando $Z=1$, obtém-se $E(Y)=\alpha+\gamma+(\beta+\delta) X$

Onde:

Y = percentual de proteínas, ou lipídeos ou carboidratos

$\mathrm{X}=\ln$ (recebimento per capita)

$Z$ = variável binária (0 para Recife e 1 para São Paulo)

Visou-se também caracterizar o padrão alimentar com base na participação relativa de grupos selecionados de alimentos na disponibilidade de energia (ou calórica) total. A referida caracterização foi elaborada para as famílias pertencentes a três estratos de recebimentos (inferior a dois salários mínimos; com recebimentos entre seis e oito salários mínimos e superior a trinta salários mínimos) das duas regiões metropolitanas. 


\section{RESULTADOS E DISCUSSÃO}

Inicialmente serão apresentadas os resultados e análises relativos à disponibilidade, no domicílio, de energia e nutrientes. Vale lembrar que, conforme descrito na seção referente à metodologia, as análises foram elaboradas tendo por base as informações das famílias integrantes da amostra, residentes nas regiões metropolitanas de Recife e São Paulo, pertencentes à totalidade $(n=10)$ dos estratos de recebimento, distinguidos na POF 1995/1996.

A Tabela 1 reúne os dados referentes à disponibilidade de energia e nutrientes para famílias pertencentes aos dez estratos de recebimento em salários mínimos - s.m. das duas regiões metropolitanas selecionadas. 
Tabela 1. Disponibilidade de energia e nutrientes nos domicílios das regiões metropolitanas de São Paulo e Recife, de acordo com o recebimento familiar per capita (em salários mínimos). 1995/1996.

\begin{tabular}{|c|c|c|c|c|c|c|c|c|c|c|}
\hline \multirow{3}{*}{ Energia e Nutrientes } & \multicolumn{10}{|c|}{ Estratos de Recebimento em Salários Mínimos } \\
\hline & \multicolumn{5}{|c|}{ São Paulo } & \multicolumn{5}{|c|}{ Recife } \\
\hline & $<2$ & 2 a 3 & 3 a 5 & 5 a 6 & 6 a 8 & $<2$ & 2 a 3 & 3 a 5 & 5 a 6 & 6 a 8 \\
\hline Energia (Kcal) & 1065 & 1102 & 1594 & 1871 & 1455 & 1257 & 1651 & 1582 & 1834 & 1860 \\
\hline Carboidrato $(\mathrm{g})$ & 160,4 & 155,3 & 233,0 & 281,5 & 204,2 & 198,5 & 259,4 & 248,0 & 287,5 & 273,9 \\
\hline Lipídeo Total (g) & 30,6 & 34,4 & 53,3 & 57,4 & 46,5 & 33,8 & 46,6 & 44,2 & 51,5 & 54,3 \\
\hline Lipídeo Insaturado (g) & 14,5 & 14,3 & 29,1 & 27,5 & 22,2 & 13,8 & 19,7 & 17,8 & 19,0 & 21,5 \\
\hline Fibra $(g)$ & 4,9 & 5,3 & 6,5 & 8,5 & 7,0 & 6,4 & 9,1 & 8,6 & 10,8 & 10,2 \\
\hline Colesterol (mg) & 123,1 & 136,2 & 157,7 & 157,5 & 320,1 & 135,2 & 176,6 & 166,7 & 185,4 & 231,7 \\
\hline Vitamina A (mg) & 971,0 & 1857,1 & 1167,3 & 3004,5 & 2777,0 & 4121,6 & 6897,4 & 4229,7 & 6355,4 & 5876,2 \\
\hline Retinol (RE) & 173,9 & 352,0 & 271,8 & 500,0 & 680,7 & 678,6 & 1052,8 & 767,5 & 979,5 & 1077,2 \\
\hline Vitamina C (mg) & 26,0 & 31,0 & 27,4 & 48,0 & 57,8 & 33,5 & 50,9 & 46,4 & 69,0 & 54,8 \\
\hline Vitamina B6 (mg) & 0,2 & 0,21 & 0,25 & 0,30 & 0,44 & 0,44 & 0,50 & 0,46 & 0,38 & 1,38 \\
\hline Vitamina B12 (mg) & 1,38 & 2,74 & 2,01 & 3,25 & 4,95 & 3,57 & 4,81 & 4,78 & 4,24 & 7,73 \\
\hline Niacina (mg) & 8,66 & 9,01 & 9,64 & 13,19 & 12,44 & 10,39 & 12,60 & 12,31 & 14,82 & 16,60 \\
\hline Folacina $(\mu \mathrm{g})$ & 47,1 & 50,8 & 47,8 & 58,2 & 66,6 & 52,8 & 70,10 & 67,23 & 85,71 & 87,10 \\
\hline Vitamina E (mg) & 7,1 & 7,1 & 16,4 & 14,7 & 11,1 & 9,0 & 12,9 & 11,3 & 12,6 & 14,7 \\
\hline Cálcio (mg) & 149,8 & 168,7 & 169,7 & 185,7 & 191,7 & 244,0 & 309,4 & 326,9 & 380,0 & 375,6 \\
\hline Magnésio (mg) & 69,4 & 66,0 & 88,5 & 107,6 & 90,8 & 82,0 & 108,8 & 101,1 & 123,9 & 126,7 \\
\hline Zinco (mg) & 2,45 & 2,30 & 2,74 & 3,66 & 3,77 & 2,62 & 3,31 & 3,34 & 3,84 & 5,51 \\
\hline Manganês (mg) & 0,47 & 0,71 & 1,27 & 1,62 & 1,58 & 0,42 & 0,44 & 1,11 & 0,74 & 1,74 \\
\hline Fósforo (mg) & 353,4 & 348,9 & 406,3 & 524,3 & 488,7 & 494,5 & 643,12 & 625,39 & 722,11 & 802,14 \\
\hline Ferro (mg) & 5,25 & 5,23 & 6,26 & 7,64 & 6,91 & 7,75 & 9,30 & 9,14 & 10,76 & 12,66 \\
\hline Cobre (mg) & 21,64 & 17,20 & 0,99 & 1,17 & 0,90 & 11,15 & 15,44 & 15,44 & 17,99 & 18,84 \\
\hline Selênio $(\mu \mathrm{g})$ & 29,91 & 29,35 & 29,86 & 33,78 & 36,96 & 25,77 & 29,99 & 33,11 & 40,41 & 51,64 \\
\hline
\end{tabular}


Tabela 1. Disponibilidade de energia e nutrientes nos domicílios das regiões metropolitanas de São Paulo e Recife, de acordo com o recebimento familiar per capita (em salários mínimos). 1995/1996.

\begin{tabular}{|c|c|c|c|c|c|c|c|c|c|c|}
\hline \multirow{3}{*}{ Energia e Nutrientes } & \multicolumn{10}{|c|}{ Estratos de Recebimento em Salários Mínimos } \\
\hline & \multicolumn{5}{|c|}{ São Paulo } & \multicolumn{5}{|c|}{ Recife } \\
\hline & 8 a 10 & 10 a 15 & 15 a 20 & 20 a 30 & mais de 30 & 8 a 10 & 10 a 15 & 15 a 20 & 20 a 30 & mais de 30 \\
\hline Energia (Kcal) & 1347 & 1405 & 1506 & 2336 & 1761 & 1791 & 2022 & 1937 & 1772 & 2278 \\
\hline Carboidrato (g) & 200,8 & 191,5 & 196,8 & 313,0 & 237,6 & 271,3 & 304,2 & 301,2 & 256,5 & 361,2 \\
\hline Lipídeo Total (g) & 40,4 & 44,3 & 51,5 & 78,6 & 58,0 & 52,2 & 58,4 & 55,7 & 53,6 & 62,8 \\
\hline Lipídeo Insaturado (g) & 19,0 & 20,1 & 23,7 & 30,6 & 20,0 & 19,0 & 21,1 & 22,6 & 18,7 & 19,1 \\
\hline Fibra $(\mathrm{g})$ & 6,2 & 6,5 & 6,0 & 17,3 & 10,0 & 9,1 & 11,5 & 11,4 & 10,7 & 13,8 \\
\hline Colesterol (mg) & 151,9 & 172,2 & 175,0 & 407,3 & 226,6 & 214,3 & 220,9 & 151,8 & 238,1 & 236,3 \\
\hline Vitamina A (mg) & 1540,8 & 2583,4 & 2482,1 & 6670,6 & 4403,0 & 5959,8 & 8271,0 & 3585,2 & 5385,5 & 6705,8 \\
\hline Retinol (RE) & 298,5 & 365,7 & 338,5 & 1121,1 & 645,2 & 1066,4 & 1284,0 & 495,4 & 924,6 & 865,5 \\
\hline Vitamina C (mg) & 37,1 & 50,8 & 54,0 & 132,3 & 87,8 & 61,5 & 82,1 & 76,1 & 78,2 & 130,2 \\
\hline Vitamina B6 (mg) & 0,29 & 0,59 & 0,48 & 0,92 & 0,61 & 0,40 & 0,65 & 1,21 & 0,51 & 1,47 \\
\hline Vitamina B12 (mg) & 1,89 & 2,08 & 2,04 & 5,96 & 2,94 & 6,59 & 6,11 & 1,51 & 5,60 & 1,03 \\
\hline Niacina (mg) & 10,60 & 12,57 & 12,34 & 21,40 & 14,70 & 15,34 & 16,59 & 13,57 & 16,18 & 17,33 \\
\hline Folacina $(\mu \mathrm{g})$ & 48,9 & 65,4 & 68,3 & 123,6 & 92,9 & 86,6 & 100,2 & 87,9 & 100,3 & 120,2 \\
\hline Cálcio (mg) & 168,2 & 220,9 & 198,1 & 389,6 & 354,5 & 348,2 & 443,7 & 424,0 & 473,8 & 592,3 \\
\hline Magnésio (mg) & 77,3 & 89,6 & 100,7 & 157,1 & 112,2 & 111,9 & 130,1 & 108,0 & 116,0 & 130,5 \\
\hline Zinco (mg) & 2,89 & 4,18 & 4,39 & 6,60 & 4,88 & 3,94 & 4,42 & 3,80 & 4,49 & 3,16 \\
\hline Manganês (mg) & 0,55 & 1,27 & 1,26 & 2,03 & 3,10 & 0,98 & 1,00 & 0,85 & 0,90 & 2,03 \\
\hline Fósforo (mg) & 399,8 & 515,3 & 518,5 & 940,9 & 669,8 & 718,0 & 833,5 & 730,2 & 817,4 & 878,7 \\
\hline Ferro (mg) & 5,75 & 6,62 & 7,07 & 12,27 & 8,63 & 10,55 & 11,58 & 11,13 & 10,89 & 11,84 \\
\hline Cobre (mg) & 0,71 & 0,74 & 0,93 & 1,58 & 1,00 & 17,68 & 17,64 & 15,90 & 11,40 & 15,13 \\
\hline Selênio $(\mu \mathrm{g})$ & 31,10 & 43,73 & 42,83 & 68,53 & 52,96 & 44,95 & 47,24 & 46,36 & 52,90 & 46,73 \\
\hline
\end{tabular}


Analisando os resultados apresentados na Tabela 1, nota-se que a disponibilidade de energia (per capita) para famílias com renda inferior a dois salários mínimos (cerca de 1065 kcal e 1257 kcal para São Paulo e Recife, respectivamente) são inferiores aos verificados para os indivíduos integrantes de famílias cuja renda situa-se entre seis e oito salários mínimos $\approx 1455$ para São Paulo e $\approx 1860$ para Recife) e para os grupos com recebimentos superiores a trinta salários mínimos $\approx 1761 \mathrm{kcal}$ para São Paulo e $\approx 2278 \mathrm{kcal}$ para Recife). Isso revela que, como esperado, o grupo mais rico tem disponível, no domicílio, alimentos que fornecem quantidades substancialmente maiores de energia, quando se compara as informações com os dados obtidos para indivíduos mais pobres. Comparando-se os resultados, considerando a mesma faixa de rendimentos, observa-se também que indivíduos da região metropolitanos de Recife dispõem de um conteúdo de energia mais elevado quando se compara com a região metropolitana de São Paulo, para as três faixas de renda $k 2$ s.m., 6 a 8 s.m. e superior a 30 s.m.). Este resultado é surpreendente uma vez que se esperava que famílias da região sudeste, considerada mais rica, revelassem indivíduos com consumo desse item maior que o encontrado para a região nordeste, reconhecida com a mais pobre do Brasil.

Em geral, de acordo com Dutra-de-Oliveira \& Marchini (1988), é recomendada a ingestão diária de $2000 \mathrm{kcal}$ para mulheres adultas $(55,0 \mathrm{~kg}$ de peso corpóreo e altura média de 1,63 m - "indivíduo padrão") e 2.700 kcal para homens adultos (70,0 kg de peso corpóreo e altura média de1,73 m - "indivíduo padrão"). Note-se que, a quantidade média de energia disponível para as famílias das duas regiões pesquisadas está abaixo da recomendação preconizada para adultos.

No entanto, é importante frisar que a análise refere-se exclusivamente à disponibilidade de energia domiciliar, não incluindo o consumo fora da casa. Sabe-se, também, que na região metropolitana de São Paulo é substancial o 
número de indivíduos de todos os estratos de renda, que consomem alimentos fora do domicílio.

É interessante registrar que no Brasil, o principal pólo gastronômico é a cidade de São Paulo, onde é possível observar a maior variedade de restaurantes, com todos os tipos de culinária (local, regional e internacional).

Philippi \& Colucci (2002) ressaltam a disponibilidade de amplo número de locais para a aquisição de ingredientes ou alimentos preparados (prontos para consumo), possibilitando o acesso aos mais refinados e exóticos alimentos e também æ̀ mais simples identificadas como "preparações de rua".

Ainda de acordo com Philippi \& Colucci (2002) é interessante lembrar que a "refeição trivial e familiar de São Paulo" concentra-se em arroz branco, feijão tipo "carioquinha" (caldo marrom), na presença da "mistura", que invariavelmente envolve as alternativas como bife, carne assada, moída, frango, salsicha, lingüiça ou ainda o ovo, batata frita e a salada, composta por tomate e alface.

Quando se examina as alternativas para o consumo de alimentos fora de casa, é preciso destacar que somente a cidade de São Paulo comporta uma rede de restaurantes, bares, lanchonetes, que oferecem refeições com grande variação (por exemplos cozinha internacional e as peculiaridades das cozinhas regionais, como a mineira, baiana, entre outras). Entre os referidos estabelecimentos merece atenção especial as churrascarias, revelando a importância desproporcional que a carne assume na alimentação, em relação aos demais alimentos. Mais recentemente, além dos cortes tradicionais de carne, como é o caso da picanha, alguns estabelecimentos incorporaram nos cardápios as carnes exóticas (exemplos: javali, jacaré, capivara).

Philippi \& Colucci (2002) alertam que em uma churrascaria do tipo rodízio é possível, em uma refeição, um adulto consumir cerca de um quilo de alimento e, portanto, cerca de $2350 \mathrm{kcal}$ ( $18,75 \%$ de proteínas, $28,22 \%$ de carboidratos e $53,03 \%$ de lipídeos). Vale lembrar que é recomendado para uma refeição a 
participação, no conteúdo energético total, de $10 \%$ a 15\% de proteínas, $20 \%$ a $30 \%$ de lipídeos e $50 \%$ a $60 \%$ de carboidratos.

Nos últimos anos os restaurantes do tipo self-service "por quilo" proliferam por praticamente todos os bairros da região metropolitana de São Paulo. Esses estabelecimentos oferecem variedades de preparações e caracterizam-se por atrair pessoas que trabalham no entorno e optam por refeições rápidas e de menor custo, quando se considera as opções tradicionais, como por exemplo o serviço a la carte.

Às rotinas da população, especificamente da cidade de São Paulo, foram incorporadas as opções dos serviços oferecidos pelas cadeias de fast-food. Invariavelmente o predomínio é da oferta de refeição rápida e além de sanduíches ${ }^{1}$, também vem se popularizando a culinária árabe, com predomínio de quibes e esfihas, por meio de rede de fast-food.

Tradicionalmente há oferta de pastel, cachorro-quente e churros comercializados em carrinhos, automóveis e barracas, freqüentemente expostos em ruas que exibem intensa movimentação de pedestres.

Especificamente com relação ao pastel, vale lembrar que é comercializado em pastelarias ou ainda em barracas de feiras livres. Em média um pastel (sabor carne) contém $286 \mathrm{kcal}$ e o cachorro quente (simples), 220 kcal.

Philippi \& Colucci (2002) destacam a existência de barracas, distribuídas pela cidade, com ofertas, invariavelmente, de frutas da época e ainda, em alguns casos, o coco verde é, também comercializado, com preferência dos consumidores pela água gelada de coco. Os autores registram que, em média, o conteúdo do referido líquido contém $63 \mathrm{kcal}$.

\footnotetext{
${ }^{1}$ De acordo com Philippi \& Colucci (2002) um sanduíche do tipo cheeseburger acompanhado de batatas fritas e refrigerante contém $915 \mathrm{kcal}$.
} 
Ainda com relação à disponibilidade de energia, registra-se que o consumo de energia (médio) por pessoa, observado pelo ENDEF, realizado em meados da década de 70 (IBGE, 1977), situava-se em torno de $1.619 \mathrm{kcal}$ (IBGE, 1978). Note-se que naquela época o consumo fora do domicílio era praticamente nulo e, portanto, o valor observado se distanciava, e muito, das recomendações ( $\approx 2.073 \mathrm{kcal} /$ pessoa/dia).

Salienta-se que os dados da POF (1987/1988) praticamente não revelaram mudanças, se comparados aos dados do ENDEF, isto é, o valor observado manteve-se em torno de $1.638 \mathrm{kcal}$. No entanto, é interessante notar que começava a ser intensificado o consumo fora do domicílio e também a ampliação nas grandes metrópoles da cobertura dos programas de suplementação alimentar, como é o caso do Programa de Alimentação do Trabalhador - PAT e Programa Nacional de Alimentação Escolar - PNAE.

No tocante à cobertura dos programas gratuitos de alimentação, vale destacar que no Estado de São Paulo, os dados mostram uma situação bastante favorável, quando se analisa o contingente de crianças com acesso a alimentação gratuita.

De forma geral, $98,48 \%$ das crianças que freqüentam creche, recebem as refeições. Quando se considera o grupo dos $10 \%$ mais pobres, $98,68 \%$ têm acesso à alimentação gratuita, enquanto a proporção alcança 99,25\% quando se analisa o grupamento considerado mais rico (10\% com maior rendimento familiar per capita.

A situação é igualmente satisfatória quando se analisa o programa de merenda escolar. É possível notar que $93,80 \%$ dos alunos (pertencentes ao grupamento dos $10 \%$ mais pobres) recebem a merenda gratuita. Inversamente, conforme o esperado, entre os $10 \%$ mais ricos, apenas $19,45 \%$ se beneficiam do programa. É possível que esse alunos tenham acesso a outros tipos de serviços, como por exemplo, a aquisição de alimentos comercializados nas cantinas escolares ou ao comércio ambulante de alimentos, freqüentemente praticado no entorno dos estabelecimentos de ensino. 
Vale esclarecer que devido a não disponibilidade de informações, é possível elaborar uma análise da qualidade nutricional das refeições distribuídas às crianças. Desse modo, desconhece-se a contribuição de energia e nutrientes, das refeições servidas nas creches e, também, no âmbito das escolas, para o atendimento das recomendações diárias preconizadas para 0 grupo.

Quando se compara o número de beneficiados pelo Programa de Alimentação do Trabalhador - PAT, com o grupo de trabalhadores formais que receberam algum tipo de auxílio alimentação ${ }^{4}$, observa-se a existência de apenas cerca de 800 mil (10\%) trabalhadores que foram beneficiados por auxílio-alimentação distinto do PAT. Os mesmos dados da PNDA-1999 mostram que $19,2 \%$ dos trabalhadores sem carteira de trabalho recebem algum tipo de auxílio alimentação. Há, portanto, a possibilidade de que parcela das empresas cria seus próprios mecanismos para atender seus trabalhadores, independentemente dos benefícios fiscais que venham receber.

Vale enfatizar, também, que o número de beneficiados pelo PAT aumentou entre 1991 e 1995, de 6,8 milhões para 7,1 milhões de trabalhadores, chegando a 7,7 milhões em 2000.

Constata-se que, se por um lado, o número de trabalhadores envolvidos no programa vem aumentando, por outro, a participação dos mesmos na totalidade dos trabalhadores formais do Brasil passou de 29,7\% para $37,4 \%$ entre 1991 e 1995, depois caiu de 37,4\% para 28\%, entre 1995 e 2000 (Guerra \& Cazzuni, 2001).

Esclarece-se que são considerados trabalhadores formais aqueles que possuem carteira de trabalho assinada, estatutários e militares.

Resumidamente, registra-se que, durante a década de 90, o PAT atingiu em média cerca de $32,4 \%$ do mercado de trabalho brasileiro, atendendo 7,691 milhões de trabalhadores formais.

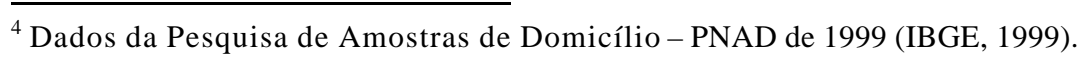


É interessante destacar que os beneficiários do PAT são, em sua maioria, pertencentes a empresas de grande porte (acima de mil empregados). "Apesar de reduzir sua participação de 53\% para 44,2\%, entre 1999 e 2000, a distribuição dos beneficiários continua bastante concentrada na grande empresa, que tinha, em 1999, 44,2\% dos beneficiários do PAT (Guerra \& Cazzuni, 2001). A proporção de atendidos cai para $10 \%$ quando se considera as empresas com menos de cem funcionários.

Os beneficiários do PAT são trabalhadores que recebem, em sua maioria, até cinco salários mínimos. Entre os anos de 1992 e 1999, os beneficiários que recebiam até dois salários mínimos reduziram sua participação de $16,1 \%$ para $14,7 \%$. Os beneficiários, pertencentes ao estrato de recebimento de dois a cinco salários mínimos elevaram sua participação no programa de $37,4 \%$ para $40,8 \%$.

Registra-se que, entre os trabalhadores com maiores salários (acima de cinco salários mínimos) reduziram sua participação, entre 1999 e 2000, de 38\% para $34 \%$.

Ainda de acordo com Guerra \& Cazzuni (2001), os trabalhadores beneficiados pelo PAT que recebiam, em média, até dois salários mínimos, representavam 19,3\% em 1992 e 16,2\% em 1999. Essa proporção é crescente para maiores faixas salariais, sendo que os beneficiários com emuneração média anual acima de 5,01 salários mínimos representavam 48,3\% em 1992 e 39,3\% em 1999 dos trabalhadores formais situados na mesma faixa de remuneração. Conclui-se, portanto, que entre os trabalhadores mais pobres, a cobertura do PAT é menor.

Análises elaboradas por Guerra \& Cazzuni (2001) revelam que o PAT é bastante concentrado na Região Sudeste (alcança cerca de $70 \%$ dos trabalhadores beneficiários), principalmente no estado de São Paulo (em torno de $40 \%$ dos trabalhadores beneficiados) e Rio de Janeiro (cerca de $11 \%$ dos trabalhadores beneficiados), ficando clara a sua deficiência em outras 
localidades como é o caso de Rondônia, Acre, Amapá, Tocantins, Paraíba, Alagoas e Mato Grosso.

Cabe destacar que segundo Guerra \& Cazzuni (2001), é muito relevante uma divulgação ampla do programa, aliada à realização de atividades de conscientização e educação alimentar dos trabalhadores, por meio de campanhas e de programas de educação permanente, promovidos "pelo governo federal por meio de parcerias articuladas entre os diversos setores coresponsáveis (trabalhadores, empregadores, associações e sindicatos profissionais)".

Ainda tendo por base os dados da Tabela 1 é possível notar que o consumo de proteínas da população da região de Recife apresenta-se um pouco mais elevado ( $43,2 \mathrm{~g}$ para a faixa mais baixa e 73,7 para a intermediária) que o verificado para São Paulo (38,8g para a faixa mais baixa e 55,6g para a faixa intermediária) quando se analisa os dados das duas faixas de rendimentos (<2 s.m. e 6 a 8 s.m), sendo que os indivíduos de São Paulo dispõem de um conteúdo mais elevado de proteínas $(73,7 \mathrm{~g})$ quando confrontado com os dados de Recife $(70,6 \mathrm{~g})$ quando se considera a faixa de renda mais elevada. É interessante notar ainda que o grupo pertencente ao estrato de rendimento intermediário (6-8 salários mínimos) da região de Recife apresenta um conteúdo maior disponível de proteínas $(73,7 \mathrm{~g})$ quando confrontado com a informação do grupo de renda mais elevada $(70,6 \mathrm{~g})$. Confrontando esses resultados com as recomendações diárias de ingestão de proteínas verifica-se que, exceto os valores das faixas de renda abaixo de dois salários mínimos $(38,8 \mathrm{~g})$ e entre seis e oito salários mínimos $(55,6 \mathrm{~g})$ da região de São Paulo e abaixo de 2 salários mínimos $(43,2)$ da região de Pecife, os outros valores superam a recomendação. Note-se que, de acordo com Dutra-de-Oliveira \& Marchini (1998), as recomendações diárias são de $44 \mathrm{~g}$ de proteínas para mulheres adultas ("indivíduo padrão) e $56 \mathrm{~g}$ para homens adultos ("indivíduo padrão"). 
Vale lembrar que neste trabalho não está sendo considerado, para as estimativas do valor energético total-VET, o conteúdo nutricional dos alimentos consumidos fora do domicílio. Os valores de proteínas observados podem ser ainda mais elevados, considerando a freqüência de consumo fora do lar, como é o caso, mais sistematicamente observado, nas regiões metropolitanas.

Nas grandes metrópoles, o tempo para percorrer grandes distâncias (e o conseqüente encarecimento do transporte) entre o domicílio e o local do trabalho tem aumentado nos últimos anos. Tal situação impõe às pessoas uma "adaptação" ao que o entorno pode oferecer. Assim proliferam estabelecimentos como lanchonetes, restaurantes, que invariavelmente oferecem refeições rápidas e serviços eficientes.

Abreu (2000) implementou pesquisa com vistas a analisar a contribuição dos alimentos e bebidas, disponíveis para o consumo em quatro restaurantes, identificados pelo autor como "por quilo" da região de Cerqueira César, São Paulo (capital), para a alimentação dos clientes. O autor verificou que nesses estabelecimentos, a contribuição dos alimentos atingiu valor aproximado de $67,5 \%$ da necessidade de energia diária, ou seja, um valor muito superior ao recomendado para a refeição (almoço). Esse resultado também revela uma opção dos clientes por alimentação de alta densidade energética.

A composição centesimal dos alimentos e preparações revelou que não há harmonia entre nutrientes, apresentando-se com elevado teor de gorduras, pobre em carboidratos e elevado em proteínas (Abreu, 2000).

Quanto aos lipídeos, nota-se que para o estrato de recebimento inferior a dois salários mínimos, o consumo médio na região de Recife $(33,84 \mathrm{~g})$ é superior ao consumo na região de São Paulo (30,63g). O mesmo ocorre com os estratos de recebimento entre seis e oito salários mínimos $(54,29 \mathrm{~g}$ para Recife e 46,53g para São Paulo) e acima de trinta salários mínimos $(60,79 \mathrm{~g}$ para Recife e 57,96g para São Paulo). Esses resultados merecem atenção em função da estreita relação existente entre o consumo de lipídeos e as doenças crônico-degenerativas. Vale lembrar também que os lipídeos conferem sabor, 
melhoram a palatabilidade dos alimentos, conferem sensação de saciedade e fornecem ácidos graxos essenciais. De acordo com Santos (1998) os ácidos trans são encontrados em alimentos gordurosos, freqüentemente industrializados e têm sido associados ao aumento de LDL-colesterol, que podem acarretar prejuízos àsaúde.

Além dos ácidos graxos trans, o incremento da ingestão de ácidos graxos saturados também tem sido relacionado ao aumento do colesterol e conseqüentemente a elevação do risco de desenvolvimento das doenças cardíacas (Santos, 1998).

Indiscutivelmente as análises do conteúdo de lipídeos presentes na dieta podem subsidiar, entre outras, diversas ações de intervenções que visem especialmente à orientação da população quanto ao consumo saudável de alimentos. Vale lembrar que segundo Navarro (1997), os lipídeos desempenham papel relevante no desenvolvimento de doenças do sistema imune e doenças cardiovasculares, hipertensão, obesidade e cada vez mais se tem associado a elevada ingestão de lipídeos ao aparecimento de diversos tipos de tumores. Lichtenstein et al (1998) destacam que estudos mais recentes têm demonstrado uma forte associação entre a ingestão de gordura e o aumento dos riscos de doenças crônico-degenerativas, dos níveis de colesterol sanguíneo e do aumento da massa corpórea.

Antecedendo as análises relativas à disponibilidade de fibras para a população das duas regiões metropolitanas cabe lembrar que, de acordo com Dwyer (1993), a incidência de casos de câncer de cólon e reto bem como a mortalidade pela doença é substancial em países ocidentais e tem aumentado nos países em desenvolvimento e que além dos fatores indesejáveis da dieta, a elevada ingestão de energia bem como o pequeno gasto da mesma, aumentam os riscos de se contrair câncer de cólon independentemente dos outros fatores da dieta. Ainda de acordo com o referido autor, nos anos setenta popularizou-se a idéia de que dietas deficientes em fibras estavam associadas ao desenvolvimento de câncer de cólon e de reto e de que eram um "convite" para 
o aparecimento de outras doenças crônico-degenerativas. O autor cita um estudo envolvendo pacientes portadores de câncer cólon-retal e pacientes nãoportadores (controle), onde por meio de análise de regressão, foi verificado que o aumento do consumo de fibras promovia uma diminuição do risco relativo de contrair a doença, demonstrando que existe uma relação inversa entre o risco de câncer de cólon e a ingestão de dietas ricas em fibras. Segundo o estudo, as fibras realmente possuem um efeito protetor contra esse tipo de câncer sendo necessário ingerir cerca de $13 \mathrm{~g}$ de fibras/dia o que corresponde ao consumo diário de uma maçã de tamanho médio e de meio copo de legumes cozidos.

$\mathrm{Na}$ presente pesquisa foi possível verificar (Tabelas 1) que a disponibilidade de fibras é baixa para os indivíduos das duas regiões pesquisadas, pois não atinge o limite mínimo recomendado de ingestão de $27 \mathrm{~g} /$ dia de fibra dietética total. Verifica-se ainda que nas duas regiões, a faixa de renda mais pobre dispõe de conteúdo inferior de fibras $(6,4 \mathrm{~g}$ para Recife e $4,9 \mathrm{~g}$ para São Paulo) que a observada para a mais rica (13,8g para Recife e 10,0g para São Paulo). Observa-se também que a disponibilidade é maior na região de Recife, quando se considera os três estratos de recebimentos $k 2$ s.m.; 6 a 8 s.m. e > 30 s.m.), quando se compara com a situação observada para a região metropolitana de São Paulo. É interessante frisar que, de acordo Pouchert-Campos (1998) a fibra dietética corresponde aos resíduos de paredes celulares e tecidos de sustentação dos vegetais usados na alimentação. Ainda de acordo com o mesmo autor, possui duas frações, a solúvel e a insolúvel em água. Acredita-se que a primeira fração traz maiores benefícios à saúde como diminuição do colesterol sangüíneo e proteção contra câncer colorretal. À segunda fração relaciona-se o aumento do bolo fecal prevenindo a constipação. Outras funções são atribuídas à fibra dietética tais como intervenção no metabolismo dos lipídeos e carboidratos e na fisiologia do trato gastro-intestinal e promoção de uma absorção mais lenta dos nutrientes provocando sensação de saciedade. 
Tendo em vista a importância dos minerais para o crescimento e desenvolvimento dos indivíduos e, também, para a proteção contra doenças crônico-degenerativas, é interessante destacar os resultados, obtidos nesta pesquisa, relativos ao ferro, cálcio, zinco e selênio.

Baseando-se nos dados apresentados na Tabela 1, verifica-se que os valores observados, quando se examina os três $k 2$ s.m.; 6 a 8 s.m. e $>30$ s.m.) estratos de recebimentos (região metropolitana de São Paulo), não alcançam os valores médios recomendados de ferro para os indivíduos (cerca de $12 \mathrm{mg} / \mathrm{dia})$.

Os resultados obtidos talvez possam ser atribuídos em parte ao declínio do consumo de feijão, considerado importante fonte de ferro para a população brasileira.

Estudo de Hoffmann (1995) tece considerações sobre o declínio do consumo de feijão em áreas urbanas, ao longo do tempo. De acordo com o autor, um dos condicionantes da queda poderia estar associado ao preço real em relação aos outros alimentos. No entanto, o autor demonstra por meio da análise da série de preços (deflacionado pelo índice de preços de alimentos da Fundação Instituto de Pesquisas Econômicas da USP), que não houve tendência de crescimento real.

Especificamente com relação ao Estado de São Paulo, pesquisa realizada pelo IBGE (ENDEF, 1974/1975) mostrou que o feijão era o produto que contribuía, em meados da década de 70 , com $17,3 \%$ do total de aminoácidos essenciais e nada menos do que $30,8 \%$ do consumo de ferro entre os paulistas (IBGE, 1978).

A ocorrência da menor freqüência do consumo do feijão (em refeições consumidas no ambiente doméstico) pode estar associada àurbanização o que levou maior número de mulheres para o mercado de trabalho. Tal comportamento invariavelmente contribui para que o tempo dedicado æ̀s atividades de preparo de alimentos seja reduzido (Silva, 1996). 
Senauer et al (1986) demonstraram que na área urbana do Srilanka, o crescimento do custo de oportunidade do trabalho doméstico das mulheres aumenta a demanda por pão, no caso, em detrimento da demanda de arroz, alimento até então considerado tradicional na dieta daquela população, como o feijão o é para os brasileiros.

Vale registrar também que Lerner (1994) estudando o consumo alimentar de jovens da região metropolitana de São Paulo verificou que os mesmos substituíam o jantar tradicional por lanches que têm como base pão e queijo ou embutidos, como por exemplos, a mortadela e apresuntados.

Ainda com base nos dados apresentados na Tabela 1, pode ser observado que a situação para os indivíduos dos três estratos de recebimentos selecionados, de Recife, revela-se relativamente mais satisfatória. Para os dois grupos de maior rendimento, os valores encontrados superam $10 \mathrm{mg}$ de ferro.

Embora não tenha sido objetivo deste trabalho avaliar a prevalência de anemia e ou deficiência de ferro entre os indivíduos, é pertinente ressaltar que os trabalhos de Molina (1989) e Uchimura (1994) apontam para o forte impacto da renda sobre a anemia.

De acordo com Molina (1989), crianças pertencentes a famílias pobres exibem tendência de maior risco (altamente significativo) para anemia do que aquelas de famílias de melhor nível socioeconômico.

Uchimura (1994), estudando escolares do Estado do Paraná, constatou que $84 \%$ dos anêmicos pertencem a famílias com renda inferior a um salário mínimo per capita. Observou, também, que mais da metade das crianças com renda per capita inferior a 0,50 salário mínimo foram diagnosticadas como anêmicas.

Os resultados obtidos nesta pesquisa poderão subsidiar as ações de intervenções em curto prazo de tempo, pois a deficiência de ferro tem sido associada ao aumento na incidência de infecções, principalmente entre crianças e gestantes. Algumas enzimas que contém ferro atuam de forma decisiva, no sistema imunológico, como é caso, por exemplo, da 
mieloperoxidase (heme) e ribonucleotídeo redutase (não-heme). A ribonucleotídeo redutase atua na multiplicação dos linfócitos e na conseqüente produção de anticorpos específicos. A mieliperoxidase é encontrada em vacúolos fagocitários dos neutrófilos, promovendo conversão de peróxido de hidrogênio e do cloreto em ácido hipocloroso e água (Fairbanks, 1994).

Outro mineral cuja análise da disponibilidade merece muita atenção é o zinco que, assim como o cobre, ocorre no organismo firmemente ligado a proteínas celulares. Tem função estrutural, muitas vezes contribuindo para a manutenção da estrutura tridimensional e catalítica nas enzimas e proteínas. Nas proteínas nucleares, que se ligam ao DNA como função de controle na expressão gênica, o zinco ajuda a manter a estrutura finger. Incluem-se entre essas, as que se ligam aos hormônios sexuais (androgênio e estrogênio) (Fairbanks, 1994).

Nesta pesquisa a disponibilidade de zinco, nos domicílios, revelou-se muito reduzida, não alcançando a quantidade de $6 \mathrm{mg} / \mathrm{per}$ capita/dia para famílias pertencentes aos três estratos (Tabela 1) de rendimentos familiares selecionados de ambas regiões (Recife e São Paulo). Vale registrar que em média são recomendados (para indivíduos adultos) cerca de $15 \mathrm{mg} / \mathrm{dia}$. Os dados obtidos nesta pesquisa merecem atenção, pois não atendem $30 \%$ do valor recomendado. Mesmo considerando que as análises são restritas à disponibilidade de nutrientes no ambiente doméstico e que não foram incluídos nas análises os alimentos consumidos "fora do domicílio", é pouco provável que a população consiga alcançar, mesmo consumindo alimentos fora do domicílio, a meta de ingestão preconizada para o nutriente zinco.

Tem merecido atenção especial dos pesquisadores também o selênio, cuja atuação mais conhecida é como antioxidante. Esta função ocorre por meio da atuação da glutationa peroxidase, o tripeptídeo GLU-CYS-GLY, presente tanto no plasma como no interior das células. 
Vale registrar, também, que em média a população adulta americana, cujo consumo de alimentos foi analisado em duas pesquisas (realizadas em 1988 e 1994), ingeria cerca de $130 \mu \mathrm{g}$ de selênio/dia (Farfan et al, 2001).

É interessante registrar que, de acordo com os resultados obtidos por Galeazzi et al (1997), os quatro municípios integrantes do Estudo Multicêntrico de Consumo Alimentar (Campinas, Rio de Janeiro, Ouro Preto e Goiânia), das famílias com renda até dois salários mínimos revelaram risco nutricional no tocante aos macronutrientes e micronutrientes, com destaque para o cálcio, ferro, retinol e riboflavina (inadequação variou de 20 a 70\%). De acordo com os autores as porcentagens das famílias expostas à situação foram de 3,2\% em Campinas, 3,6\% no Rio de Janeiro, 8,7\% em Goiânia e 20,3\% em Ouro Preto.

Ainda tendo por base os dados da Tabela 1, verifica-se que para os indivíduos pertencentes à famílias com menor rendimento $(<2$ salários mínimos per capita) a disponibilidade não alcança $30 \mu \mathrm{g}$. Para a região metropolitana de São Paulo os valores são superiores $(29,9 \mu \mathrm{g}$ para os mais pobres e 52,9 $\mu$ g quando se considera o maior estrato de renda ).

Quando se examina os dados da região metropolitana de Recife a situação somente é relativamente melhor para o grupamento de rendimento intermediário (entre 6 e 8 salários mínimos).

Vale enfatizar que é recomendado para os indivíduos adultos, cerca de $70 \mu \mathrm{g} / \mathrm{dia}$. Considerando a importância do nutriente para a prevenção de doenças e os dados obtidos nesta pesquisa, é altamente recomendado propor que medidas de intervenção sejam adotadas com vistas a estimular o consumo de selênio pela população.

Registros da Organização Mundial de Saúde (1998) ressaltam que a deficiência conjunta de selênio e iodo - Síndrome de Deficiência de lodo - SDI são consideradas muito graves.

O cálcio é um macromineral importante para a formação dos ossos e dentes, participa do crescimento, é um co-fator/regulador de várias reações 
químicas como a liberação de energia para a contração muscular, participa da coagulação sanguínea, da liberação inicial de neurotransmissores, da absorção de cianocobalamina, da ação da lipase, da secreção da insulina etc. Suas principais fontes são leite e derivados, a sardinha, a amêndoa e a semente de gergelim.

Vale ressaltar que a recomendação diária de cálcio para indivíduos adultos gira em torno de $1.200 \mathrm{mg} /$ dia (Farfan et al, 2001).

Do exame dos dados da Tabela 1, depreende-se, também, que mesmo a disponibilidade do cálcio para os indivíduos que integram as famílias com maior renda ( 30 s.m.) de Recife (melhor situação observada quando se compara com os dados de São Paulo) o valor não alcança $50 \%$ da recomendação do nutriente para, por exemplo, os indivíduos adultos (Farfan et al, 2001).

Vale ressaltar que para todos os estratos de recebimento a situação observada em Recife se revelou mais favorável quando comparado à região metropolitana de São Paulo.

Para os indivíduos pertencentes à famílias integrantes dos estratos de menor renda da região metropolitana de São Paulo (Tabela 1) verificou-se disponibilidade, em nível domiciliar, bastante reduzida do cálcio $(\approx 149,8 \mathrm{mg}$ e $\approx$ 244,0 mg, para São Paulo e Recife, respectivamente).

Conforme descrito na seção reservada a metodologia, nesta pesquisa, julgou-se pertinente identificar a participação da proteína de alto valor biológico na disponibilidade total de proteína nos domicílios das regiões metropolitanas de Recife e São Paulo. Adotou-se o valor de 35\% de proteína de origem animal, em relação àdisponibilidade protéica total (Vanucchi et al, 1990).

$\mathrm{Na}$ Tabela 2, apresentada a seguir, é mostrada a composição percentual da disponibilidade de proteínas nos domicílios, conforme a origem (animal ou vegetal) e a totalidade dos estratos de recebimentos das famílias das regiões metropolitanas de Recife e São Paulo. 
Tabela 2. Disponibilidade de proteína, nos domicílios, de acordo com a origem (animal e vegetal) e estratos de recebimento familiar. 1995/1996.

\begin{tabular}{|c|c|c|c|c|c|c|c|c|c|c|}
\hline \multirow{2}{*}{$\begin{array}{l}\text { Região Metropolitana } \\
\text { Origem da Proteína }\end{array}$} & \multicolumn{10}{|c|}{ Estratos de Recebimento (em salários mínimos) } \\
\hline & Até 2 & $\begin{array}{l}\text { Mais de } \\
2 \text { a } 3 \\
\end{array}$ & $\begin{array}{l}\text { Mais de } \\
3 \text { a } 5 \\
\end{array}$ & $\begin{array}{c}\text { mais de } \\
5 \text { a } 6 \\
\end{array}$ & $\begin{array}{c}\text { mais de } \\
6 \text { a } 8 \\
\end{array}$ & $\begin{array}{c}\text { Mais de } \\
8 \text { a } 10 \\
\end{array}$ & $\begin{array}{l}\text { mais de } \\
10 \text { a } 15 \\
\end{array}$ & $\begin{array}{c}\text { mais de } \\
15 \text { a } 20\end{array}$ & $\begin{array}{l}\text { mais de } \\
20 \text { a } 30\end{array}$ & $\begin{array}{c}\text { mais de } \\
30\end{array}$ \\
\hline \multicolumn{11}{|l|}{ Recife } \\
\hline Proteína Animal & 54 & 50 & 51 & 51 & 53 & 56 & 58 & 52 & 58 & 62 \\
\hline $\begin{array}{l}\text { Proteína Vegetal } \\
\text { São Paulo }\end{array}$ & 46 & 50 & 49 & 49 & 47 & 44 & 42 & 48 & 42 & 38 \\
\hline Proteína Animal & 49 & 59 & 49 & 51 & 57 & 56 & 58 & 58 & 65 & 59 \\
\hline Proteína Vegetal & 51 & 41 & 51 & 49 & 43 & 44 & 42 & 42 & 35 & 41 \\
\hline
\end{tabular}


Analisando os dados da Tabela 2 verifica-se que para as duas regiões metropolitanas e totalidade dos estratos de recebimento, a participação da proteína animal supera o valor recomendado (35\%). Note-se que a participação da proteína que precedem de fontes animais supera $50 \%$, quando se examina os resultados referentes à totalidade dos estratos de recebimentos. Note-se que, para a região metropolitana de Recife, a menor proporção (50\%) foi observada para o grupo com rendimentos entre 2 e 3 salários mínimos. Entre os indivíduos com recebimentos que superam 30 salários mínimos, a participação de proteína de origem animal alcançou $62 \%$.

Quando se considera os dados obtidos para a região metropolitana de São Paulo o menor percentual (49\%) de participação de proteína de origem animal é verificado no grupamento mais pobre (recebimentos de até dois s.m.). Inversamente, a maior (65\%) proporção foi verificada entre as famílias com rendimentos entre 20 e 30 salários mínimos.

Monteiro et al (2000) registraram que em todo o país cresceu o percentual de proteínas de origem animal (cerca de 60\% em 1988 e 63\% em 1996).

Mondini \& Monteiro (1994) analisando a evolução do consumo alimentar nas áreas metropolitanas brasileiras entre as décadas de 60 e 80, observaram expansão no œnsumo relativo de alimentos de origem animal (sobretudo leite e derivados, mas também de carnes e ovos) em detrimento de cereais, leguminosas, raízes e tubérculos.

De acordo com Vanucchi et al (1990) as razões para a limitação de alguns alimentos de origem animal, considerados fontes de proteína de alto valor biológico dizem respeito ao conteúdo de ácidos graxos saturados e seu provável efeito aterogênico.

$\mathrm{Na}$ Tabela 3, foram reunidos os resultados referentes a participação dos macronutrientes no conteúdo energético disponível nos domicílios das regiões metropolitanas selecionadas. 
Tabela 3. Disponibilidade nos domicílios, das regiões metropolitanas de São Paulo e Recife, de energia e participação dos macronutrientes (proteínas, carboidratos e lipídeos) de acordo com o recebimento familiar per capita. 1995/1996.

\begin{tabular}{llcccc}
\hline $\begin{array}{c}\text { Região } \\
\text { Metropolitana }\end{array}$ & $\begin{array}{c}\text { Estrato de } \\
\text { Recebimento } \\
\text { (em salários } \\
\text { mínimos) }\end{array}$ & $\begin{array}{c}\text { Energia } \\
\text { (Kcal) }\end{array}$ & $\begin{array}{c}\text { Proteína } \\
(\%)\end{array}$ & $\begin{array}{c}\text { Carboidrato } \\
(\%)\end{array}$ & $\begin{array}{c}\text { Lipídeo } \\
(\%)\end{array}$ \\
\hline São Paulo & Até 2 & 1065 & 15 & 59 & 26 \\
Recife & Até 2 & 1257 & 14 & 62 & 24 \\
São Paulo & mais de 2 a 3 & 1102 & 16 & 56 & 28 \\
Recife & mais de 2 a 3 & 1651 & 13 & 62 & 25 \\
São Paulo & mais de 3 a 5 & 1594 & 12 & 58 & 30 \\
Recife & mais de 3 a 5 & 1582 & 13 & 62 & 25 \\
São Paulo & mais de 5 a 6 & 1871 & 13 & 59 & 28 \\
Recife & mais de 5 a 6 & 1834 & 13 & 62 & 25 \\
São Paulo & mais de 6 a 8 & 1455 & 15 & 56 & 29 \\
Recife & mais de 6 a 8 & 1860 & 16 & 58 & 26 \\
São Paulo & mais de 8 a 10 & 1347 & 15 & 58 & 27 \\
Recife & mais de 8 a 10 & 1791 & 14 & 60 & 26 \\
São Paulo & mais de 10 a 15 & 1405 & 17 & 55 & 28 \\
Recife & mais de 10 a 15 & 2022 & 15 & 59 & 26 \\
São Paulo & mais de 15 a 20 & 1506 & 17 & 52 & 31 \\
Recife & mais de 15 a 20 & 1937 & 13 & 61 & 26 \\
São Paulo & mais de 20 a 30 & 2336 & 17 & 53 & 30 \\
Recife & mais de 20 a 30 & 1772 & 15 & 58 & 27 \\
São Paulo & mais de 30 & 1761 & 17 & 53 & 30 \\
Recife & mais de 30 & 2254 & 12 & 63 & 25 \\
\hline
\end{tabular}

A Tabela 3 mostra a disponibilidade alimentar de acordo com a participação dos macronutrientes,onde é possível verificar que o maior valor (31\%), referente a participação dos lipídios no VET é observado na região metropolitana de São Paulo (famílias com rendimento entre 15 e 20 s.m.). Valor também considerado elevado, foi observado em São Paulo para famílias pertencentes aos estratos de 3 a 5, 20 a 30 e acima de 30 salários mínimos.

No tocante a participação dos carboidratos, vale enfatizar que os maiores percentuais (63\% e 62\%) foram verificados na região metropolitana de Recife.

Registra-se que a comparação dos dados obtidos pelas POFs 1988 e 1996, revelou que a participação de carboidratos tende a declinar entre as pesquisas nas áreas metropolitanas do Norte-Nordeste, sendo esse declínio 
compensado em partes semelhantes, pelo aumento na oferta de proteínas e lipídios. Embora ascendente, de acordo com Monteiro et al (2000), a participação dos lipídios no VET no Norte e Nordeste (23\% em 1987 e 23,8\% em 1996) ainda é bem inferior a observada no Centro-Sul (29,5\% em 1988 e 28,4\% em 1996).

A seguir apresenta-se os resultados referentes æ̀s análises relativas a variação da disponibilidade de energia e nutrientes, de acordo com o logaritmo do recebimento familiar per capita nas regiões metropolitanas de Recife e São Paulo (Tabelas 4, 5 e 6). 
Tabela 4. Estimativas dos parâmetros e testes relativos ao modelo de análise da disponibilidade de energia e nutrientes selecionados em função dos recebimentos per capita nas regiões metropolitanas de Recife e São Paulo, 1995/1996.

\begin{tabular}{|c|c|c|c|c|c|c|c|}
\hline \multirow{2}{*}{$\begin{array}{l}\text { Energia e } \\
\text { Nutrientes }\end{array}$} & \multicolumn{4}{|c|}{ Estimativas } & \multirow[t]{2}{*}{$R^{2}$} & \multirow[t]{2}{*}{$F^{(I)}$} & \multirow[t]{2}{*}{$F^{(2)}$} \\
\hline & $\alpha$ & $\beta$ & $\gamma$ & $\delta$ & & & \\
\hline Energia & 413,94 & $\begin{array}{r}257,90 \\
(1,66)\end{array}$ & $\begin{array}{r}53,99 \\
(0,061)\end{array}$ & $\begin{array}{l}-65,98 \\
(-0,39)\end{array}$ & 0,39 & 1,24 & 1,26 \\
\hline Proteínas & 13,96 & $\begin{array}{r}8,95 \\
(1,53)\end{array}$ & $\begin{array}{l}-23,63 \\
(-0,71)\end{array}$ & $\begin{array}{r}3,36 \\
(0,52)\end{array}$ & 0,60 & 0,58 & 0,62 \\
\hline Carboidratos & 76,99 & $\begin{array}{l}37,18 \\
(1,64)\end{array}$ & $\begin{array}{l}34,39 \\
(0,27)\end{array}$ & $\begin{array}{l}-18,39 \\
(-0,74)\end{array}$ & 0,34 & $2,78^{*}$ & $2,71^{*}$ \\
\hline $\begin{array}{l}\text { Lipídios } \\
\text { (Totais) }\end{array}$ & 7,96 & $\begin{array}{r}8,04 \\
(1,45)\end{array}$ & $\begin{array}{r}0,51 \\
(0,016)\end{array}$ & $\begin{array}{r}-0,69 \\
(-0,11)\end{array}$ & 0,40 & $3,61^{* *}$ & 0,11 \\
\hline $\begin{array}{l}\text { Lipídios } \\
\text { insaturados }\end{array}$ & 9,52 & $\begin{array}{r}1,79 \\
(0,64)\end{array}$ & $\begin{array}{l}10,77 \\
(0,68)\end{array}$ & $\begin{array}{r}-1,39 \\
(-0,46)\end{array}$ & 0,13 & 0,83 & 0,77 \\
\hline Fibra & 0,20 & $\begin{array}{r}1,85 \\
(1,12)\end{array}$ & $\begin{array}{r}-2,47 \\
(-0,26)\end{array}$ & $\begin{array}{r}-0,10 \\
(-0,057)\end{array}$ & 0,31 & 2,40 & 1,20 \\
\hline Colesterol & 40,85 & $\begin{array}{l}28,98 \\
(0,66)\end{array}$ & $\begin{array}{l}-50,00 \\
(-0,20)\end{array}$ & $\begin{array}{r}9,07 \\
(0,19)\end{array}$ & 0,22 & 1,47 & 0,02 \\
\hline Vitamina A & 2444,31 & $\begin{array}{r}615,63 \\
(0,90)\end{array}$ & $\begin{array}{r}-6749,073 \\
(-1,74)\end{array}$ & $\begin{array}{r}631,44 \\
(0,84)\end{array}$ & 0,63 & $3,27^{\star \star \star}$ & $10,30^{\star * \star}$ \\
\hline Retinol & 559,23 & $\begin{array}{l}67,57 \\
(0,51)\end{array}$ & $\begin{array}{r}-950,52 \\
(-1,27)\end{array}$ & $\begin{array}{l}85,36 \\
(0,54)\end{array}$ & 0,47 & $4,68^{* *}$ & $5,90^{* *}$ \\
\hline Vitamina $\mathrm{E}$ & 5,46 & $\begin{array}{r}1,33 \\
(0,81)\end{array}$ & $\begin{array}{r}7,56 \\
(0,81)\end{array}$ & $\begin{array}{r}-1,64 \\
(-0,91)\end{array}$ & 0,059 & 0,33 & 0,49 \\
\hline Vitamina D & $-5,49$ & $\begin{array}{r}1,77 \\
(2,94)\end{array}$ & $\begin{array}{r}4,43 \\
(1,30)\end{array}$ & $\begin{array}{r}-1,35 \\
(-2,04)\end{array}$ & 0,53 & $6,06^{\star \star \star}$ & $7,84^{* * *}$ \\
\hline
\end{tabular}

Nota: ${ }^{*},{ }^{* *} \mathrm{e}^{* \star *}$ indicam que o teste é significativo a $10 \%, 5 \%$ e $1 \%$, respectivamente. - entre parênteses são registrados os testes $t$ para a hipótese de que o parâmetro é igual a zero.

${ }^{(1)}$ Teste $\mathrm{F}$ para a hipótese de que os três coeficientes de regressão são iguais a zero $(\beta=\gamma=\delta=0$ ).

(2) Teste F para a hipótese de que $\gamma=\delta=0$. 
Tabela 5. Estimativas dos parâmetros e testes relativos ao modelo de análise da disponibilidade de nutrientes (vitaminas hidrossolúveis) selecionados em função dos recebimentos per capita nas regiões metropolitanas de Recife e São Paulo, 1995/1996.

\begin{tabular}{|c|c|c|c|c|c|c|c|}
\hline \multirow[t]{2}{*}{ Nutrientes } & \multicolumn{4}{|c|}{ Estimativas } & \multirow[t]{2}{*}{$R^{2}$} & \multirow[t]{2}{*}{$F^{(1)}$} & \multirow[t]{2}{*}{$F^{(2)}$} \\
\hline & $\alpha$ & $\beta$ & & $\delta$ & & & \\
\hline Tiamina & $-39,22$ & $\begin{array}{l}43,23 \\
(2,77)\end{array}$ & $\begin{array}{r}132,21 \\
(1,49)\end{array}$ & $\begin{array}{l}-28,51 \\
(-1,66)\end{array}$ & 0,43 & 4,02 & 1,58 \\
\hline Riboflavina & 33,35 & $\begin{array}{l}25,84 \\
(1,40)\end{array}$ & $\begin{array}{l}34,99 \\
(0,34)\end{array}$ & $\begin{array}{l}-15,13 \\
(-0,74)\end{array}$ & 0,26 & 1,86 & 2,10 \\
\hline Niacina & 3,46 & $\begin{array}{r}2,06 \\
(1,45)\end{array}$ & $\begin{array}{r}-4,44 \\
(-0,55)\end{array}$ & $\begin{array}{r}0,32 \\
(-0,21)\end{array}$ & 0,49 & $5,22^{* *}$ & 1,44 \\
\hline Vitamina $B_{6}$ & $-0,50$ & $\begin{array}{r}0,24 \\
(2,33)\end{array}$ & $\begin{array}{l}0,056 \\
(0,10)\end{array}$ & $\begin{array}{r}-0,08 \\
(-0,71)\end{array}$ & 0,55 & $6,57^{\star \star \star}$ & 4,44 \\
\hline Vitamina $B_{12}$ & 5,20 & $\begin{array}{r}-0,11 \\
(-0,13)\end{array}$ & $\begin{array}{r}-4,55 \\
(-0,92)\end{array}$ & $\begin{array}{r}0,51 \\
(0,53)\end{array}$ & 0,21 & 1,38 & 2,05 \\
\hline Vitamina C & $-50,28$ & $\begin{array}{l}22,12 \\
(1,92)\end{array}$ & $\begin{array}{l}-32,12 \\
(-0,49)\end{array}$ & $\begin{array}{r}2,30 \\
(0,18)\end{array}$ & 0,61 & $8,38^{* \star *}$ & $1,18^{* *}$ \\
\hline Folacina & $-11,83$ & $\begin{array}{l}18,14 \\
(2,18)\end{array}$ & $\begin{array}{l}-25,90 \\
(-0,55)\end{array}$ & $\begin{array}{r}0,47 \\
(0,051)\end{array}$ & 0,65 & $9,71^{\star \star *}$ & $2,93^{*}$ \\
\hline $\begin{array}{l}\text { Ácido } \\
\text { Pantotênico }\end{array}$ & $-2,40$ & $\begin{array}{r}1,29 \\
(2,23)\end{array}$ & $\begin{array}{r}1,43 \\
(0,44)\end{array}$ & $\begin{array}{r}-0,87 \\
(-1,37)\end{array}$ & 0,58 & $7,41^{\star \star *}$ & $10,65^{\star \star \star}$ \\
\hline
\end{tabular}

Nota: ${ }^{*},{ }^{* *} \mathrm{e}^{* * *}$ indicam que o teste é significativo a 10\%, $5 \%$ e $1 \%$, respectivamente. - entre parênteses são registrados os testes t para a hipótese de que o parâmetro é igual a zero.

(1) Teste $F$ para a hipótese de que os três coeficientes de regressão são iguais a zero $(\beta=\gamma=\delta=0)$.

(2) Teste $\mathrm{F}$ para a hipótese de que $\gamma=\delta=0$. 
Tabela 6. Estimativas dos parâmetros e testes relativos ao modelo de análise da disponibilidade de nutrientes (minerais) selecionados em função dos recebimentos per capita nas regiões metropolitanas de Recife e São Paulo, 1995/1996.

\begin{tabular}{|c|c|c|c|c|c|c|c|}
\hline \multirow[t]{2}{*}{ Nutrientes } & \multicolumn{4}{|c|}{ Estimativas } & \multirow[t]{2}{*}{$\overrightarrow{R^{2}}$} & \multirow[t]{2}{*}{$F^{\prime \prime \prime}$} & \multirow[t]{2}{*}{$F^{(2)}$} \\
\hline & $\alpha$ & $\beta$ & $\gamma$ & $\delta$ & & & \\
\hline lodo & 0,81 & $\begin{array}{r}0,12 \\
(0,29)\end{array}$ & $\begin{array}{r}2,50 \\
(1,061)\end{array}$ & $\begin{array}{r}-0,26 \\
(-0,56)\end{array}$ & 0,29 & 2,23 & 3,29 \\
\hline Sódio & 1188,45 & $\begin{array}{l}532,15 \\
(1,001)\end{array}$ & $\begin{array}{r}62,12 \\
(0,021)\end{array}$ & $\begin{array}{r}-226,96 \\
(-0,39)\end{array}$ & 0,21 & 1,43 & 1,60 \\
\hline Cálcio & $-74,57$ & $\begin{array}{l}87,23 \\
(3,54)\end{array}$ & $\begin{array}{r}-114,12 \\
(-0,82)\end{array}$ & $\begin{array}{l}-14,47 \\
(-0,53)\end{array}$ & 0,82 & $24,29^{* \star *}$ & $21,24^{\star \star \star}$ \\
\hline Magnésio & 42,73 & $\begin{array}{r}13,25 \\
(1,27)\end{array}$ & $\begin{array}{l}-35,55 \\
(-0,60)\end{array}$ & $\begin{array}{r}2,53 \\
(0,22)\end{array}$ & 0,45 & $4,34^{\star \star}$ & 1,76 \\
\hline Zinco & 1,42 & $\begin{array}{r}0,45 \\
(0,99)\end{array}$ & $\begin{array}{l}-3,096 \\
(-1,23)\end{array}$ & $\begin{array}{r}0,54 \\
(1,10)\end{array}$ & 0,61 & $8,29^{\star \star \star}$ & 0,87 \\
\hline Manganês & $-0,76$ & $\begin{array}{r}0,34 \\
(1,30)\end{array}$ & $\begin{array}{r}-1,62 \\
(-1,09)\end{array}$ & $\begin{array}{r}0,34 \\
(1,17)\end{array}$ & 0,71 & $12,90^{* * *}$ & 0,72 \\
\hline Potássio & $-335,88$ & $\begin{array}{r}211,72 \\
(1,90)\end{array}$ & $\begin{array}{r}-473,91 \\
(-0,75)\end{array}$ & $\begin{array}{l}59,98 \\
(0,49)\end{array}$ & 0,67 & $10,78^{* \star \star}$ & 0,99 \\
\hline Fósforo & 127,80 & $\begin{array}{r}111,50 \\
(1,74)\end{array}$ & $\begin{array}{r}-316,32 \\
(-0,87)\end{array}$ & $\begin{array}{r}14,05 \\
(-0,20)\end{array}$ & 0,61 & $8,27^{* * *}$ & $5,39^{* *}$ \\
\hline Ferro & 3,70 & $\begin{array}{r}1,27 \\
(1,48)\end{array}$ & $\begin{array}{r}-3,85 \\
(-0,79)\end{array}$ & $\begin{array}{r}0,024 \\
(0,026)\end{array}$ & 0,56 & $6,74^{\star * *}$ & $6,90^{* * *}$ \\
\hline Cobre & 9,40 & $\begin{array}{r}1,15 \\
(0,42)\end{array}$ & $\begin{array}{l}11,47 \\
(0,73)\end{array}$ & $\begin{array}{r}-4,27 \\
(-1,40)\end{array}$ & 0,58 & $7,38^{* * *}$ & $5,79^{* *}$ \\
\hline Selênio & $-2,31$ & $\begin{array}{r}8,14 \\
(1,95)\end{array}$ & $\begin{array}{l}-13,51 \\
(-0,57)\end{array}$ & $\begin{array}{r}1,83 \\
(0,40)\end{array}$ & 0,67 & $10,70^{* \star *}$ & 0,46 \\
\hline
\end{tabular}

Nota: ${ }^{*},{ }^{* *} \mathrm{e}^{* * *}$ indicam que o teste é significativo a $10 \%, 5 \%$ e $1 \%$, respectivamente. -entre parênteses são registrados os testes t para a hipótese de que o parâmetro é igual a zero.

(1) Teste $F$ para a hipótese de que os três coeficientes de regressão são iguais a zero $(\beta=\gamma=\delta=0)$.

(2) Teste F para a hipótese de que $\gamma=\delta=0$. 
As tabelas 4,5 e 6 mostram os resultados do ajustamento do modelo de regressão que procura captar como a disponibilidade de nutrientes varia com o logaritmo do recebimento per capita nas regiões metropolitanas de Recife e São Paulo. Para diversos nutrientes foi possível detectar diferenças importantes entre Recife e São Paulo,como mostram os valores de $F$ significativos na última coluna dessas tabelas. Quanto aos carboidratos, por exemplo, examinando também a figura 17, nota-se que a disponibilidade é mais elevada e tende a crescer mais rapidamente com a renda em Recife. No caso da vitamina $A$ (fenômeno semelhante é observado no caso do retinol) a diferença de comportamento da relação disponibilidade/renda é significativa a 1\%. A figura 11 mostra que a disponibilidade é maior, mas tende a crescer mais lentamente com o logaritmo do recebimento per capita em Recife.

Já no caso da vitamina $D$, chama a atenção o crescimento mais rápido da disponibilidade com a renda em Recife.

Para a niacina o modelo não capta diferença significativa de comportamento entre Recife e São Paulo,mas a figura 2 mostra que em 9 dos 10 estratos de recebimento familiar a disponibilidade é maior em Recife do que em São Paulo. O modelo simplificado ( correspondendo ao par de retas paralelas da figura 2) mostra que o efeito é significativo ( a 1\%) do logaritmo do recebimento per capita sobre a disponibilidade de niacina.

llustram os resultados as Figuras de número 1 a 30, apresentadas a seguir.Ao examinar as figuras é importante lembrar que foi considerado para as análises o logaritmo do recebimento familiar per capita. 


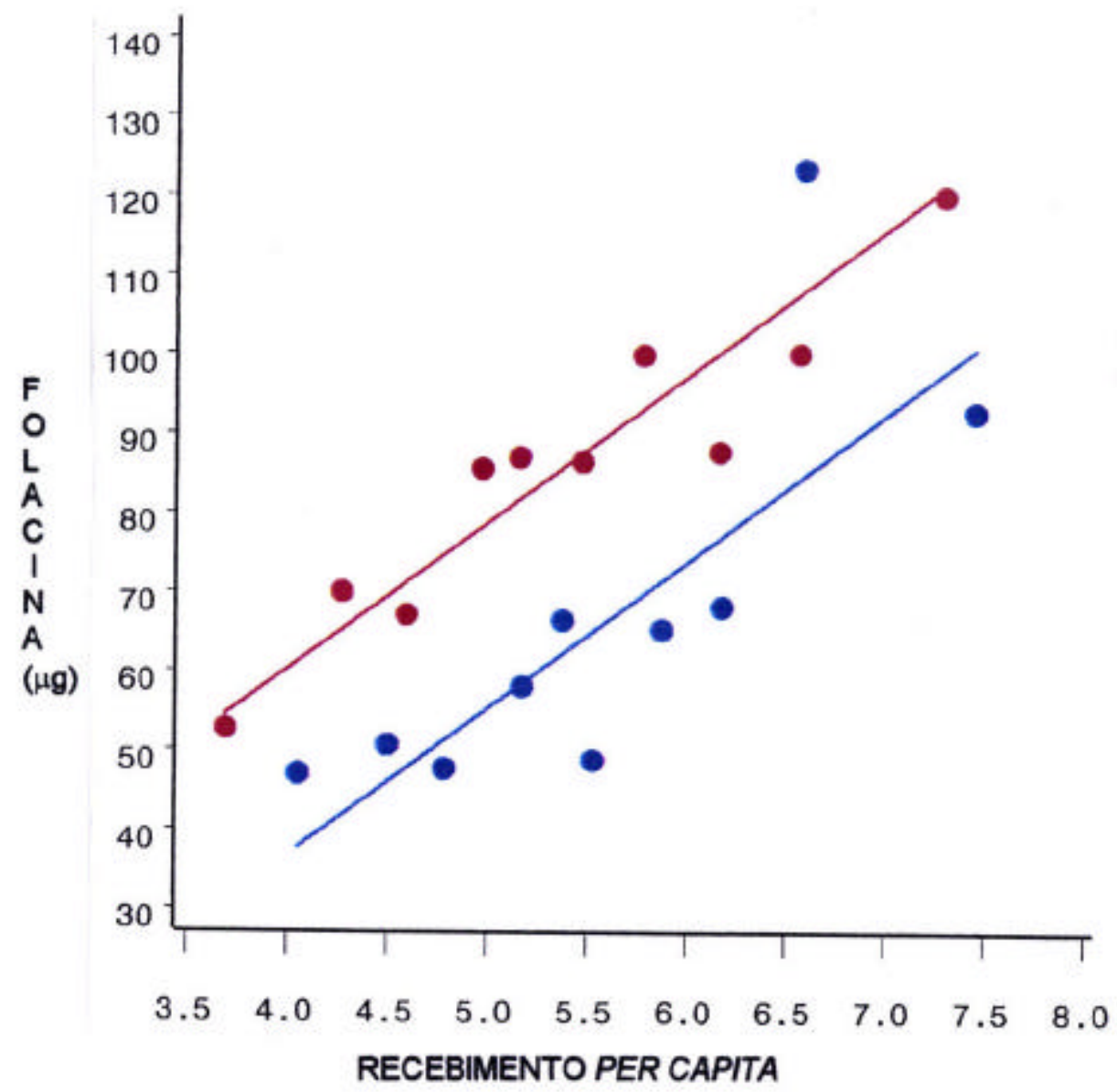

- Região Metropolitana de Recife

- Região Metropolitana de São Paulo

Figura 1 - Variação da disponibilidade de folacina, no domicílio, de acordo com o recebimento familiar per capita, nas regiões metropolitanas de Recife e São Paulo. 


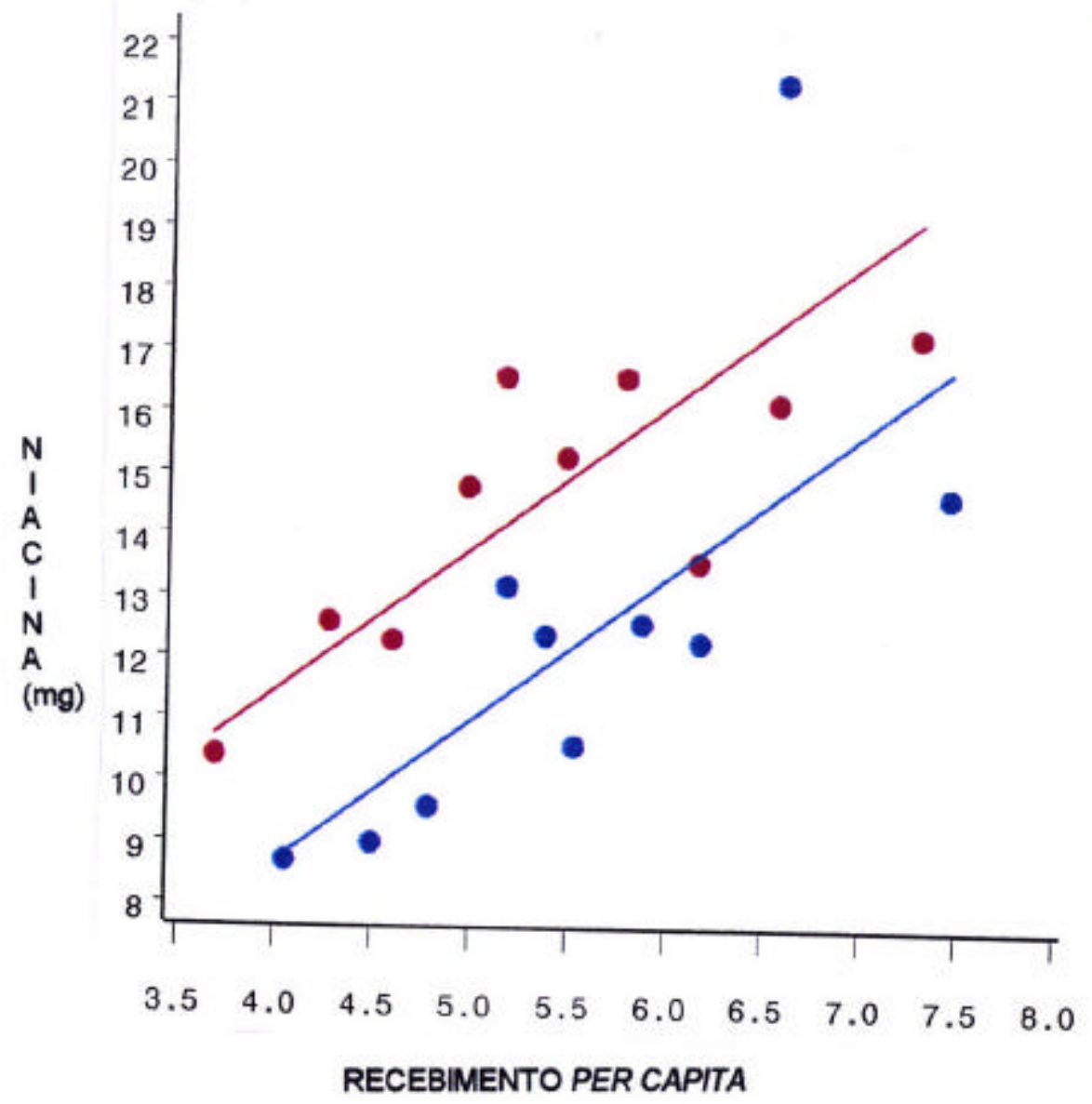

- Regiăo Metropolitana de Recife

- Regiăo Metropolitana de Săo Paulo

Figura 2 - Variação da disponibilidade de niacina, no domicílio, de acordo com o recebimento familiar per capita, nas regiões metropolitanas de Recife e São Paulo. 


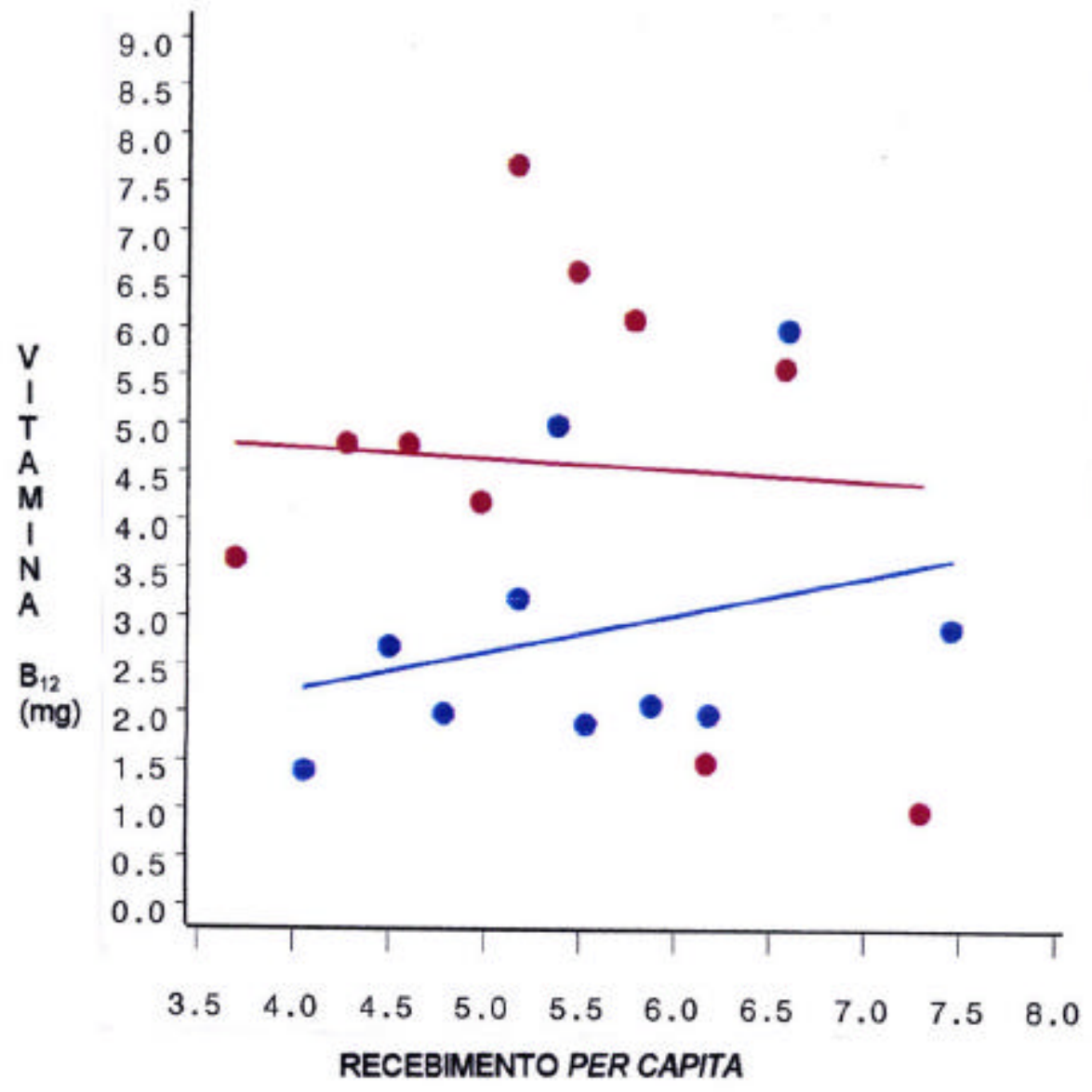

- Regiäo Metropolitana de Recife

- Regiäo Metropolitana de São Paulo

Figura 3 - Variação da disponibilidade de vitamina $B_{12}$, no domicílio, de acordo com o recebimento familiar per capita, nas regiões metropolitanas de Recife e São Paulo. 


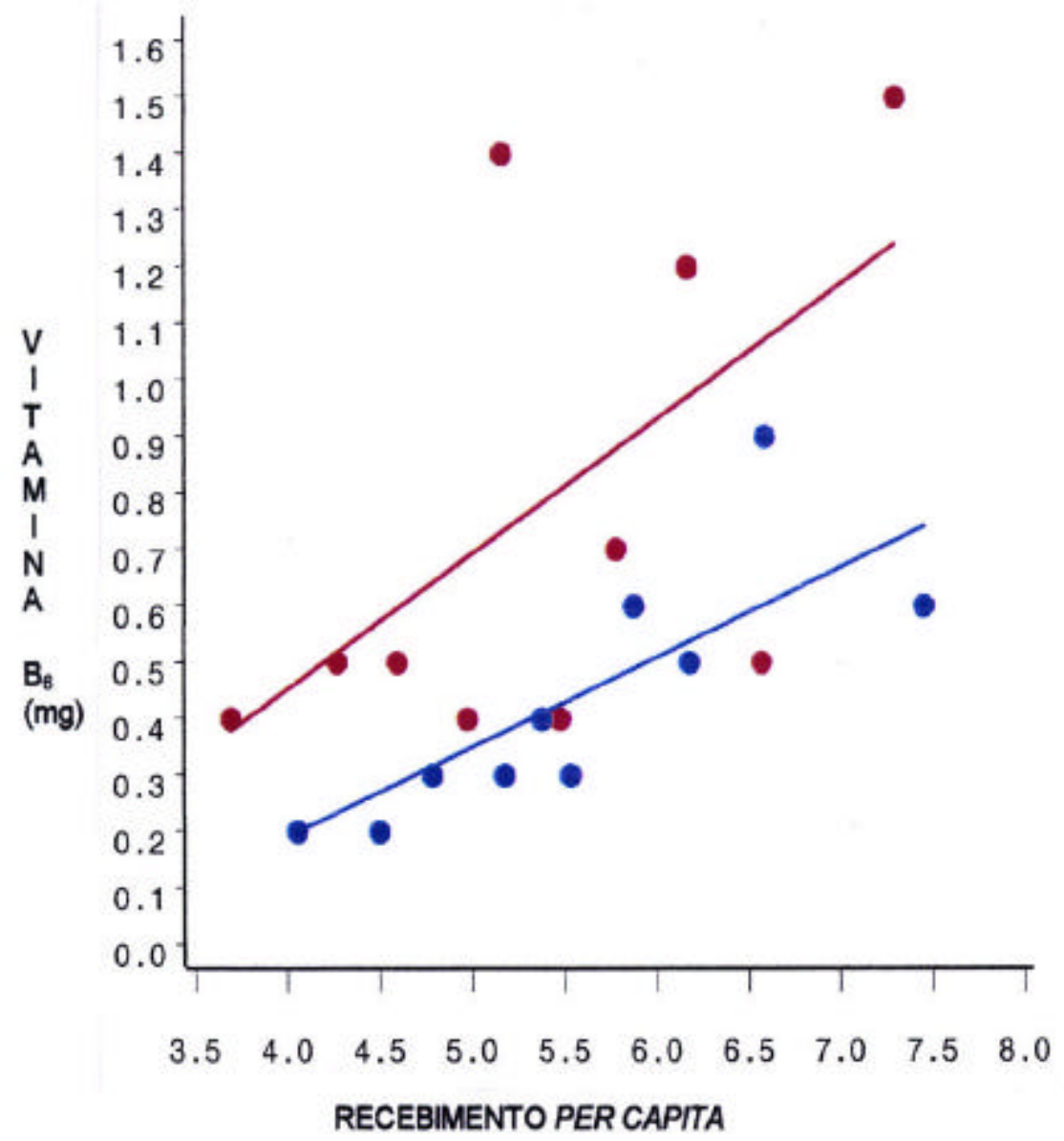

- Regiäo Metropolitana de Recife

- Região Metropolitana de São Paulo

Figura 4 - Variação da disponibilidade de vitamina $B_{6}$, no domicílio, de acordo com o recebimento familiar per capita, nas regiões metropolitanas de Recife e São Paulo. 


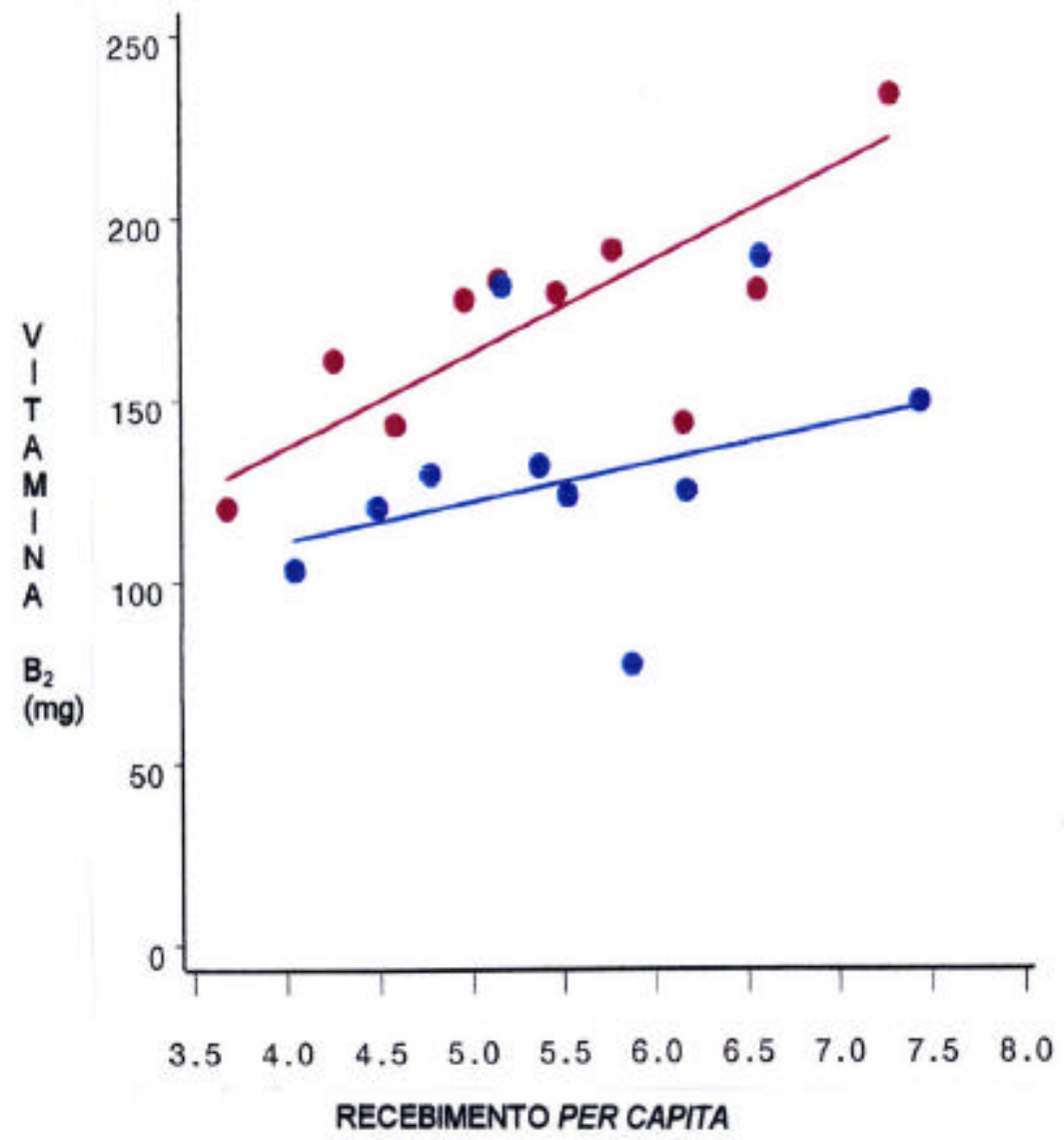

- Regiáo Metropolitana de Recife

- Regiáo Metropolitana de Săo Paulo

Figura 5 - Variação da disponibilidade de vitamina $B_{2}$, no domicílio, de acordo com o recebimento familiar per capita, nas regiões metropolitanas de Recife e São Paulo. 


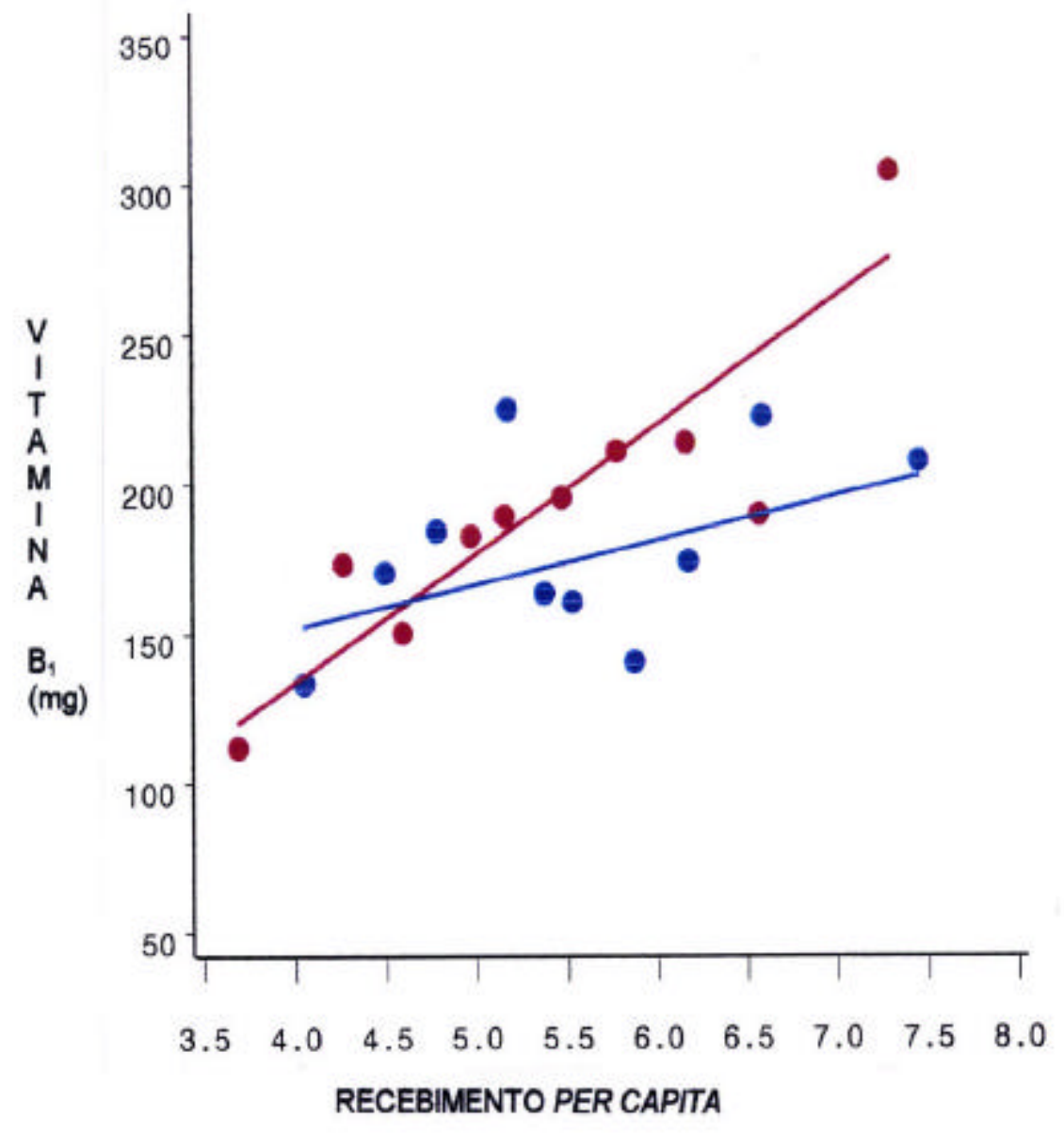

- Regiäo Metropolitana de Recife

- Regiáo Metropolitana de Săo Paulo

Figura 6 - Variação na disponibilidade de vitamina $B_{1}$, no domicílio, de acordo com o recebimento familiar per capita, nas regiões metropolitanas de Recife e São Paulo. 


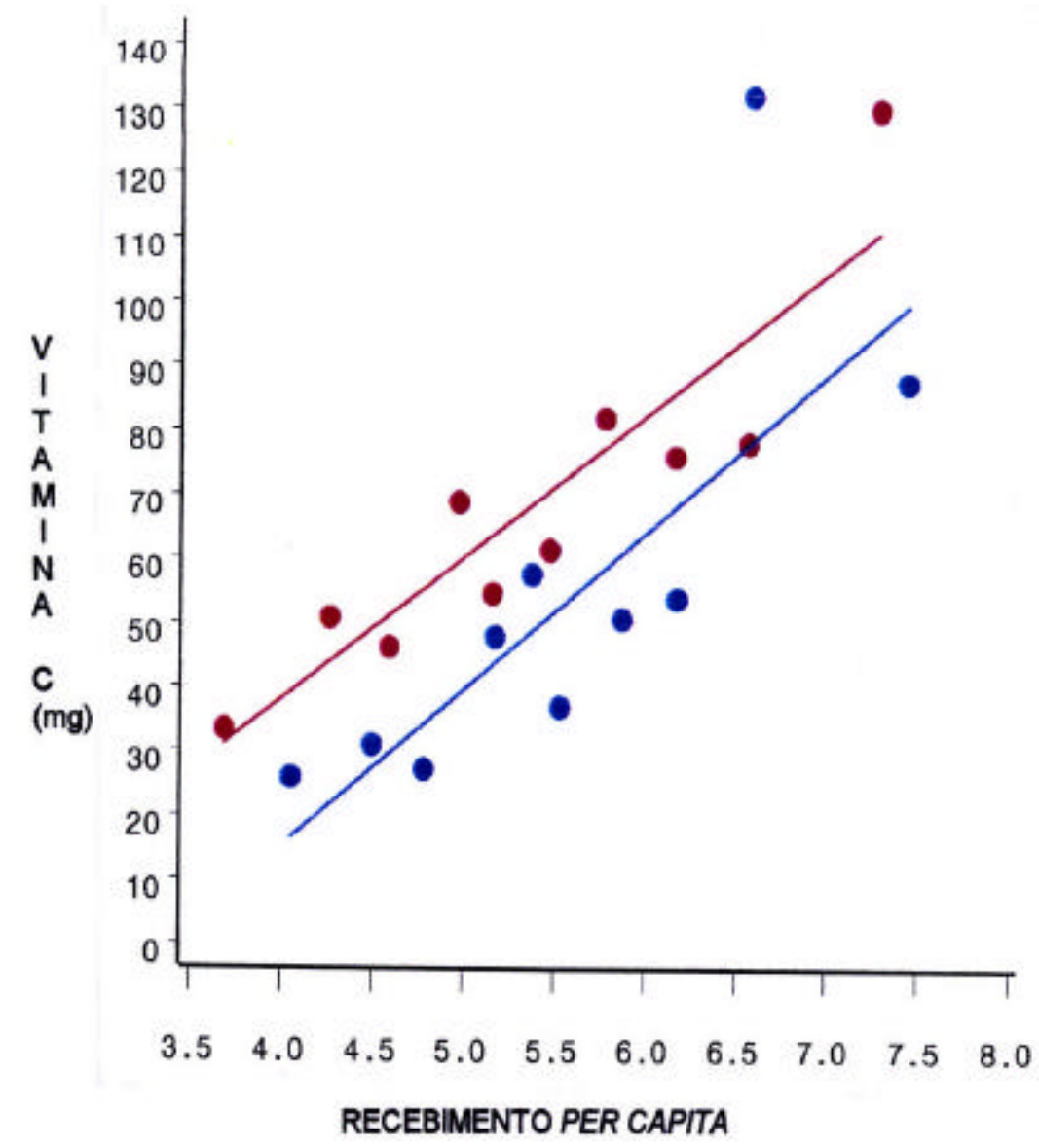

- Região Metropolitana de Recife

- Região Metropolitana de Săo Paulo

Figura 7 - Variação da disponibilidade de vitamina $C$, no domicílio, de acordo com o recebimento familiar per capita, nas regiões metropolitanas de Recife e São Paulo. 


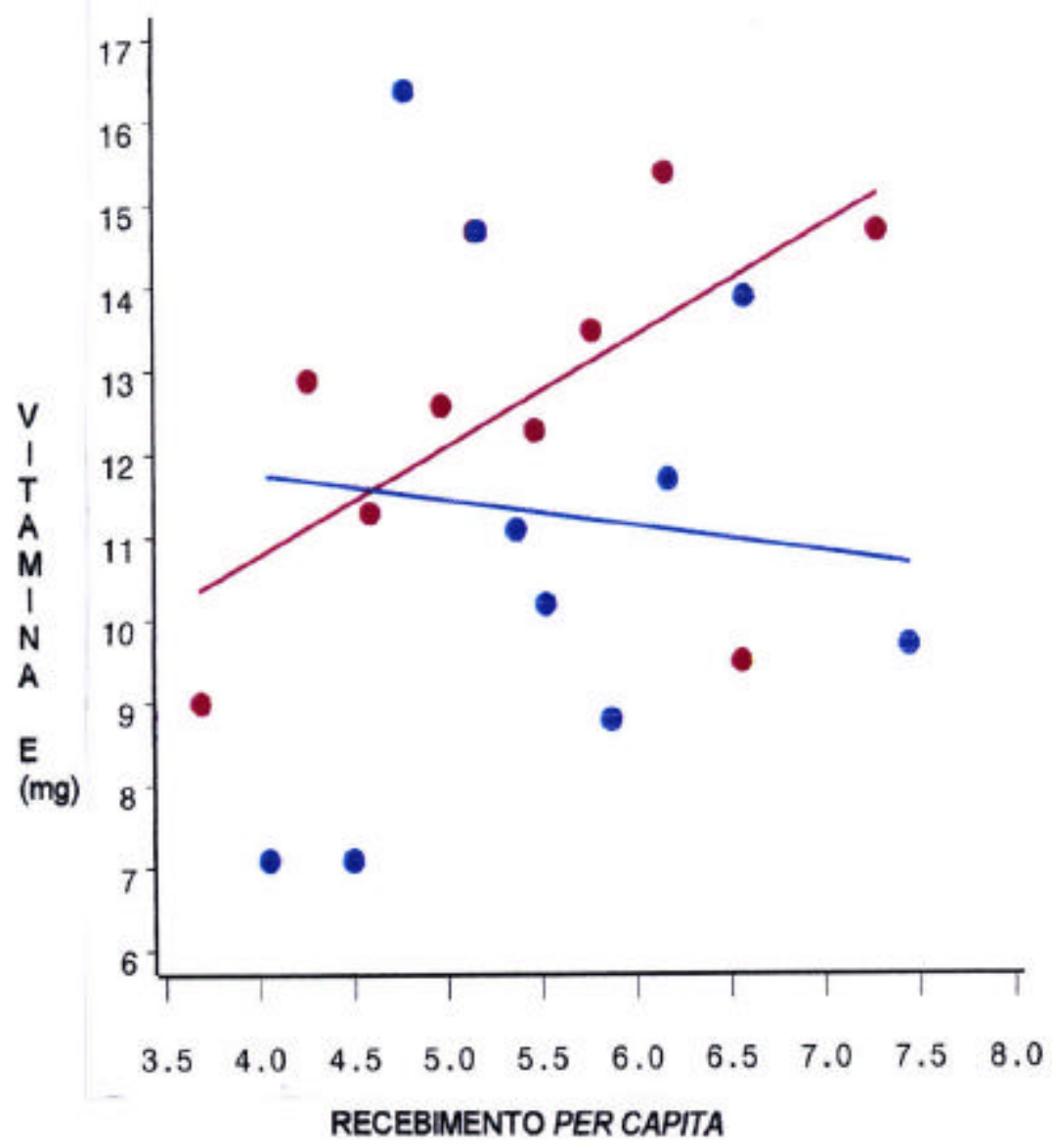

- Região Metropolitana de Recife

- Região Metropolitana de São Paulo

Figura 8 - Variação da disponibilidade de vitamina E, no domicílio, de acordo com o recebimento familiar per capita, nas regiões metropolitanas de Recife e São Paulo. 


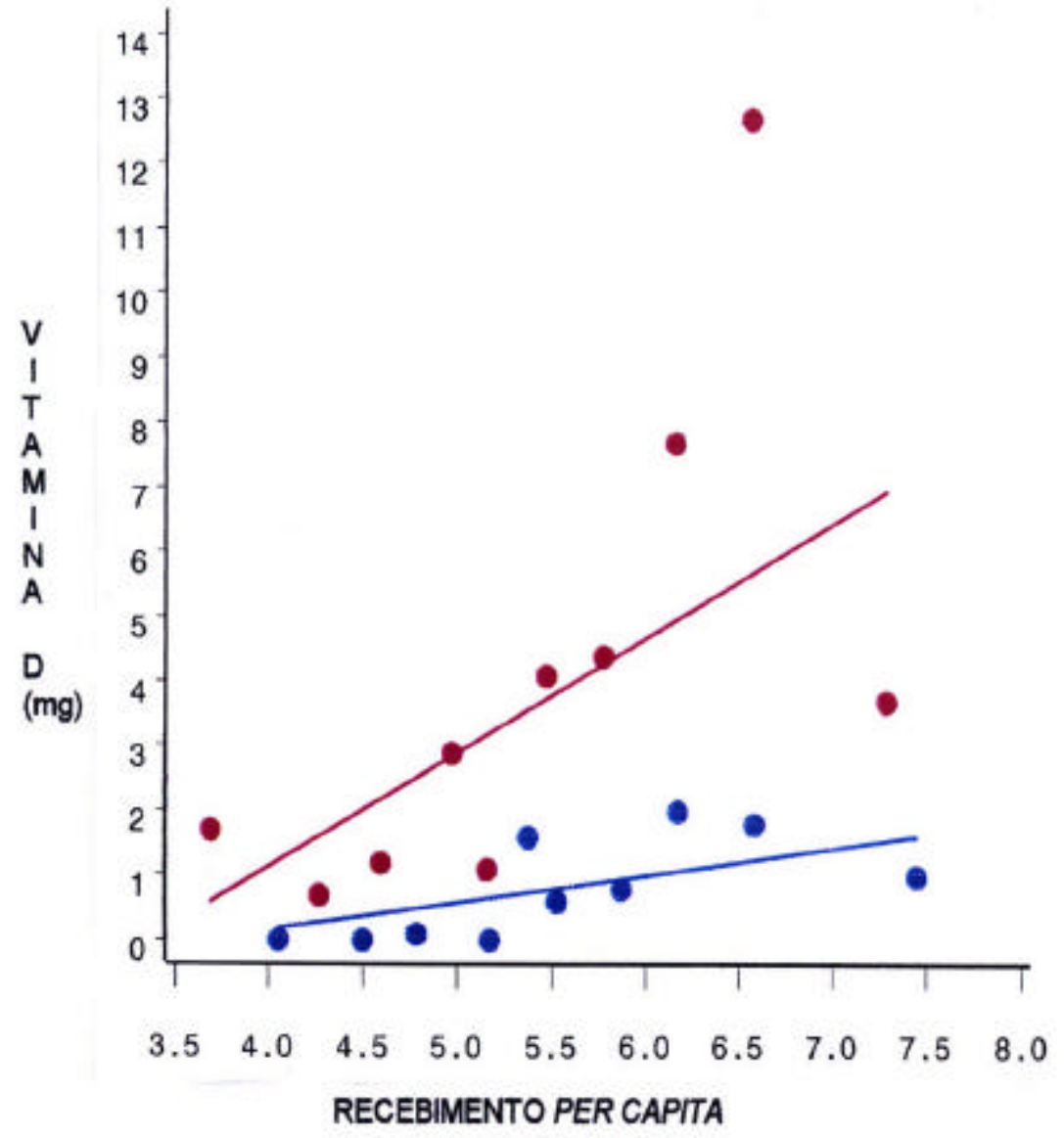

- Região Metropolitana de Recife

- Região Metropolitana de São Paulo

Figura 9 - Variação da disponibilidade de vitamina $D$, no domicílio, de acordo com o recebimento familiar per capita, nas regiões metropolitanas de Recife e São Paulo. 


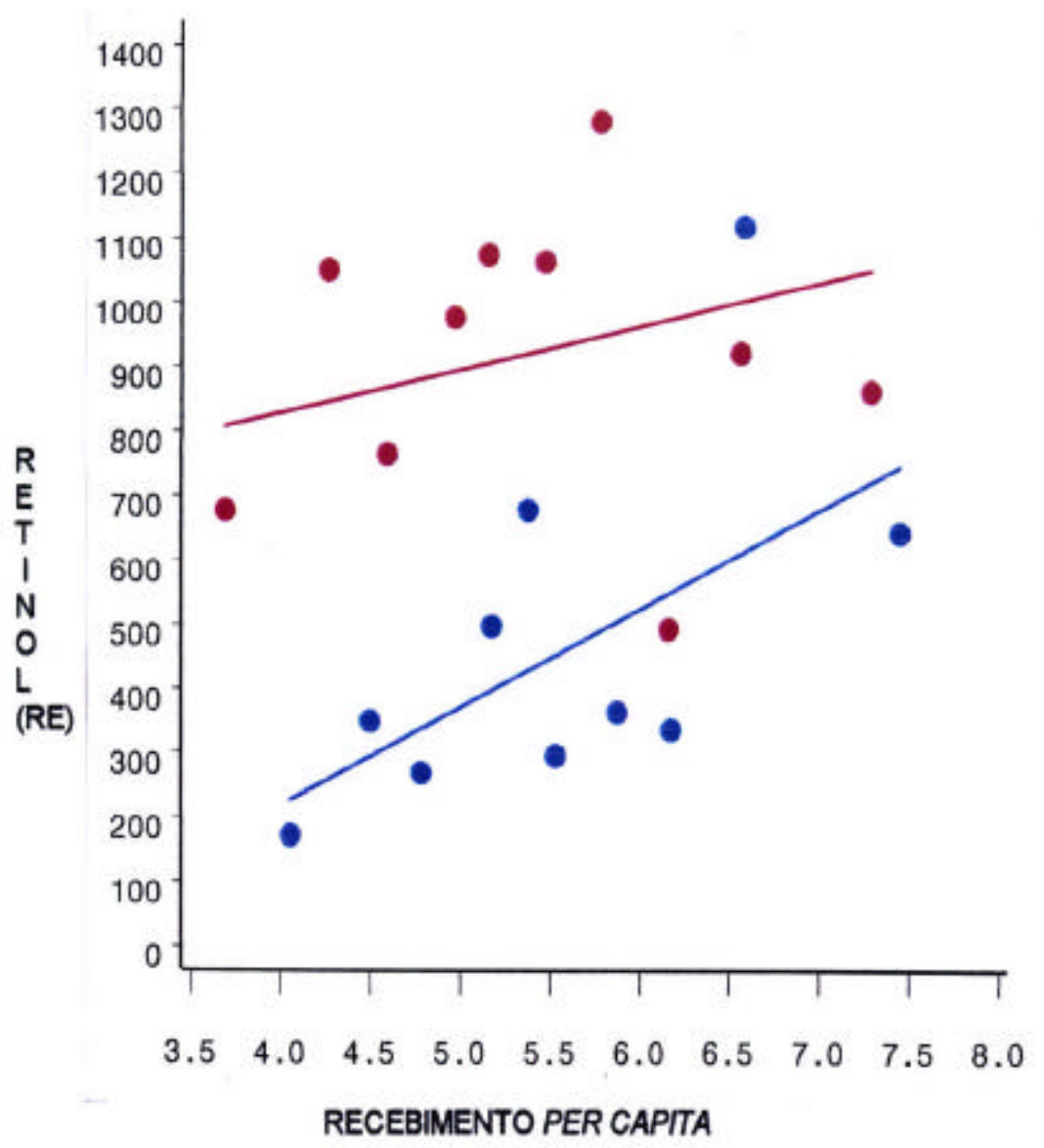

- Região Metropolitana de Recife

- Região Metropolitana de São Paulo

Figura 10 - Variação na disponibilidade de retinol, no domicílio, de acordo com o recebimento familiar per capita, nas regiões metropolitanas de Recife e São Paulo. 


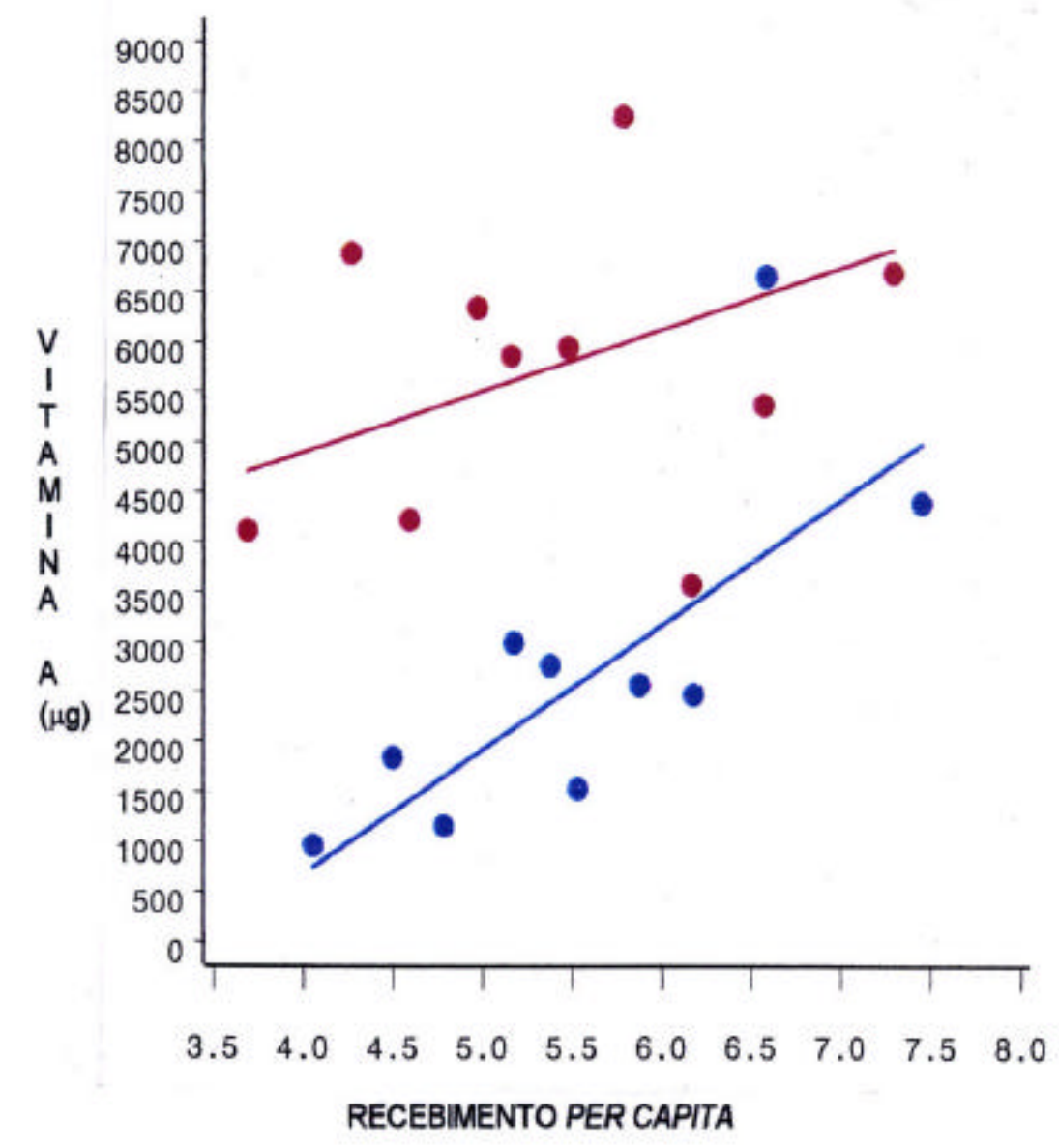

- Regiäo Metropolitana de Recife

- Região Metropolitana de São Paulo

Figura 11 - Variação na disponibilidade de vitamina A, no domicílio, de acordo com o recebimento familiar per capita, nas regiões metropolitanas de Recife e São Paulo. 


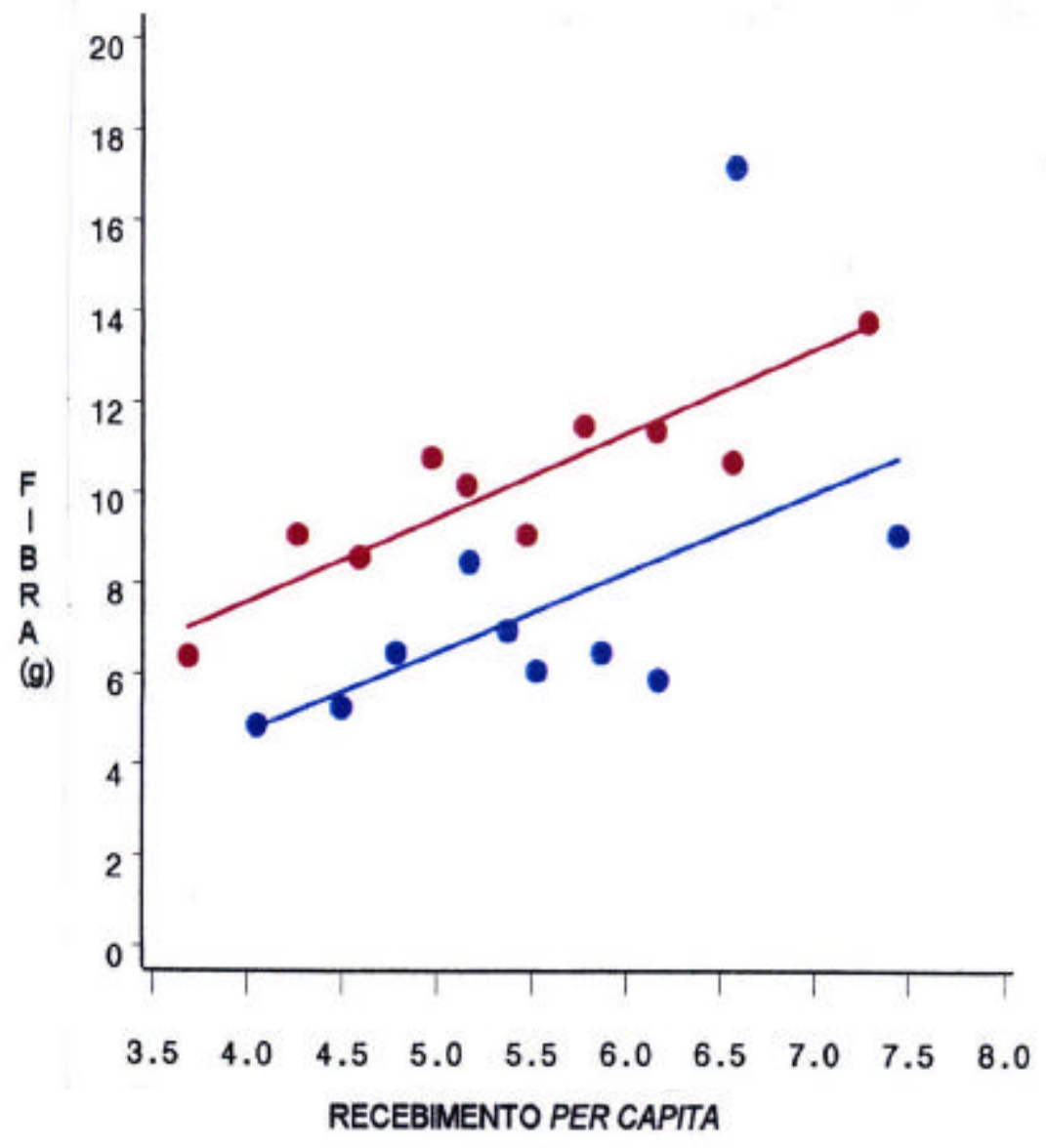

- Região Metropolitana de Recife

- Região Metropolitana de São Paulo

Figura 12 - Variação da disponibilidade de fibra, no domicílio, de acordo com o recebimento familiar per capita, nas regiões metropolitanas de Recife e São Paulo. 


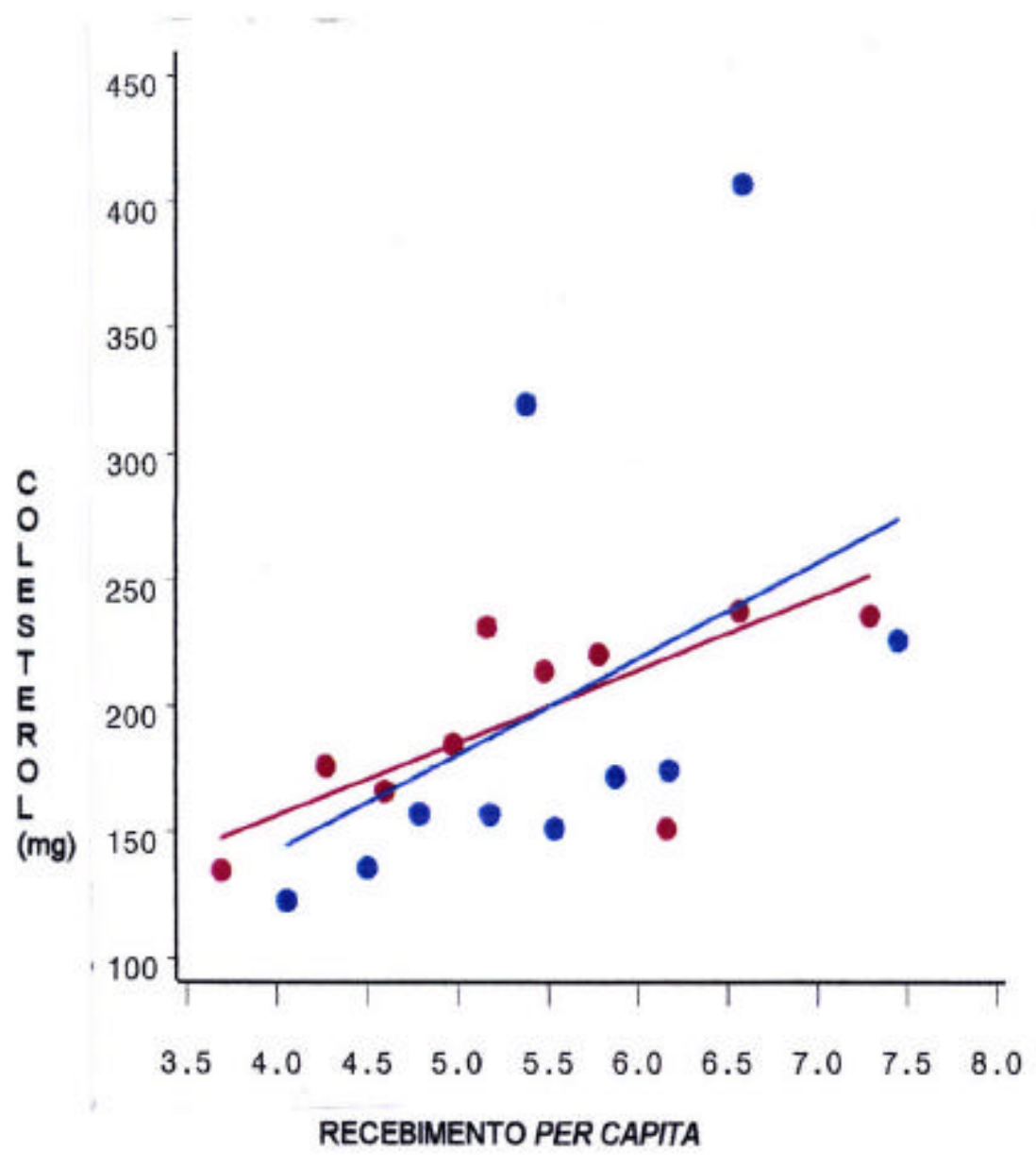

- Região Metropolitana de Recife

- Regiäo Metropolitana de São Paulo

Figura 13 - Variação na disponibilidade de colesterol, no domicílio, de acordo com o recebimento familiar per capita, nas regiões metropolitanas de Recife e São Paulo. 


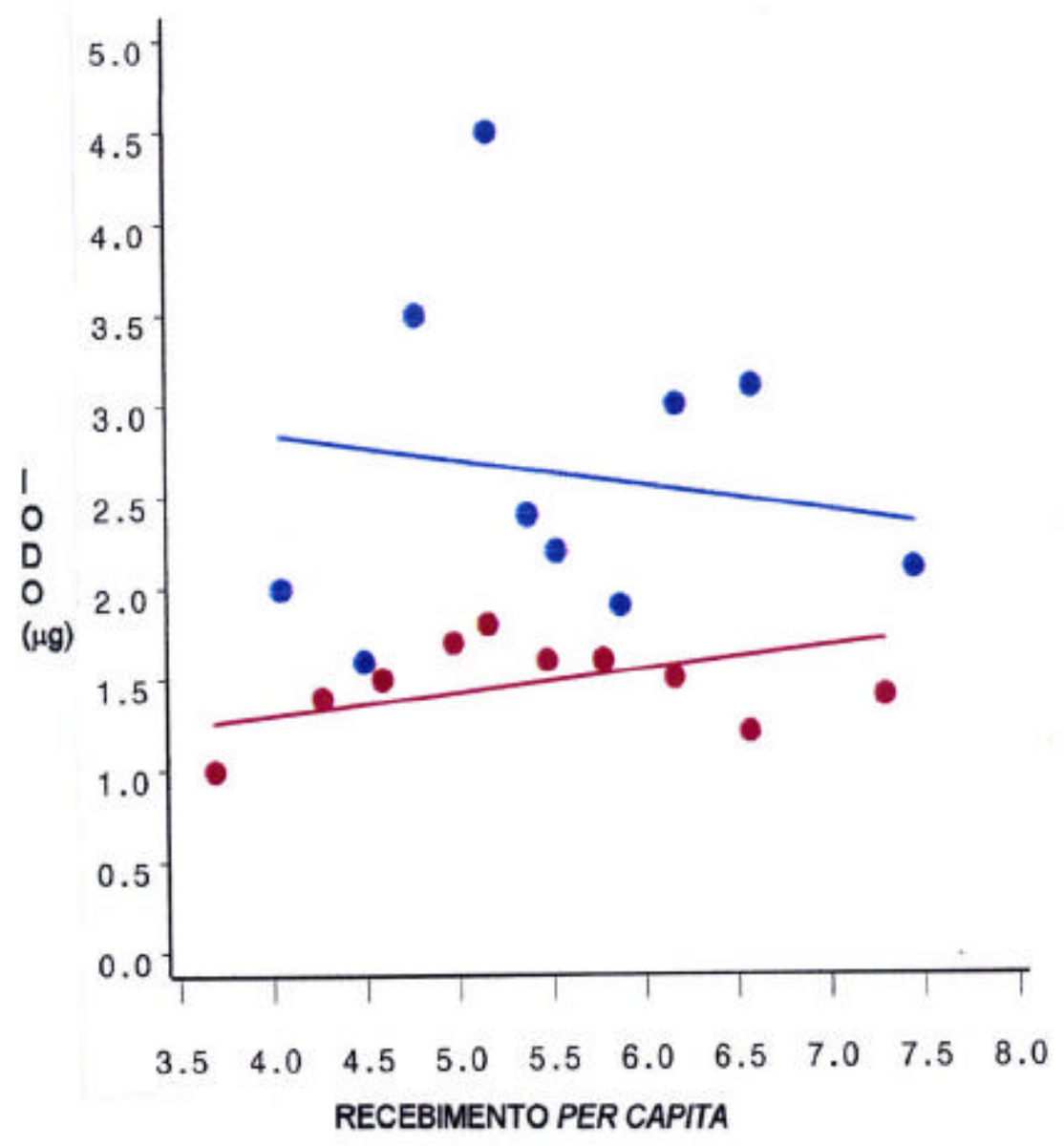

- Regiăo Metropolitana de Recife

- Região Metropolitana de São Paulo

Figura 14 - Variação da disponibilidade de lipídio insaturado, no domicílio, de acordo com o recebimento familiar per capita, nas regiões metropolitanas de Recife e São Paulo. 


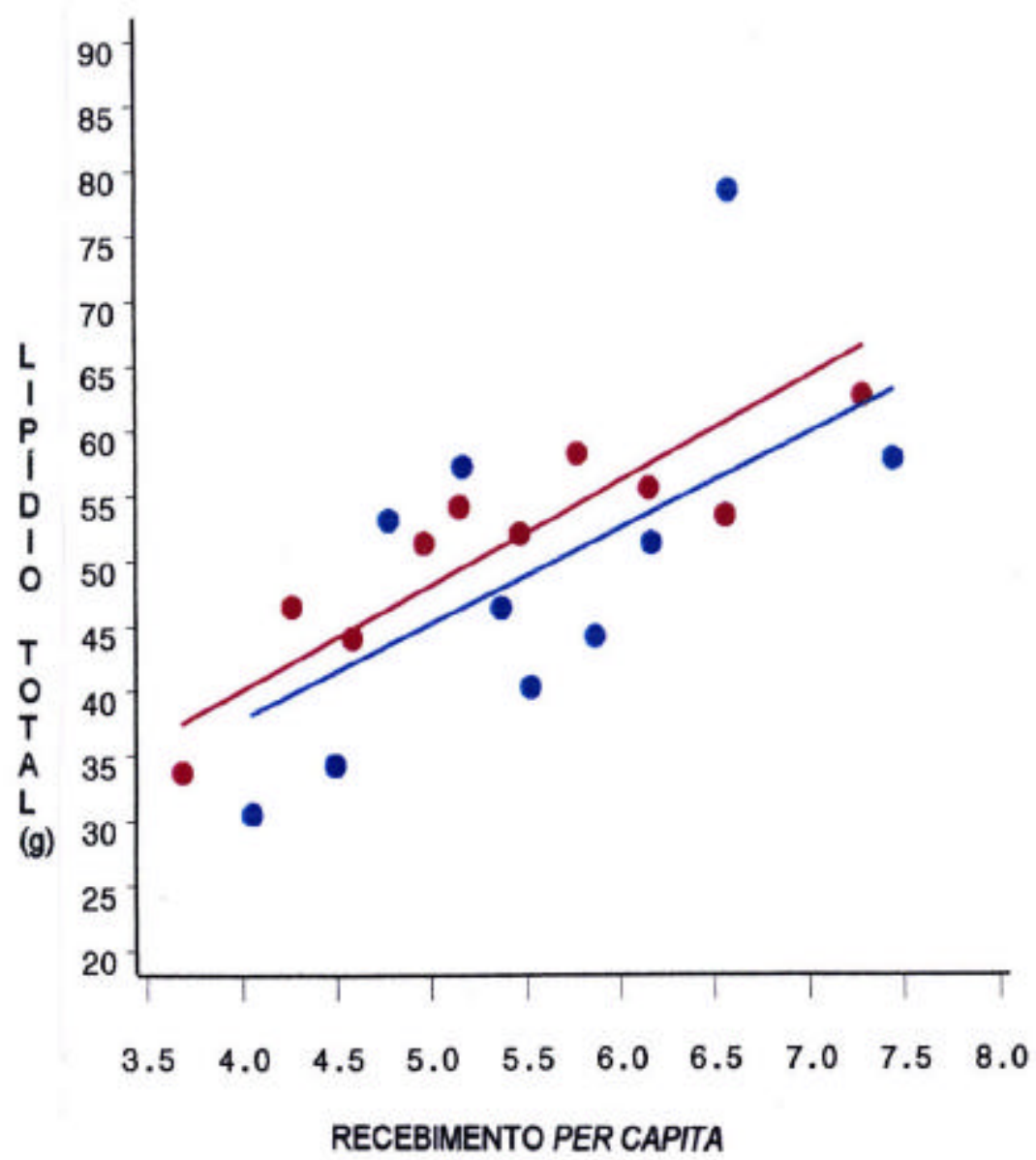

- Região Metropolitana de Recife

- Regiăo Metropolitana de São Paulo

Figura 15 - Variação da disponibilidade de lipídio total, no domicílio, de acordo com o recebimento familiar per capita, nas regiões metropolitanas de Recife e São Paulo. 


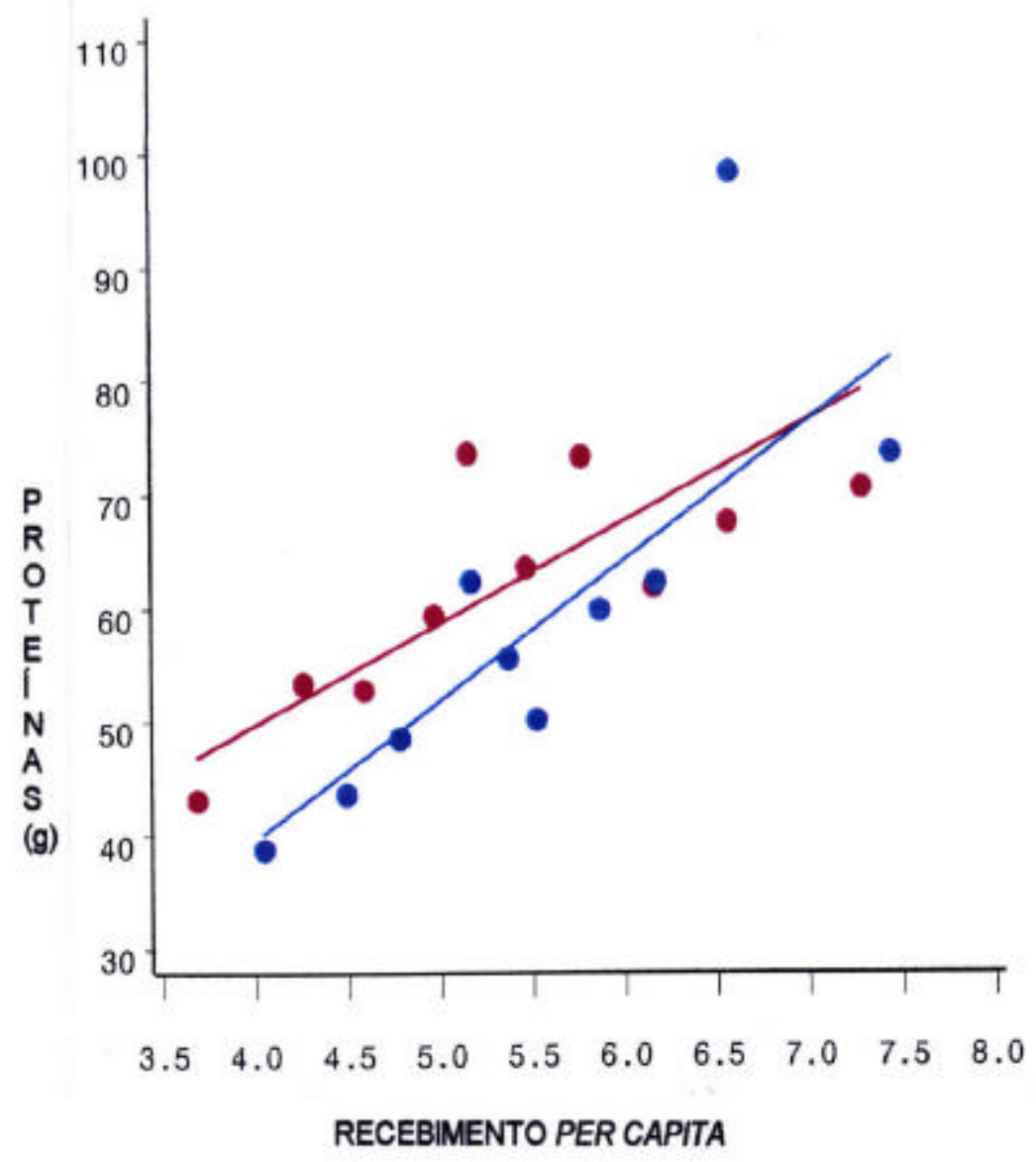

- Região Metropolitana de Recife

- Regiăo Metropolitana de São Paulo

Figura 16 - Variação da disponibilidade de proteína, no domicílio, de acordo com o recebimento familiar per capita, nas regiões metropolitanas de Recife e São Paulo. 


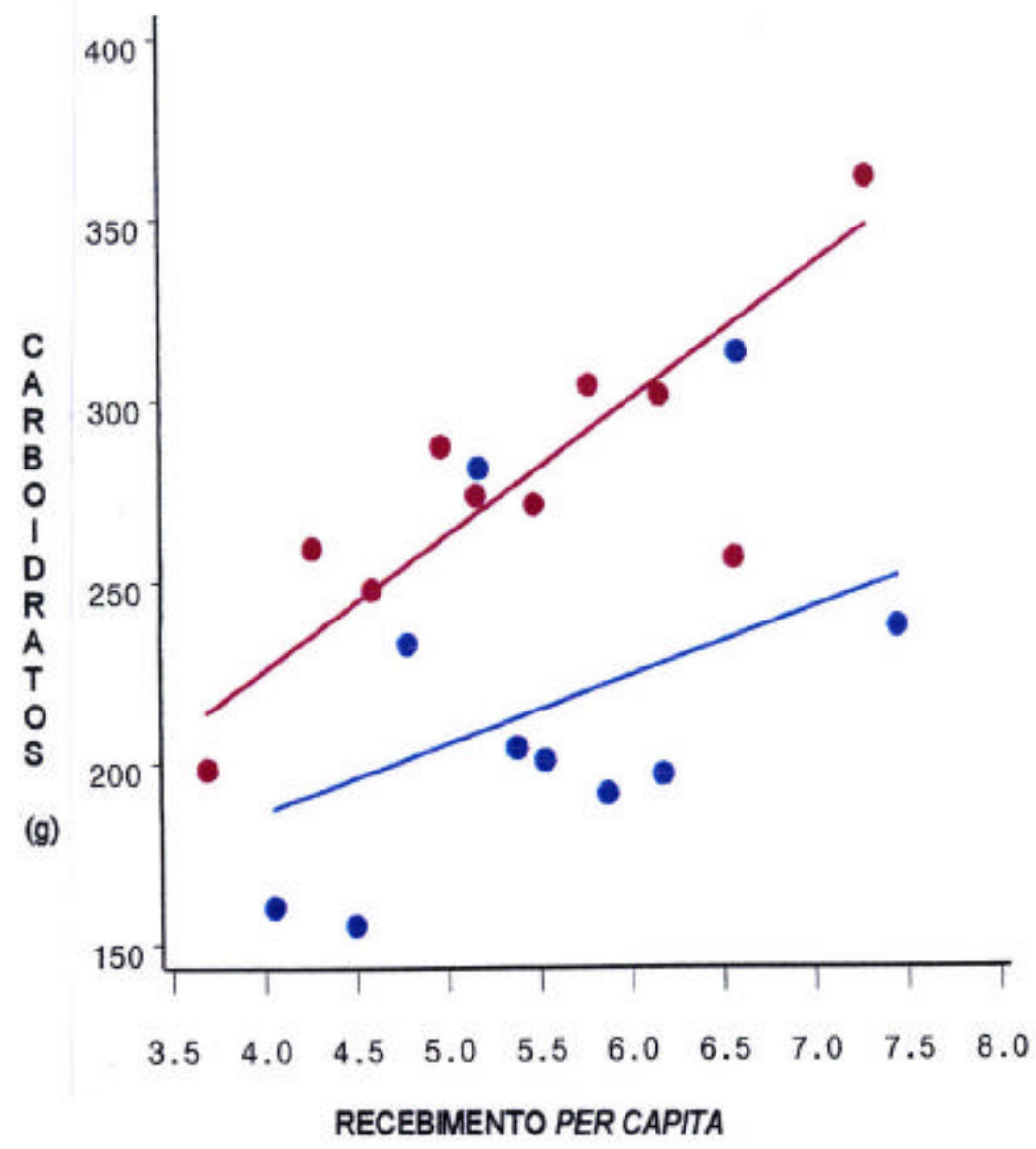

- Região Metropolitana de Recife

- Regiấo Metropolitana de São Paulo

Figura 17 - Variação na disponibilidade de carboidratos, no domicílio, de acordo com o recebimento familiar per capita, nas regiões metropolitanas de Recife e São Paulo. 


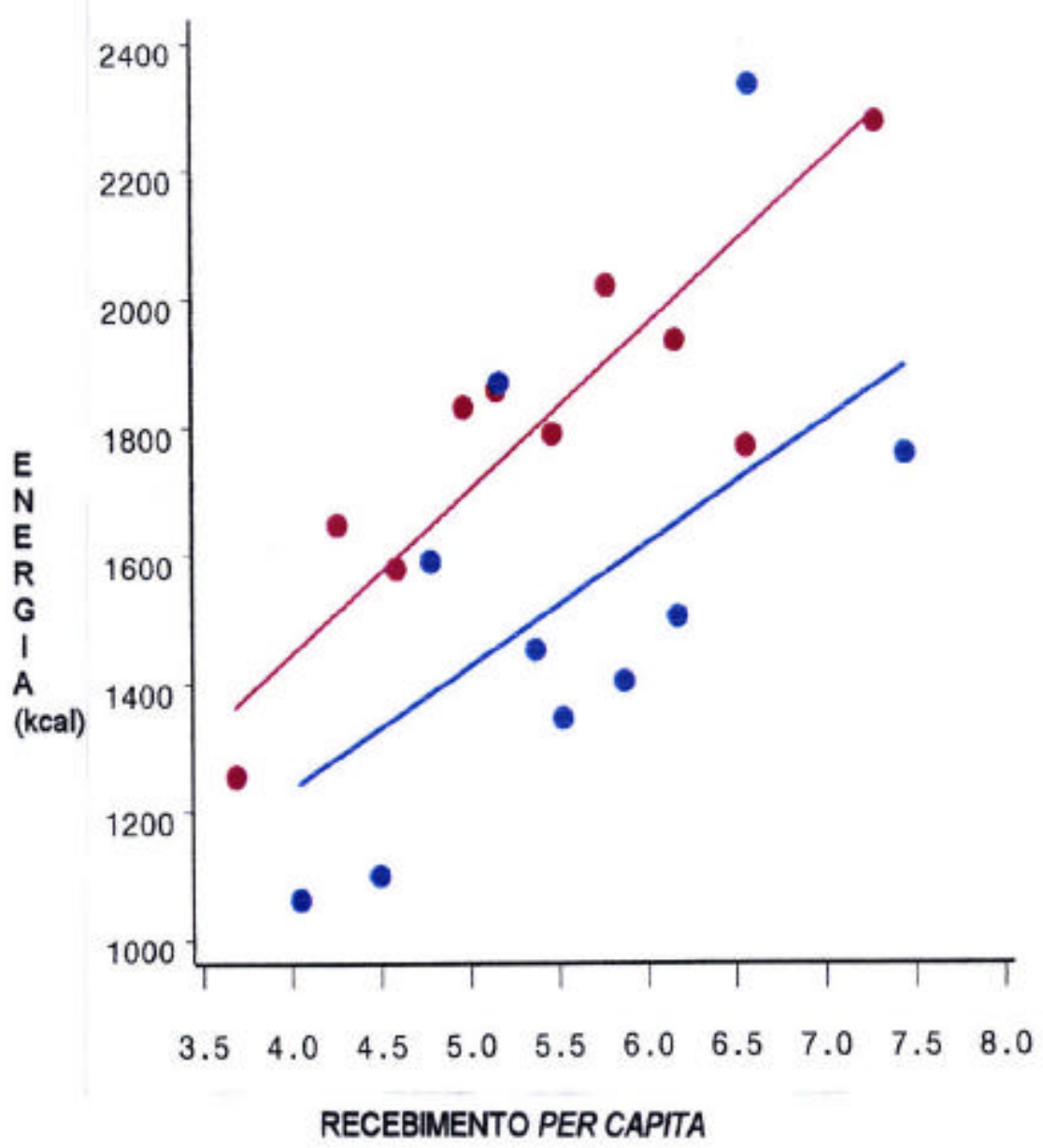

- Região Metropolitana de Recife

- Região Metropolitana de São Paulo

Figura 18 - Variação da disponibilidade de energia, no domicílio, de acordo com o recebimento familiar per capita, nas regiões metropolitanas de Recife e São Paulo. 


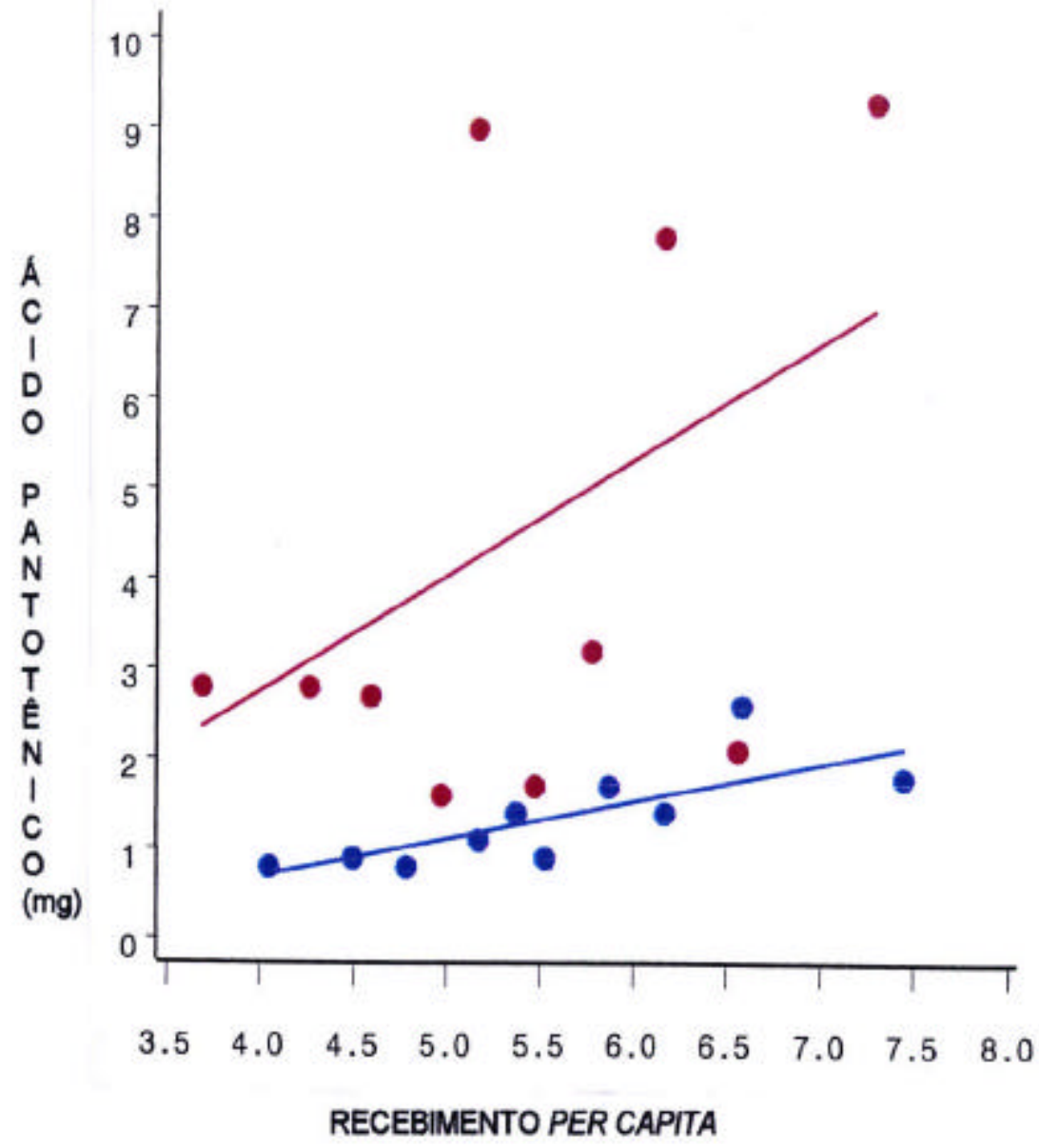

- Região Metropolitana de Recife

- Regiáo Metropolitana de Săo Paulo

Figura 19 - Variação da disponibilidade de ácido pantotênico, no domicílio, de acordo com o recebimento familiar per capita, nas regiões metropolitanas de Recife e São Paulo. 


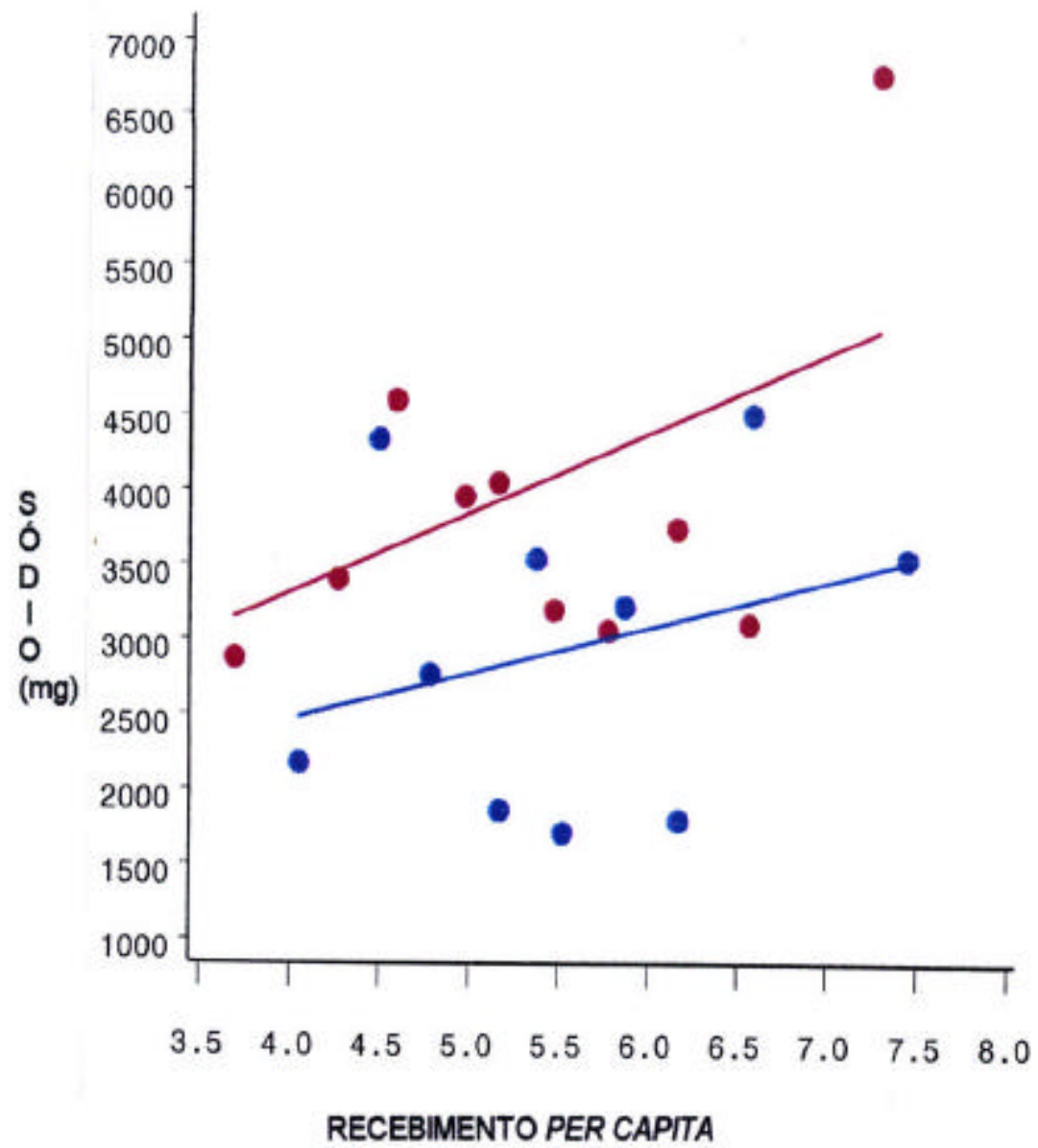

- Regiăo Metropolitana de Recife

- Região Metropolitana de São Paulo

Figura 20 - Variação na disponibilidade de sódio, no domicílio, de acordo com o recebimento familiar per capita, na regiões metropolitanas de Recife e São Paulo. 


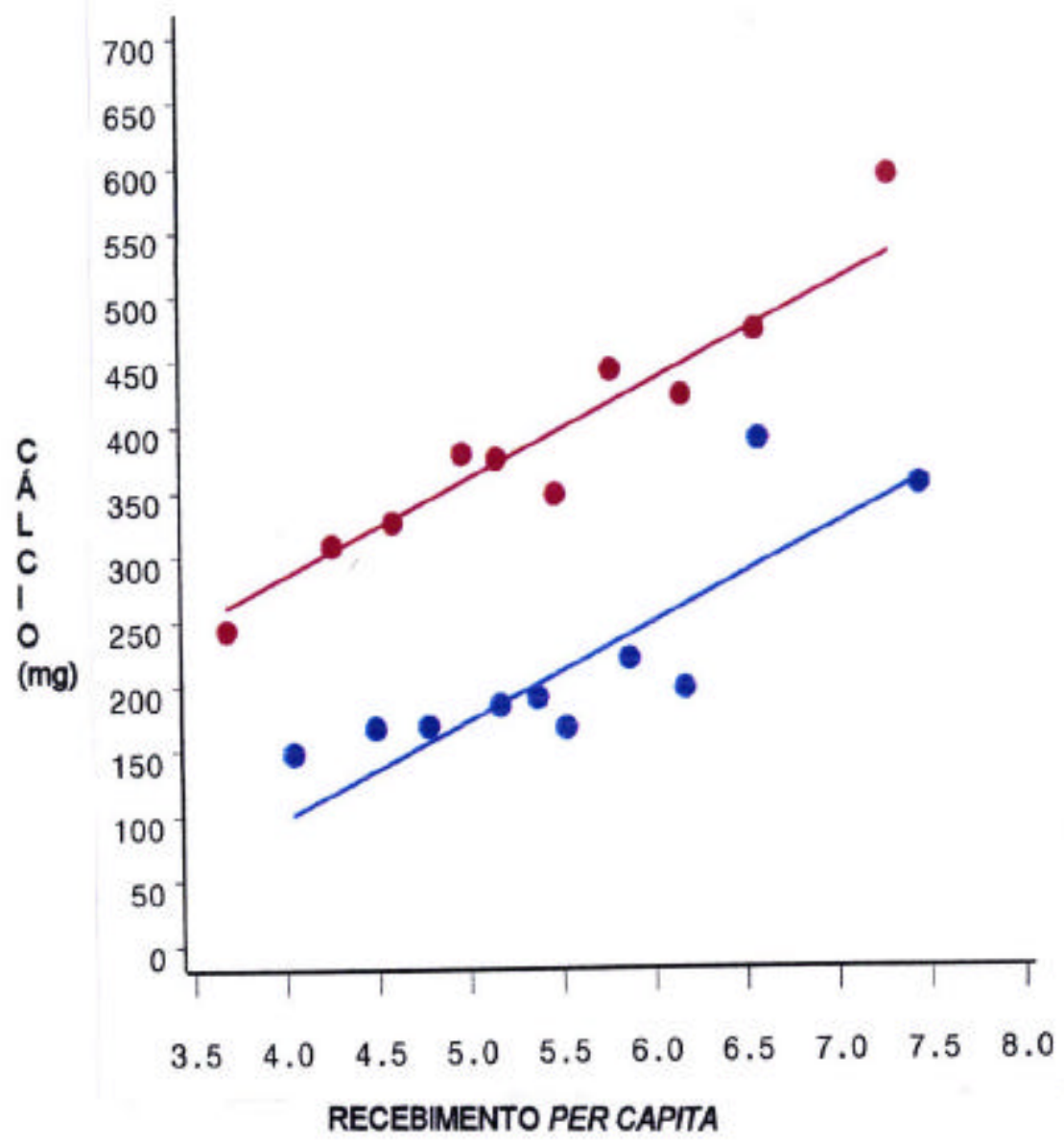

- Regiáo Metropolitana de Recife

- Região Metropolitana de Săo Paulo

Figura 21 - Variação da disponibilidade de cálcio, no domicílio, de acordo com o recebimento familiar per capita, nas regiões metropolitanas de Recife e São Paulo. 


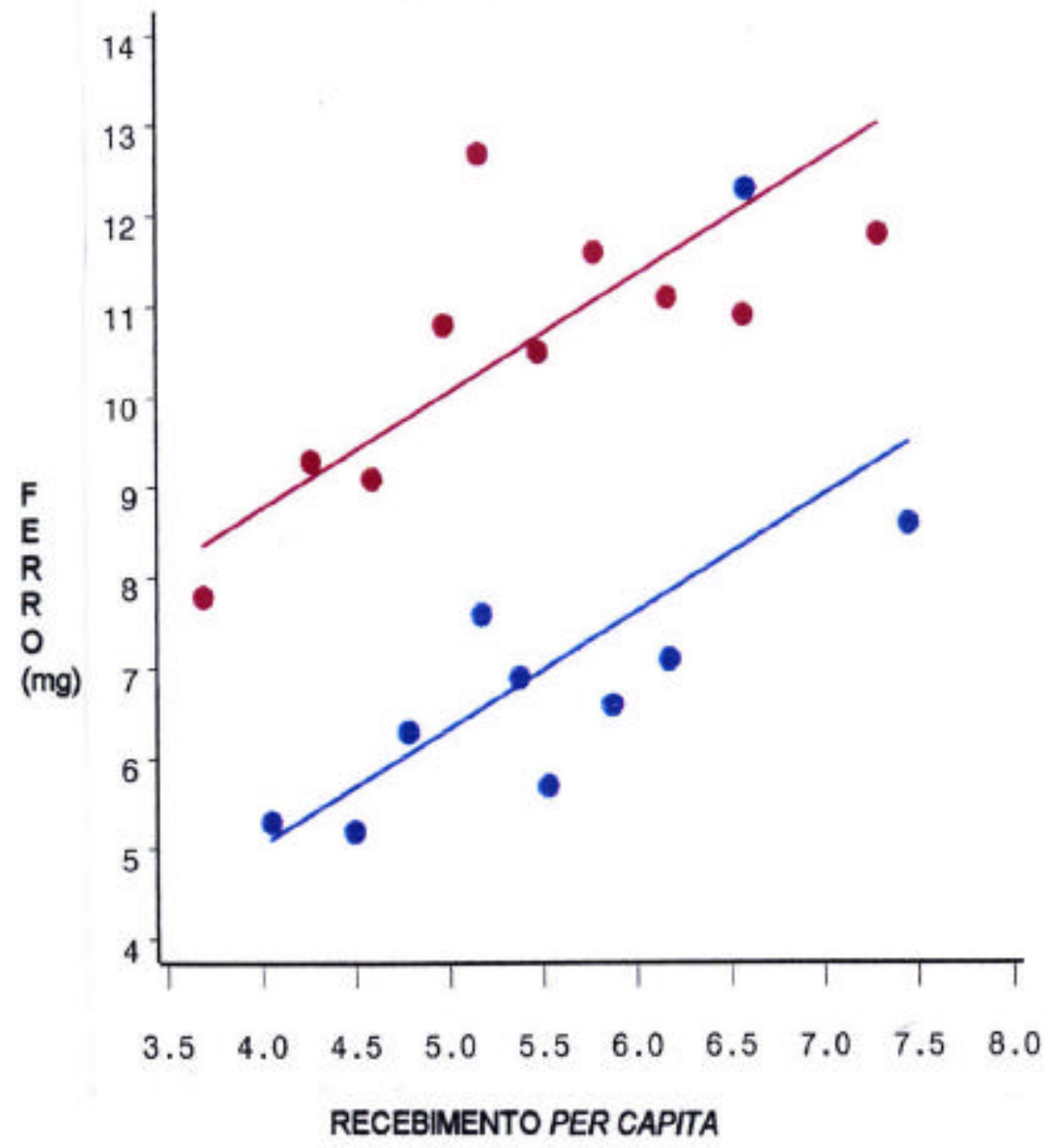

- Região Metropolitana de Recife

- Regiăo Metropolitana de Săo Paulo

Figura 22 - Variação da disponibilidade de ferro, no domicílio, de acordo com o recebimento familiar per capita, nas regiões metropolitanas de Recife e São Paulo. 


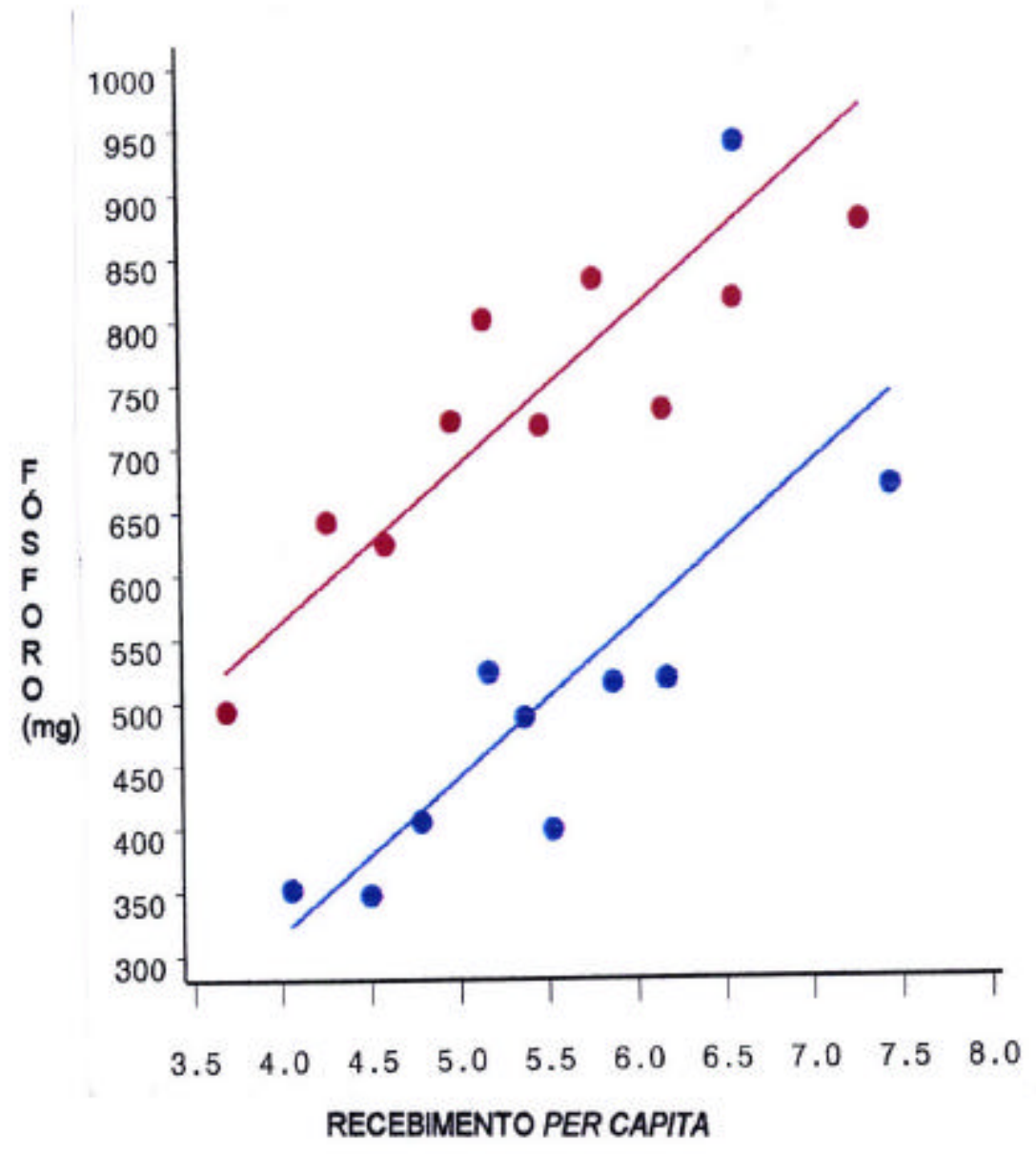

- Região Metropolitana de Recife

- Região Metropolitana de São Paulo

Figura 23 - Variação da disponibilidade de fósforo, no domicílio, de acordo com o recebimento familiar per capita, nas regiões metropolitanas de Recife e São Paulo. 


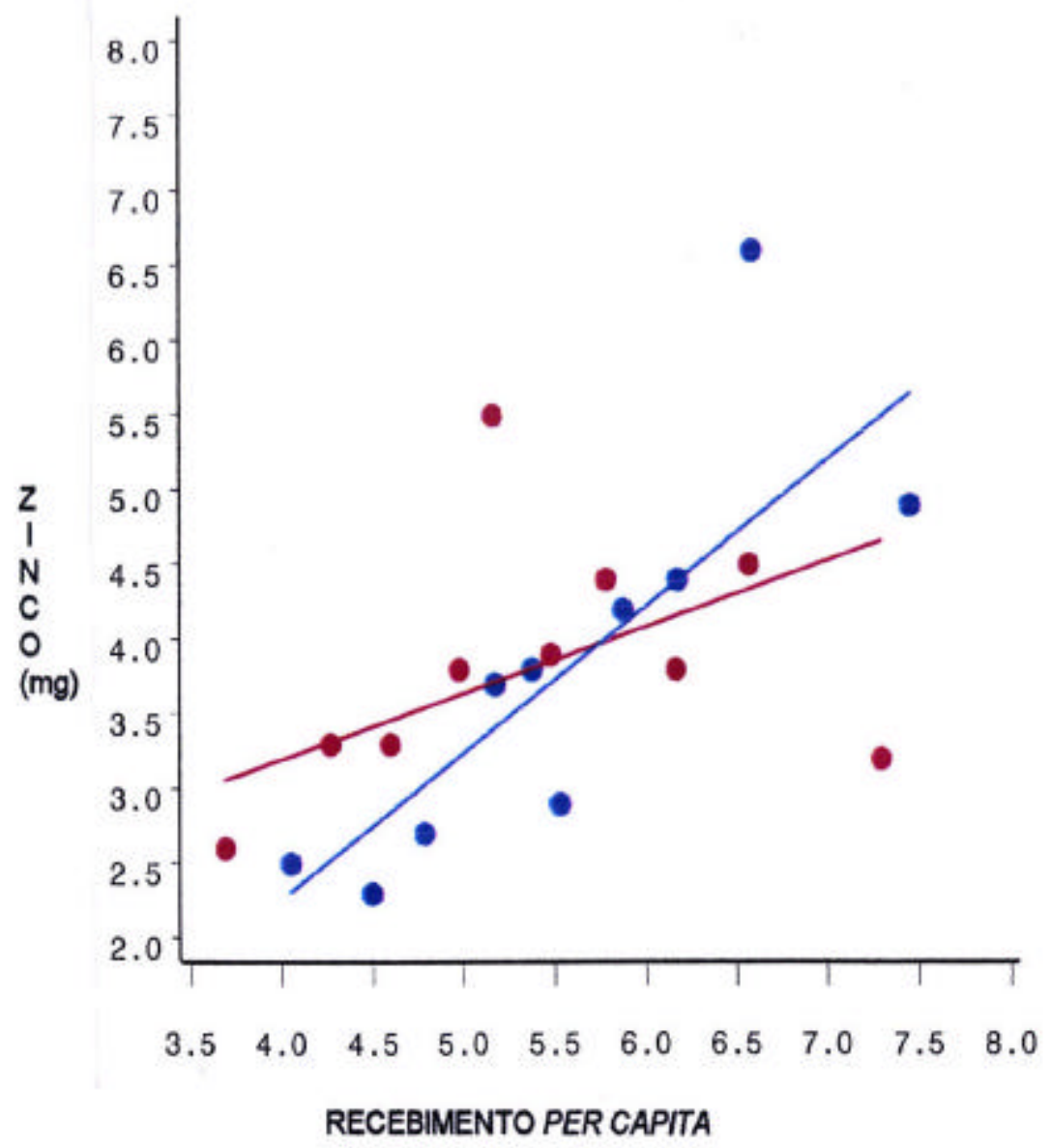

- Região Metropolitana de Recife

- Regiäo Metropolitana de São Paulo

Figura 24 - Variação da disponibilidade de zinco, no domicílio, de acordo com o recebimento familiar per capita, nas regiões metropolitanas de Recife e São Paulo. 


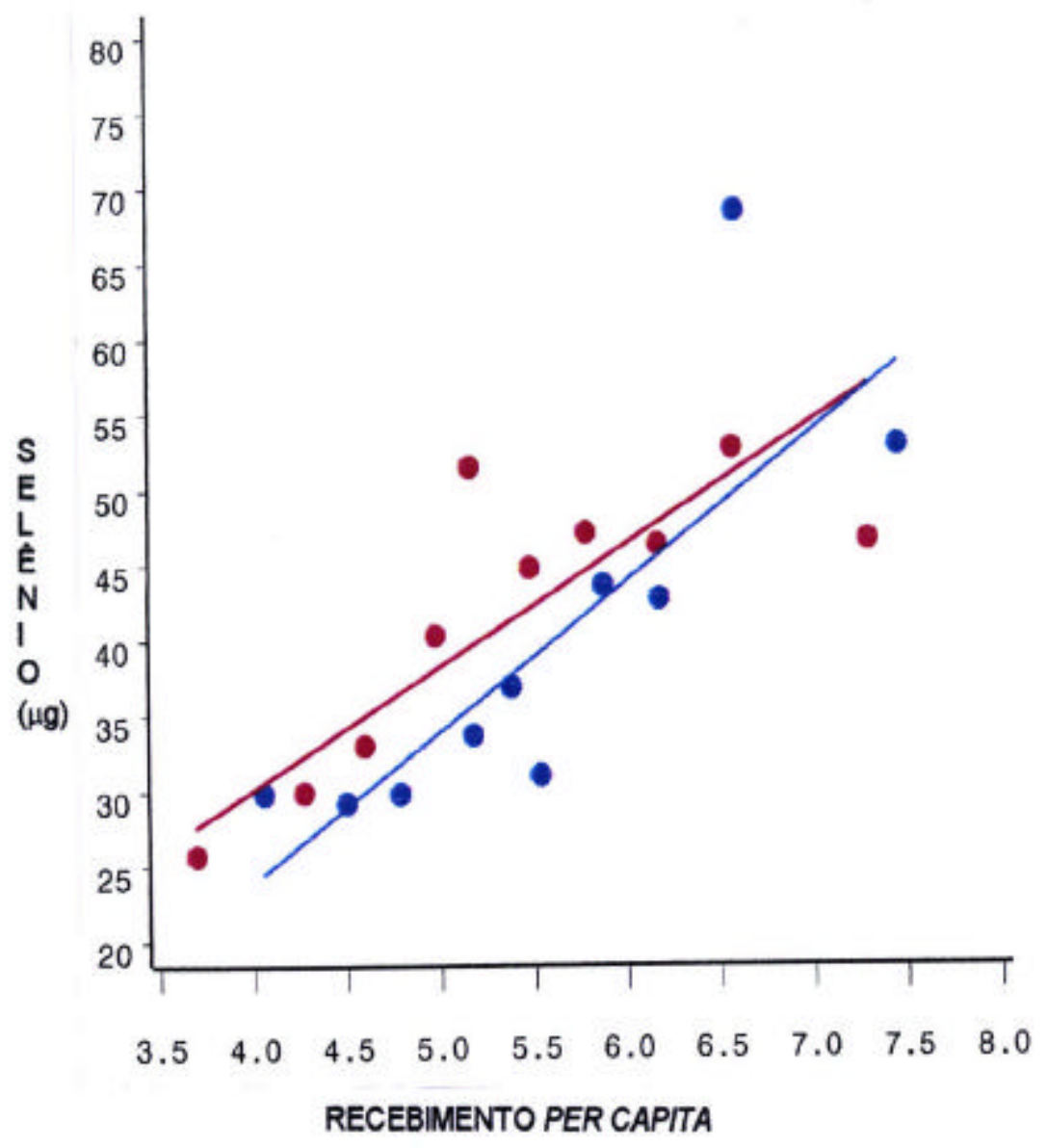

- Regiăo Metropolitana de Recife

- Região Metropolitana de São Paulo

Figura 25 - Variação na disponibilidade de selênio, no domicílio, de acordo com o recebimento familiar per capita, nas regiões metropolitanas de Recife e São Paulo. 


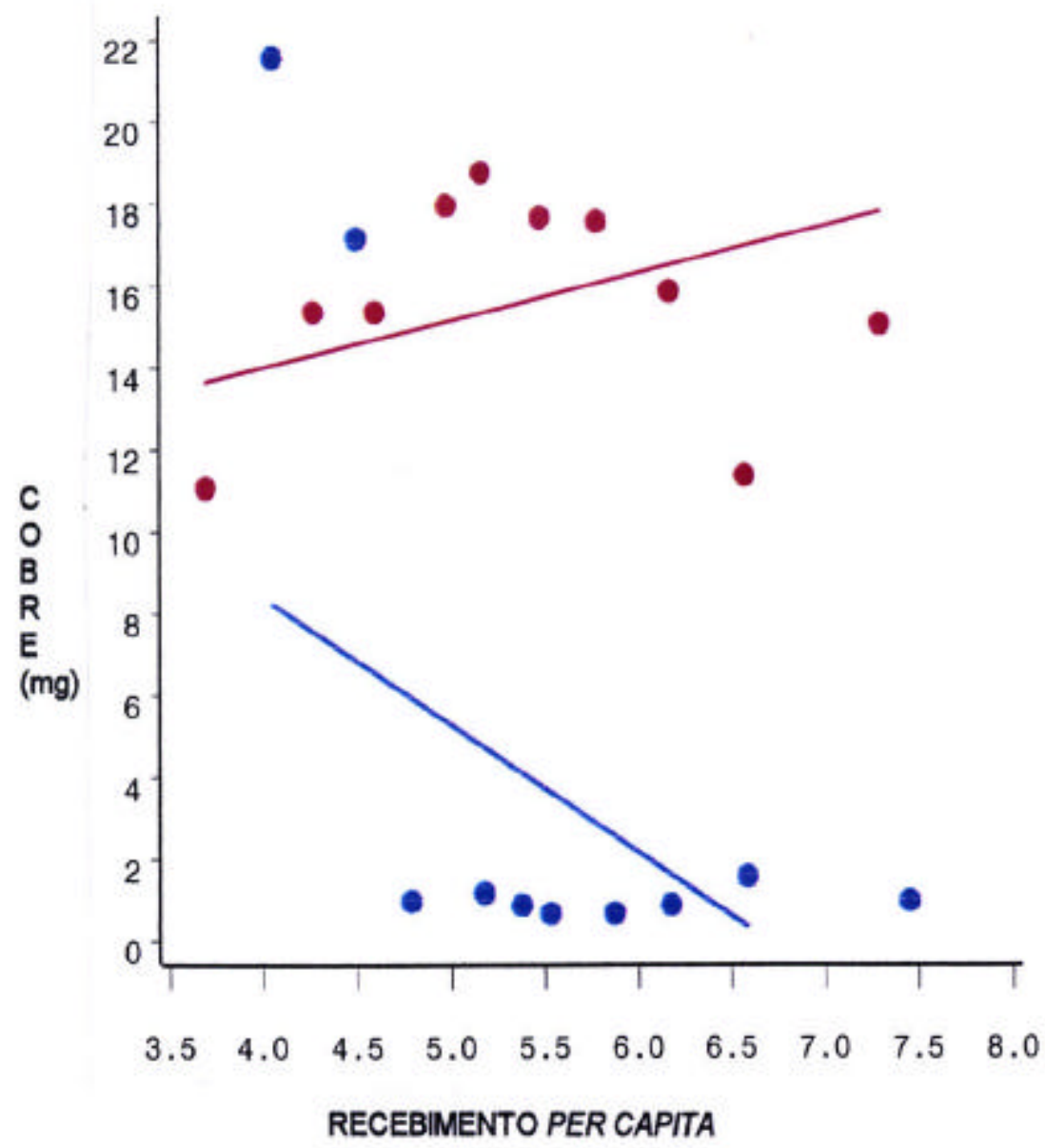

- Região Metropolitana de Recife

- Região Metropolitana de São Paulo

Figura 26 - Variação na disponibilidade de cobre, no domicílio, de acordo com o recebimento familiar per capita, nas regiões metropolitanas de Recife e São Paulo. 


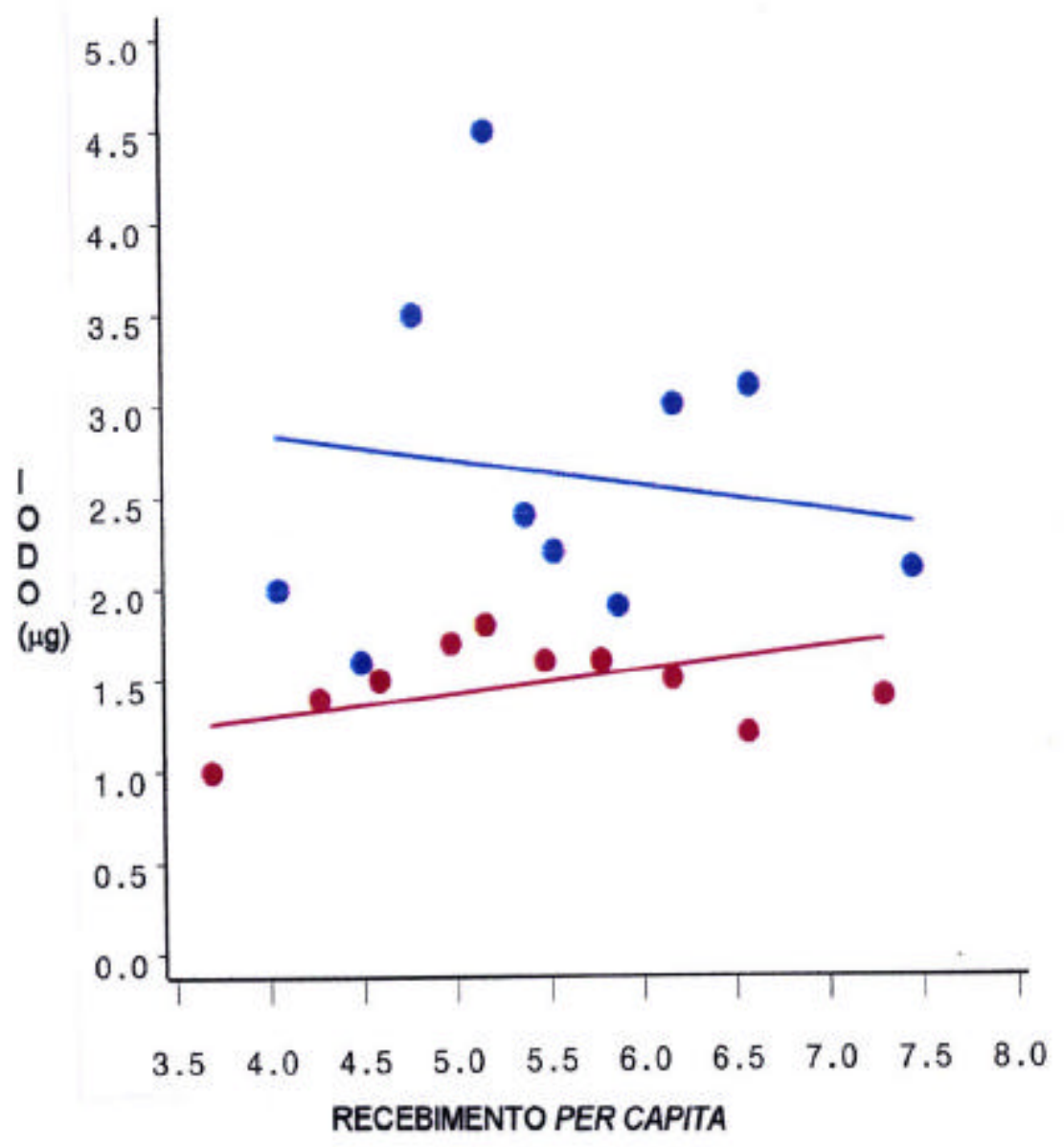

- Regiăo Metropolitana de Recife

- Região Metropolitana de São Paulo

Figura 27 - Variação da disponibilidade de iodo, no domicílio, de acordo com o recebimento familiar per capita, nas regiões metropolitanas de Recife e São Paulo. 


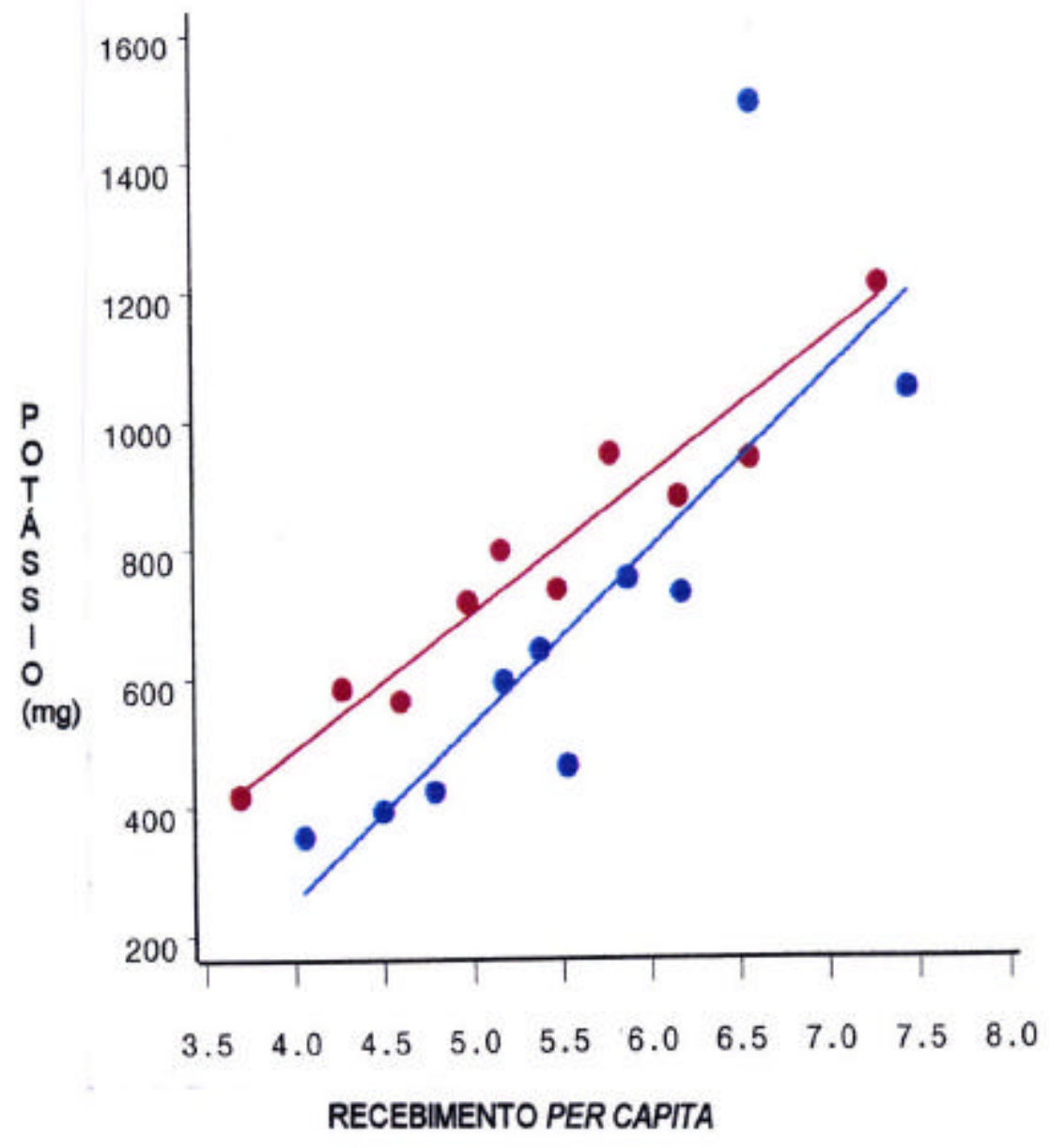

- Região Metropolitana de Recife

- Região Metropolitana de São Paulo

Figura 28 - Variação da disponibilidade de potássio, no domicílio, de acordo com o recebimento familiar per capita, nas regiões metropolitanas de Recife e São Paulo. 


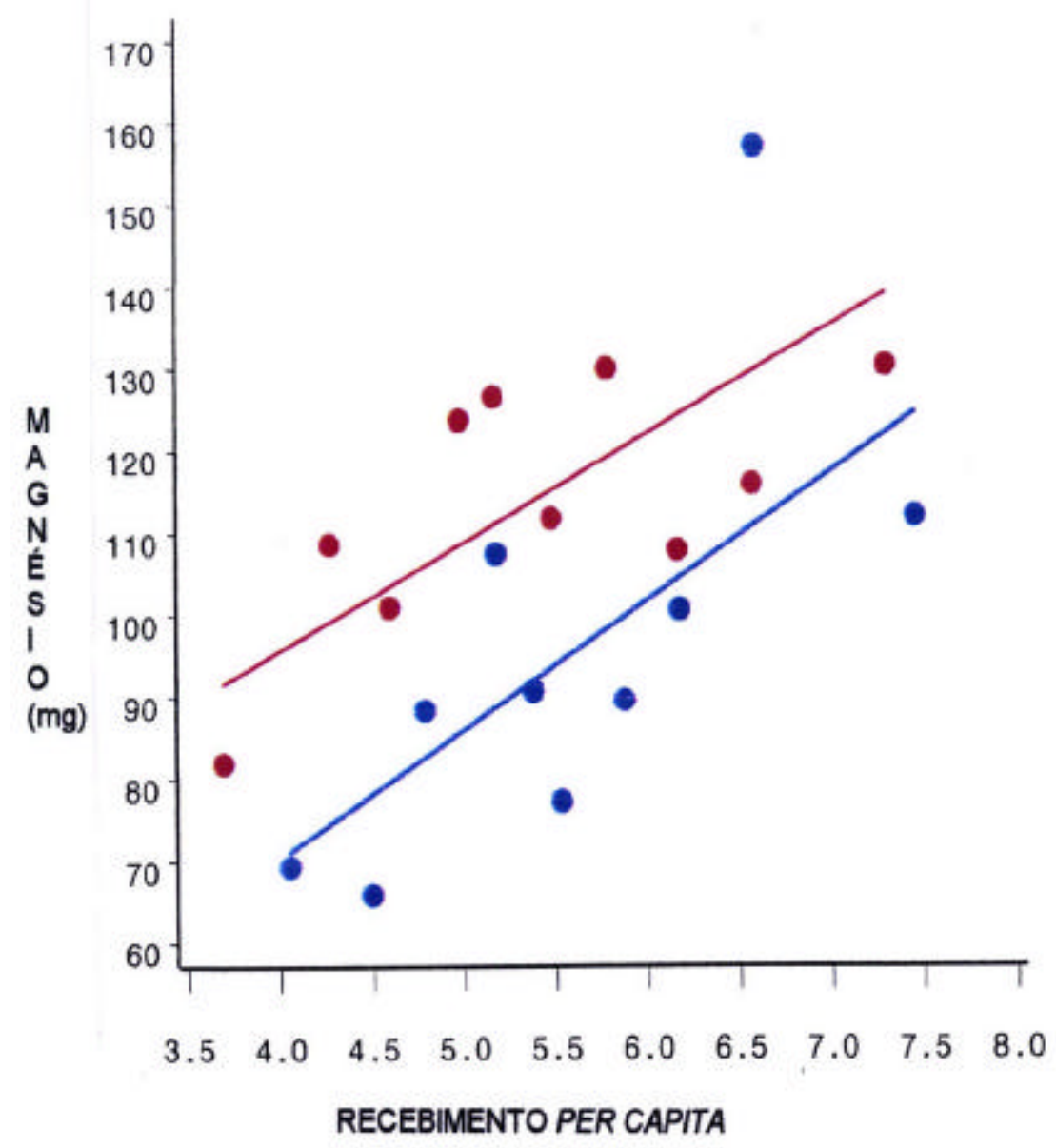

- Região Metropolitana de Recife

- Região Metropolitana de Săo Paulo

Figura 29 - Variação da disponibilidade de magnésio, no domicílio, de acordo com o recebimento familiar per capita, nas regiões metropolitanas de Recife e São Paulo. 


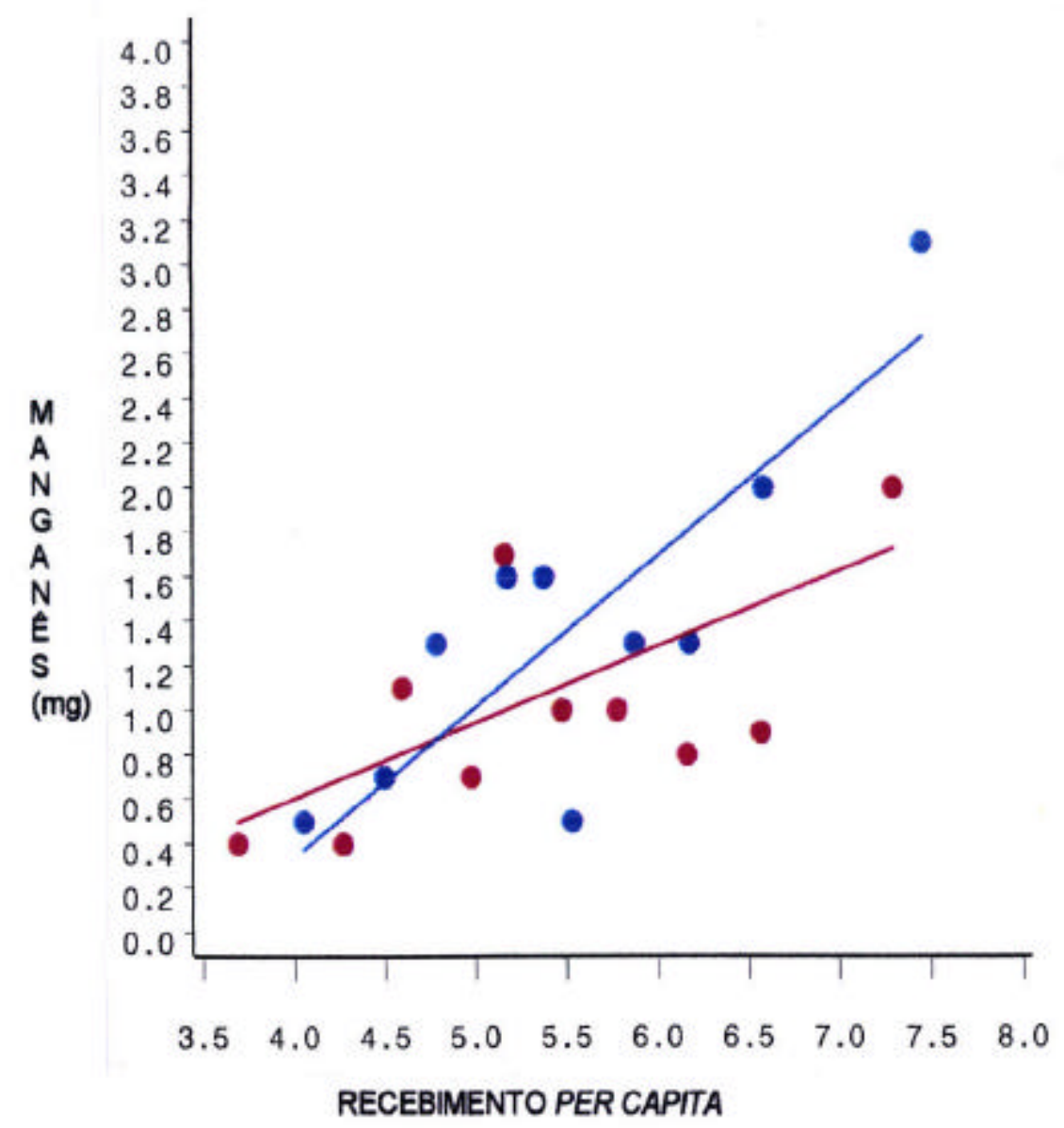

- Região Metropolitana de Recife

- Regiåo Metropolitana de Săo Paulo

Figura 30 - Variação da disponibilidade de manganês, no domicílio, de acordo com o recebimento familiar per capita, nas regiões metropolitanas de Recife e São Paulo. 
Tabela 7. Estimativa dos parâmetros relativos ao modelo de análise de regressão da proporção dos macronutrientes (carboidratos, proteínas e lipídios) no valor energético total - VET em função dos recebimentos nas regiões metropolitanas de Recife e São Paulo. 1995/1996.

\begin{tabular}{|c|c|c|c|c|c|c|c|}
\hline \multirow[t]{2}{*}{ Macroutrientes } & \multicolumn{4}{|c|}{ Estimativas } & \multirow[t]{2}{*}{$R^{2}$} & \multirow[t]{2}{*}{$F$} & \multirow[t]{2}{*}{$F$} \\
\hline & $\alpha$ & $\beta$ & $\gamma$ & $\delta$ & & & \\
\hline Lipídios & $\begin{array}{l}0,225 \\
(6,37)\end{array}$ & $\begin{array}{r}0,0054 \\
(0,76)\end{array}$ & $\begin{array}{r}0,0204 \\
(0,51)\end{array}$ & $\begin{array}{r}0,0021 \\
(0,27)\end{array}$ & 0,65 & 9,70 & 7,14 \\
\hline Proteínas & $\begin{array}{l}0,131 \\
(3,57)\end{array}$ & $\begin{array}{l}0,00102 \\
(0,14)\end{array}$ & $\begin{array}{r}-0,0443 \\
(-0,0443)\end{array}$ & $\begin{array}{r}-0,0107 \\
(-0,0107)\end{array}$ & 0,52 & $5,84^{* \star *}$ & 1,51 \\
\hline Carboidratos & $\begin{array}{r}0,644 \\
(13,47)\end{array}$ & $\begin{array}{r}-0,0064 \\
(-0,67)\end{array}$ & $\begin{array}{r}0,0239 \\
(0,44)\end{array}$ & $\begin{array}{r}-0,0128 \\
(-1,22)\end{array}$ & 0,75 & $7,38^{* * *}$ & $16,01^{* \star \star}$ \\
\hline
\end{tabular}

Nota: * ${ }^{* *} \mathrm{e}^{* \star *}$ indicam que o teste é significativo a $10 \%, 5 \%$ e $1 \%$, respectivamente.

$\left(^{*}\right)$ teste $F$ para testar a hipótese que $\beta=\gamma=\delta=0$.

$\left({ }^{\star \star}\right)$ teste $\mathrm{F}$ para testar a hipótese que $\gamma=\delta=0$.

A equação para participação dos lipídios na energia mostra que essa tende a crescer com o recebimento nas duas áreas metropolitanas analisadas (embora esse crescimento não seja estatisticamente significativo).Para um mesmo nível de recebimento, essa participação é mais alta em São Paulo do que em Recife. $O$ teste $F$ para a hipótese de que gama e delta são iguais a zero é significativo ao nível de 1\%, indicando que a participação dos lipídios no total do conteúdo energético é substancialmente mais alto em São Paulo.

A seguir são apresentadas as Figuras 31,32 e 33 que ilustram os resultados obtidos. Ao examinar as figuras é importante lembrar que os cálculos foram elaborados tendo por base o logaritmo do recebimento familiar per capita. 


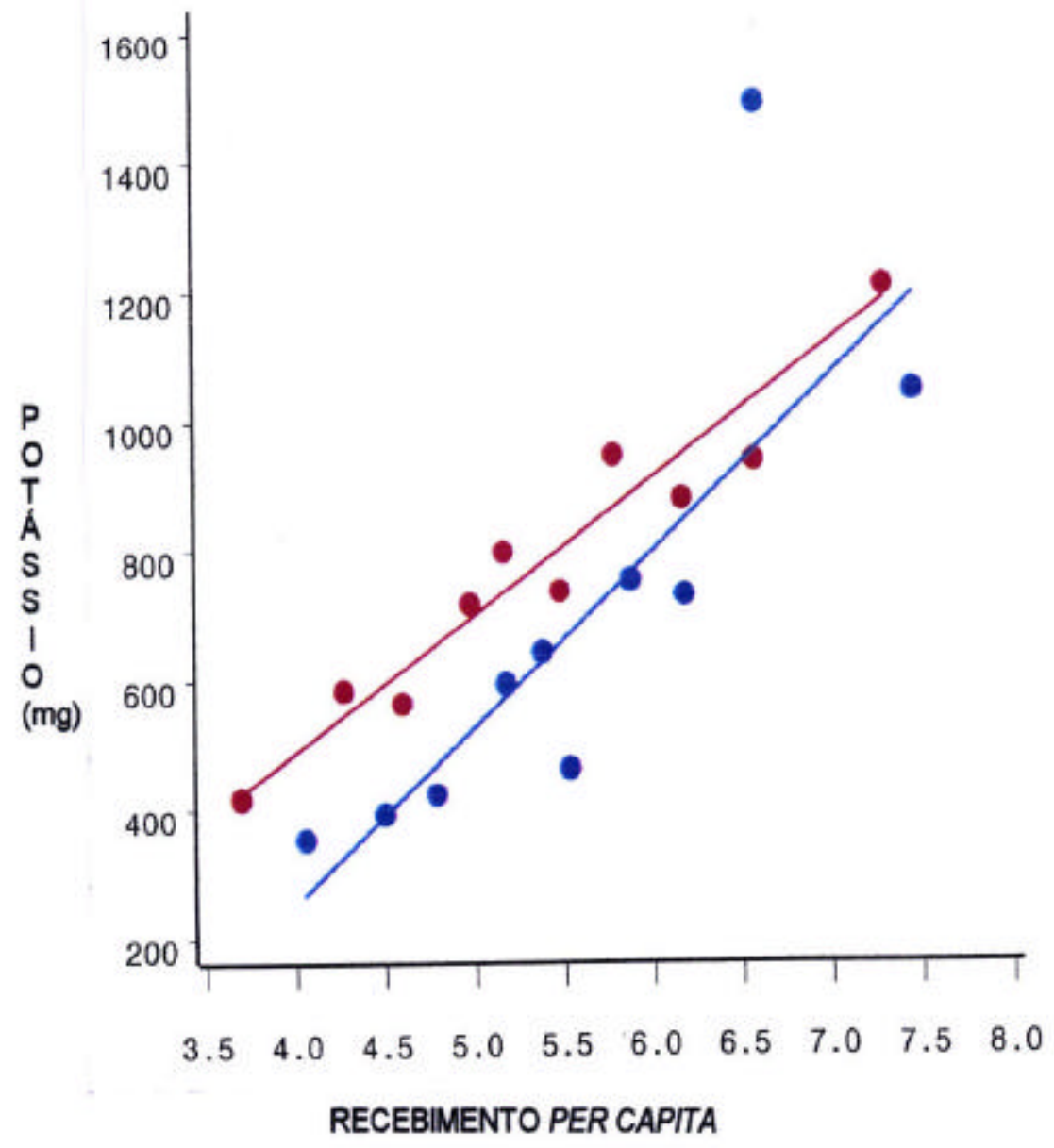

- Região Metropolitana de Recife

- Região Metropolitana de São Paulo

Figura 31 - Proporção de carboidratos, no valor energético total, de acordo com o recebimento familiar per capita e regiões metropolitanas de Recife e São Paulo. 


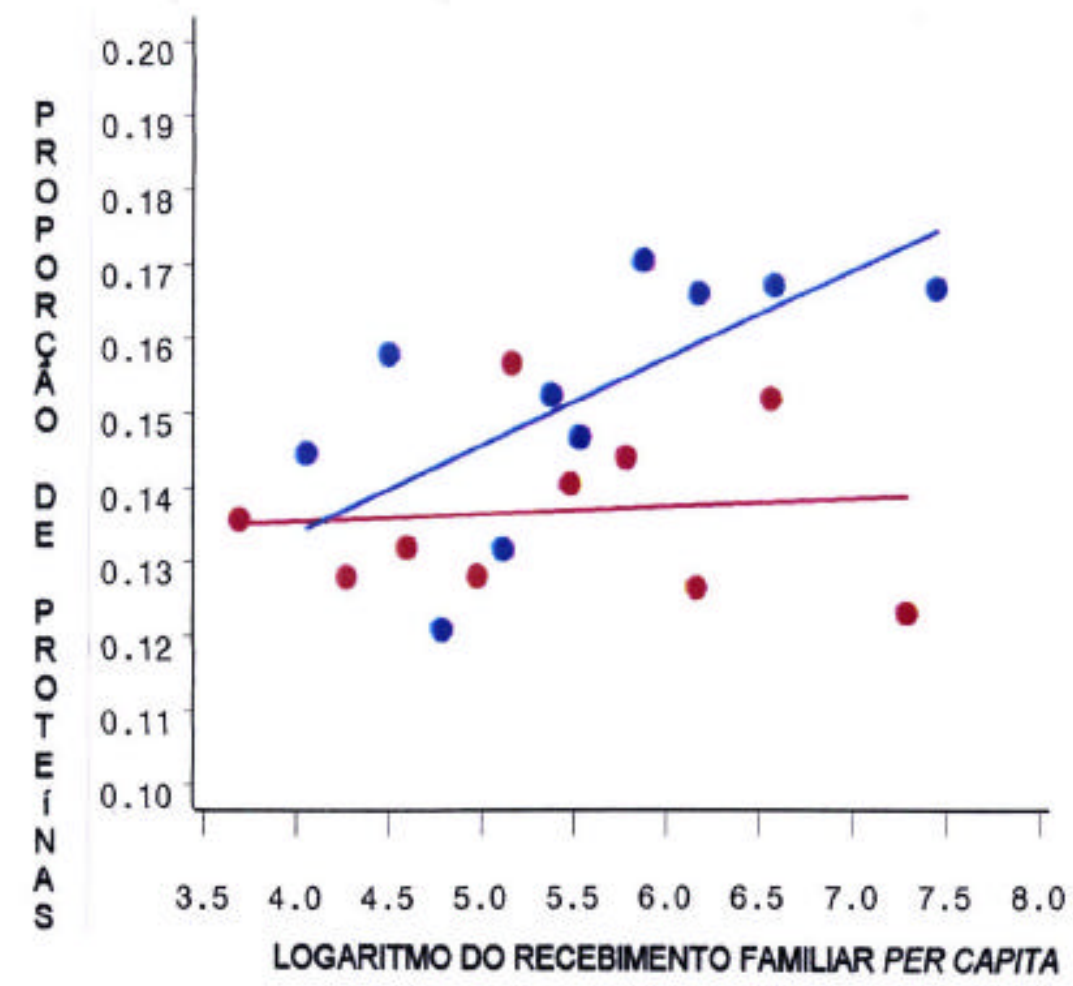

- Região Metropolitana de Recife

- Região Metropolitana de São Paulo

Figura 32 - Proporção de proteínas, no valor energético total, de acordo com o recebimento familiar per capita e regiões metropolitanas de Recife e São Paulo. 


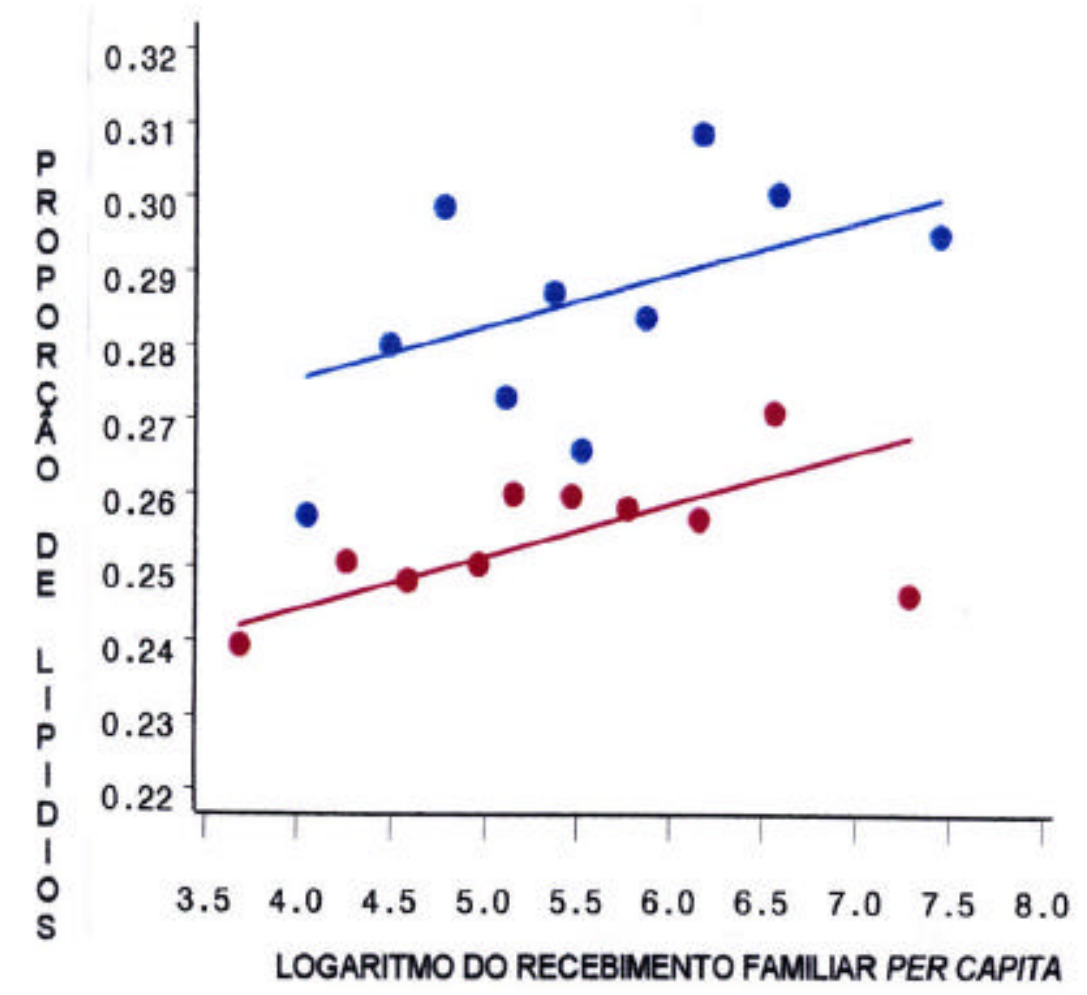

- Regiäo Metropolitana de Recife

- Regiăo Metropolitana de Săo Paulo

Figura 33 - Proporção de lipídios, no valor energético total, de acordo com o recebimento familiar per capita e regiões metropolitanas de Recife e São Paulo. 
A seguir apresenta-se as análises relativas à participação relativa de grupos de alimentos na disponibilidade de energia para indivíduos das duas regiões metropolitanas selecionadas. Visando a melhor interpretação dos resultados os dados foram organizados em três tabelas.

A Tabela 8 , mostrada a seguir, contém os dados relativos à população pertencente ao grupamento de famílias com renda inferior a dois salários mínimos.

Tabela 8. Participação relativa de grupos de alimentos na disponibilidade de energia para indivíduos das regiões metropolitanas de São Paulo e Recife, com rendimento familiar inferior a dois salários mínimos. 1995/1996.

\begin{tabular}{lcccc}
\hline \multirow{2}{*}{\multicolumn{1}{c}{ Grupos de Alimentos }} & \multicolumn{2}{c}{ São Paulo } & \multicolumn{2}{c}{ Recife } \\
\cline { 2 - 5 } & $\begin{array}{c}\text { Total de } \\
\text { Energia }\end{array}$ & $\%$ & $\begin{array}{c}\text { Total de } \\
\text { Energia }\end{array}$ & $\%$ \\
\hline Farinha, Fécula, Massas e Pães & 269,3 & 25,3 & 443,5 & 35,3 \\
Cereais & 220,0 & 20,7 & 113,0 & 9,0 \\
Açúcares e Refrigerantes & 116,7 & 11,0 & 202,0 & 16,1 \\
Óleos vegetais & 112,7 & 10,6 & 137,3 & 10,9 \\
Gordura animal & 1,7 & 0,2 & 4,3 & 0,3 \\
Leite e derivados & 112,2 & 10,5 & 59,0 & 4,7 \\
Carne (bovina) & 50,8 & 4,8 & 101,3 & 8,1 \\
Carne (aves) & 38,9 & 3,7 & 48,0 & 3,8 \\
Carne (suína) & 32,1 & 3,0 & 13,2 & 1,0 \\
Carne de outros animais & - & - & - & - \\
Coco, castanhas e nozes & - & - & 5,8 & 0,5 \\
Frutas & 26,5 & 2,5 & 24,6 & 2,0 \\
Hortaliças & 19,6 & 1,8 & 40,3 & 3,2 \\
Leguminosas & 19,1 & 1,8 & 30,9 & 2,5 \\
Ovos & 18,2 & 1,7 & 15,5 & 1,2 \\
Peixes & 5,3 & 1,3 & 8,4 & 0,7 \\
Cafés & 1,6 & 0,5 & - & - \\
Chás & 0,0 & 0,0 & 2,1 & 0,2 \\
Condimentos & 5,0 & 0,5 & 3,9 & 0,3 \\
Bebidas Alcoólicas & 0,0 & 0,0 & 2,5 & 0,2 \\
Bebidas não-alcoólicas & - & - & 0,6 & 0,0 \\
Alimentos preparados, misturas e outros & 14,3 & 1,3 & 0,8 & 0,1 \\
industriais & & & & \\
TOTAL & 1063,9 & 101,1 & 1256,8 & 100,0 \\
\hline
\end{tabular}

Nota: os traços significam que não foi observada participação do alimento no conteúdo de energia disponível. 
Tendo por base os dados da Tabela 8, observa-se que os grupos de alimentos que participam de maneira expressiva para a disponibilidade de energia são: as farinhas, fécula, massas e pães, os cereais, os açúcares e refrigerantes, os óleos vegetais, o leite e derivados e a carne bovina.

A participação do grupo integrado pelas farinhas, fécula, massas e pães na disponibilidade de energia é superior (cerca de 10\%) para os indivíduos da região metropolitana de Recife. Tal resultado possivelmente decorre dos hábitos alimentares da região nordeste do país onde o consumo, principalmente das farinhas, é tradicional.

Situação inversa é observada para os cereais, cuja participação alcança o valor de 20,7\% na região metropolitana de São Paulo enquanto na região de Recife a proporção é de 9,0\%.

Merece destaque também a participação do grupo integrado pelos açúcares e refrigerantes. O valor observado para Recife $(16,1 \%)$ é cerca de $65 \%$ superior ao observado para a região metropolitana de São Paulo $(11,0 \%)$.

Com relação à proporção de gordura animal é interessante notar que a participação é mais elevada para Recife, alcançando o percentual (embora reduzido, considerando o conjunto das informações) de $0,3 \%$, enquanto para a região metropolitana de São Paulo, o valor é menor, ou seja, 0,2\%.

Vale lembrar que neste trabalho foi considerado somente a disponibilidade de alimentos no âmbito doméstico. Contudo, tendo em vista as características da região metropolitana de São Paulo, é possível que o consumo de alimentos (entre os quais, o refrigerante) fora do domicílio seja maior, contribuindo para a elevação do percentual observado (11\%).

Surpreendentes também são os resultados verificados para a participação do leite e derivados, 10,5\% e 4,7\% no VET disponível para a população da região metropolitana de São Paulo e Recife, respectivamente.

Outro resultado que merece destaque é a participação da carne bovina no VET. Nota-se que para a população da região metropolitana de Recife, a referida participação é substancialmente maior $(8,1 \%)$ que o da região 
metropolitana de São Paulo (4,8\%), o que é surpreendente uma vez que se esperava que a participação da carne bovina fosse mais elevada na região mais rica. Todavia, cabe lembrar que essa análise considerou apenas o consumo domiciliar e, sendo o consumo de alimentos fora do domicílio possivelmente muito representativo na região de São Paulo, pode-se inferir que grande parte do consumo de carne é realizada freqüentemente fora do domicílio.

$\mathrm{Na}$ Tabela 9, observa-se os dados referentes à população pertencente ao grupamento com renda entre seis e oito salários mínimos.

Tabela 9. Participação relativa de grupos de alimentos na disponibilidade de energia para indivíduos das regiões metropolitanas de São Paulo e Recife, com rendimento familiar entre seis e oito salários mínimos. 1995/1996.

\begin{tabular}{|c|c|c|c|c|}
\hline \multirow[t]{2}{*}{ Grupos de Alimentos } & \multicolumn{2}{|c|}{ São Paulo } & \multicolumn{2}{|c|}{ Recife } \\
\hline & $\begin{array}{l}\text { Total de } \\
\text { Energia }\end{array}$ & $\%$ & $\begin{array}{l}\text { Total de } \\
\text { Energia }\end{array}$ & $\%$ \\
\hline Farinha, Fécula, Massas e Pães & 270,7 & 18,6 & 584,2 & 31,4 \\
\hline Cereais & 250,1 & 17,2 & 181,9 & 9,8 \\
\hline Açúcares e Refrigerantes & 189,7 & 13,0 & 254,1 & 13,7 \\
\hline Óleos vegetais & 173,3 & 11,9 & 205,0 & 11,0 \\
\hline Gordura animal & 0,3 & 0,0 & 7,7 & 0,4 \\
\hline Leite e derivados & 114,3 & 7,9 & 102,0 & 5,5 \\
\hline Carne (bovina) & 101,4 & 7,0 & 192,2 & 10,3 \\
\hline Carne (aves) & 63,5 & 4,4 & 70,1 & 3,8 \\
\hline Carne (suína) & 84,8 & 5,8 & 23,1 & 1,2 \\
\hline Carne de outros animais & 0,1 & 0,0 & 1,7 & 0,1 \\
\hline Coco, castanhas e nozes & - & - & 21,1 & 1,1 \\
\hline Frutas & 61,0 & 4,2 & 51,2 & 2,8 \\
\hline Hortaliças & 42,1 & 2,9 & 50,8 & 2,7 \\
\hline Leguminosas & 26,2 & 1,8 & 56,0 & 3,0 \\
\hline Ovos & 19,5 & 1,3 & 22,5 & 1,2 \\
\hline Peixes & 11,3 & 0,8 & 10,5 & 0,6 \\
\hline Cafés & 2,4 & 0,2 & 2,8 & 0,2 \\
\hline Chás & 0,0 & 0,0 & 0,1 & 0,0 \\
\hline Condimentos & 12,7 & 0,9 & 6,7 & 0,4 \\
\hline Bebidas Alcoólicas & 15,4 & 1,1 & 13,0 & 0,7 \\
\hline Bebidas não-alcoólicas & 1,9 & 0,1 & 0,4 & 0,0 \\
\hline $\begin{array}{l}\text { Alimentos preparados, misturas e outros } \\
\text { industriais }\end{array}$ & 14,1 & 1,0 & 2,5 & 0,1 \\
\hline TOTAL & 1454,9 & 100,0 & 1859,7 & 100,0 \\
\hline
\end{tabular}

Nota: os traços significam que não foi observada participação do alimento no conteúdo de energia disponível. 
Verifica-se que os grupos de alimentos que mais contribuem para a disponibilidade de energia são os mesmos observados para a faixa de renda abaixo de dois salários mínimos.

A participação do grupo de alimentos composto por farinha, fécula, massas e pães, é muito superior, quando se considera a região metropolitana de Recife (31,4\% contra 18,6\% para a região metropolitana de São Paulo). Quanto a disponibilidade de cereais verificado para a região metropolitana de São Paulo $(17,2 \%)$ nota-se que é praticamente o dobro da participação observada para a região metropolitana de Recife $(9,8 \%)$.

A análise da participação dos açúcares e refrigerantes também merece destaque, pois corresponde à cerca de $13 \%$ do VET. É interessante notar que para esse estrato de rendimento (entre seis e oito salários mínimos), o valor observado para as duas regiões apresenta-se praticamente igual (13,0 e 13,7 para a região metropolitana de São Paulo e Recife).

É interessante destacar que a disponibilidade de óleos vegetais se revela á praticamente igual para as duas regiões (11,9\% e 11,00 para a região metropolitana de São Paulo e Recife, respectivamente). Cabe observar também que o consumo de óleos vegetais parece ter substituído o consumo de gordura animal que apresenta contribuição praticamente insignificante (quase nula para a região metropolitana de São Paulo e $0,4 \%$ para a de Recife). Todavia nota-se que a participação da gordura animal na região de Recife é ligeiramente superior ao de São Paulo.

Assim como o observado para o estrato de rendimento mais baixo, a participação no VET do grupo do leite e derivados é superior na região metropolitana de São Paulo, cerca de 7,9\%, ainda que para esse estrato de rendimentos (de seis a oito salários mínimos) a diferença entre as duas regiões não seja substancial. O consumo de carne bovina, como o observado para os indivíduos pertencentes às famílias integrantes da faixa de renda de até dois salários mínimos é maior na região metropolitana de Recife $(10,3 \%)$ que na região metropolitana de São Paulo (7,0\%). 
Concluindo as análises, apresenta-se a Tabela 10, com os registros referentes à população pertencente ao grupamento com renda acima de trinta salários mínimos.

Tabela 10. Participação relativa de grupos de alimentos na disponibilidade de energia para indivíduos das regiões metropolitanas de São Paulo e Recife, com rendimento familiar superior a trinta salários mínimos. $1995 / 1996$.

\begin{tabular}{|c|c|c|c|c|}
\hline \multirow[b]{2}{*}{ Grupos de Alimentos } & \multicolumn{2}{|c|}{ São Paulo } & \multicolumn{2}{|c|}{ Recife } \\
\hline & $\begin{array}{l}\text { Total de } \\
\text { Energia }\end{array}$ & $\%$ & $\begin{array}{l}\text { Total de } \\
\text { Energia }\end{array}$ & $\%$ \\
\hline Farinha, Fécula, Massas e Pães & 370,8 & 21,0 & 625,0 & 27,7 \\
\hline Cereais & 181,1 & 10,3 & 151,4 & 6,7 \\
\hline Açúcares e Refrigerantes & 206,3 & 11,7 & 427,4 & 19,0 \\
\hline Óleos vegetais & 138,1 & 7,8 & 205,8 & 9,1 \\
\hline Gordura animal & 15,0 & 0,9 & 29,7 & 1,3 \\
\hline Leite e derivados & 231,1 & 13,1 & 246,4 & 10,9 \\
\hline Carne (bovina) & 157,2 & 8,9 & 36,3 & 1,6 \\
\hline Carne (aves) & 65,2 & 3,7 & 89,8 & 4,0 \\
\hline Carne (suína) & 67,0 & 3,8 & 9,0 & 0,4 \\
\hline Carne de outros animais & 2,9 & 0,2 & - & - \\
\hline Coco, castanhas e nozes & 10,7 & 0,6 & 6,2 & 0,3 \\
\hline Frutas & 111,1 & 6,3 & 141,2 & 6,3 \\
\hline Hortaliças & 52,0 & 3,0 & 105,6 & 4,7 \\
\hline Leguminosas & 11,9 & 0,7 & 47,5 & 2,1 \\
\hline Ovos & 21,2 & 1,2 & 37,4 & 1,7 \\
\hline Peixes & 15,0 & 0,9 & 12,5 & 0,6 \\
\hline Cafés & 3,4 & 0,2 & 3,4 & 0,2 \\
\hline Chás & 0,1 & 0,0 & 0,1 & 0,0 \\
\hline Condimentos & 13,0 & 0,7 & 21,7 & 1,0 \\
\hline Bebidas Alcoólicas & 23,4 & 1,3 & 38,3 & 1,7 \\
\hline Bebidas não-alcoólicas & 5,3 & 0,3 & 1,2 & 0,1 \\
\hline $\begin{array}{l}\text { Alimentos preparados, misturas e outros } \\
\text { industriais }\end{array}$ & 59,6 & 3,4 & 18,5 & 0,8 \\
\hline TOTAL & 1761,4 & 100,0 & 2254,4 & 100,0 \\
\hline
\end{tabular}

Nota: os traços significam que não foi observada participação do alimento no conteúdo de energia disponível.

Os alimentos que mais contribuem para a disponibilidade de energia para a faixa de renda acima de trinta salários mínimos são os mesmos dos demais estratos de renda, incluindo de maneira mais satisfatória o grupo das frutas (6,3\% para ambas as regiões metropolitanas). Vale lembrar que entre 0 
grupo de menor renda ( 2 s.m), a participação das frutas não ultrapassam 2,5 e 2,0\%, para São Paulo e Recife, respectivamente.

Quanto à participação das farinhas, fécula, massas e pães na dieta, nota-se que na região metropolitana de Recife $(27,7 \%)$, como já verificado para os demais estratos de rendimentos analisados, é superior ao de São Paulo $(21,0 \%)$.

Os cereais apresentam um valor mais elevado para São Paulo $(10,3 \%$ contra $6,7 \%$ para Recife).

Outro resultado semelhante aos observados para as outras duas faixas de rendimentos é o referente aos açúcares e refrigerantes. A participação dos mesmos na disponibilidade de energia é maior na região metropolitana de Recife (19\%) que na região metropolitana de São Paulo (11,7\%).

Quanto aos óleos vegetais, nota-se que a participação dos mesmos na disponibilidade de energia é ligeiramente maior na região metropolitana de Recife (9,1\%), enquanto em São Paulo é 7,8\%.

A participação de leite e derivados na disponibilidade de energia também é expressiva para famílias integrantes do estrato de renda acima de trinta salários mínimos, correspondendo a $13,1 \%$ na região metropolitana de São Paulo e 10,9\% na região metropolitana de Recife. Nota-se que, como o verificado para as demais faixas analisadas, ela é maior para a região mais rica.

A carne bovina apresenta, para este estrato de renda, uma participação expressiva apenas para a região metropolitana de São Paulo (8,9\%), pois, para a região metropolitana de Recife, sua participação na disponibilidade de energia da dieta pode ser considerada muito baixa $(1,6 \%)$. No entanto, lembra-se que não está sendo contabilizado o consumo fora do domicílio.

Outro resultado que merece destaque é a participação das frutas na disponibilidade de energia, 6,3\% tanto para São Paulo quanto para Recife. Esta substancial participação não foi observada para os outros dois estratos de rendimentos analisados, o que indica que a população que dispõe de maior renda têm maior acesso à aquisição e consumo de frutas. Esse resultado é 
muito positivo, pois sabe-se que as frutas são ricas em fibras, vitaminas e minerais e sua participação na pauta alimentar diária contribuí de forma inquestionável para a maior adequação do estado nutricional dos indivíduos de todas as faixas etárias.

Os resultados obtidos estão de acordo com os dados observados na revisão bibliográfica, ou seja, verificou-se o aumento da disponibilidade de proteínas de origem animal e gorduras bem como a diminuição da disponibilidade de proteínas de origem vegetal, carboidratos complexos e fibras.

Observou-se que, de uma maneira geral, os alimentos que mais contribuem para o VET são os dos seguintes grupos: farinhas, fécula, massas e pães, cereais, açúcares e refrigerantes, óleos vegetais, leite e derivados e carne bovina. Com destaque para a expressiva participação das frutas no VET de indivíduos do estrato de recebimento mais elevado.

Os referidos resultados parecem consolidar as análises que revelam a tendência de adoção de um padrão de alimentação,também identificada por alguns pesquisadores da área que, mais recentemente, passou a ser conhecido como "o padrão ocidental de alimentação". 


\section{CONCLUSÕES}

As análises elaboradas nesta dissertação mostraram que a renda é um importante condicionante da disponibilidade de alimentos e também,da participação diferenciada dos grupos de alimentos no valor energético total das dietas (VET) da população das regiões metropolitanas de São Paulo e Recife. Corrobora essa última afirmação a observação de que as frutas têm maior participação no valor energético da dieta da população de renda mais elevada de Recife e São Paulo. Quando foram consideradas as famílias, pertencentes aos três estratos de renda ( menor que 2 ; entre seis e oito; e acima de 30 salários mínimos), verificou-se maior disponibilidade média de energia nos domicílios das famílias da região metropolitana de Recife, quando comparada com a situação das famílias,com os mesmos níveis de renda da região metropolitana de São Paulo.

Ficou evidente,também que quando se considerou as informações relativas aos estratos de recebimento das famílias da região metropolitana de Recife, verificou-se maior disponibilidade de proteínas no domicílio, quando comparada à realidade encontrada para a região metropolitana de São Paulo. Situação inversa foi observada quando se considerou os dados obtidos junto æ̀ famílias pertencentes aos estratos mais elevados de rendimentos.Verificou-se ainda que, nos domicílios de famílias ,consideradas mais ricas, de maneira geral, os valores médios encontrados para a disponibilidade de proteína nos domicílios superam æ̀̀ recomendações preconizadas por agências internacionais e nacionais, como por exemplo, para indivíduos adultos. 
Quando se considerou a participação da proteína de alto valor biológico, observou-se para as duas regiões metropolitanas selecionadas, uma elevada disponibilidade de proteína de origem animal no domicílio, superando o valor recomendado, principalmente quando foram considerados os estratos de recebimentos mais elevados.

A participação dos lipídios no conteúdo total de energia revelou tendência de crescimento conforme 0 recebimento nas duas áreas metropolitanas analisadas.Para um mesmo nível de recebimento, essa participação foi mais alta em São Paulo do que em Recife. As análises estatísticas mostraram que a participação dos lipídios no total de energia disponível foi substancialmente mais elevada em São Paulo.

A disponibilidade de fibras aumenta conforme se eleva a renda, entretanto é ainda baixa nos domicílios de famílias de São Paulo e Recife, não atingindo o limite mínimo recomendado. Esse resultado é preocupante, devido ao fato das fibras exercerem reconhecido e, praticamente, insubstituível papel para a proteção do organismo contra diversas doenças crônico-degenerativas.

Quanto à disponibilidade dos minerais zinco e selênio enfatiza-se que a mesma se revelou-se abaixo dos valores médios recomendados para as famílias das duas regiões analisadas. Situação também indesejável foi verificada para a disponibilidade do ferro. Esses resultados são preocupantes tendo em vista a importância desses minerais para o crescimento, desenvolvimento e proteção dos indivíduos contra doenças crônicodegenerativas.

Quando se considerou a disponibilidade de cálcio no domicílio, os resultados mostraram que os valores médios se situaram muito abaixo do mínimo preconizado.Para as famílias da região metropolitana de Recife a situação se revelou ligeiramente mais favorável que aquela encontrada para os grupamentos da região metropolitana de São Paulo.

Observou-se que é possível que hábitos regionais exerçam forte influência no consumo alimentar da população. $O$ resultado foi muito evidente 
quando se considerou, por exemplo, o grupo das farinhas. Esse grupamento teve uma participação muito superior para o valor energético total das dietas da população moradora da região metropolitana de Recife (região nordeste do país).

Para a região metropolitana de Recife a disponibilidade dos alimentos do grupo dos açúcares e refrigerantes, do grupo da gordura animal e também da carne bovina, mostrou-se maior em relação àquela observada para as famílias dos indivíduos da região metropolitana de São Paulo, quando maior atenção foi dedicada ’̀ análises dos três grupamentos de renda (inferior a 2 ; entre seis e oito ; e maior que 30 salários mínimos). Quanto ao grupo do leite observouse uma maior contribuição do alimento para o valor energético total-VET disponível para as famílias da região metropolitana de São Paulo.

Quanto à participação relativa de grupos de alimentos na disponibilidade de energia, para o estrato de recebimento intermediário (entre seis e oito salários mínimos), foi observada diferença, especialmente no que tange a maior participação açúcares e refrigerantes que se mostrou mais elevada ( de forma distinta da observada no primeiro estrato de renda) para a região metropolitana de São Paulo.

Findas as considerações sobre os resultados, vale registrar que as análises da presente pesquisa não envolveram informações sobre o conteúdo de energia e nutrientes obtidos pelas famílias por meio do consumo fora do domicílio. Vale ressaltar ainda que, especialmente ras regiões metropolitanas, particularmente no caso de São Paulo não é desprezível o conteúdo nutricional obtido por parcela da população por meio do acesso aos programas institucionais, como por exemplos o programa de alimentação escolar e o programa de alimentação do trabalhador-PAT. 


\section{REFERÊNCIAS BIBLIOGRÁFICAS}

ABREU, E.S. Restaurante "por quilo": vale quanto pesa? Uma avaliação do padrão alimentar em restaurantes de Cerqueira César, São Paulo, S.P. São Paulo, 2000. 75p. Dissertação (Mestrado) - Faculdade de Saúde Pública, Universidade de São Paulo.

ANDRADE, T. Reforma agrária, segurança alimentar e desenvolvimento rural. In: TAKAGI, M.; SILVA, J.G. da; BELIK, W. Combate à fome e à pobreza rural. São Paulo: Instituto da Cidadania, 2002. p.199-218.

BARROS, A.L.M. O nível nutricional do brasileiro melhorou nos últimos anos. Notesalq, n.14, p.4, ago. 1996.

BERTASSO, B.F. O consumo alimentar em regiões metropolitanas brasileiras: análise da Pesquisa de Orçamentos Familiares/IBGE 1995/96. Piracicaba, 2000. 109p. Dissertação (Mestrado) - Escola Superior de Agricultura "Luiz de Queiroz", Universidade de São Paulo.

BLEIL, S.I. O padrão alimentar ocidental: considerações sobre a mudança de hábitos no Brasil. Cadernos de Debate, v.6, p.1-24, 1998.

BOURGES, H. Costumbres, practicas y habitos alimentarios deseables e indeseables. Archivos Latinoamericanos de Nutricion, v.38, n.3, p.767779, Set.1988. 
CAMPOS, M.T.F.S.; MONTEIRO, J.B.R.; ORNELO, A.P.R.C. Fatores que afetam o consumo alimentar e a nutrição do idoso. Revista de Nutrição, v.13, n.3, p.157-165, set./dez. 2000.

CASTRO, P.F.; MAGALHÃES, L.C.G. Recebimento e dispêndio das famílias brasileiras: evidências recentes da Pesquisa de Orçamentos Familiares (POF) - 1995/1996. Brasília: IPEA, 1998. 37p. (Texto para discussão, 614)

DEAN, A.G.; DEAN, J.A.; BURTON, A.H. et al. Epi Info, version 5: a word processing, database, and statistics program for epidemiology on microcomputers (software). Atlanta: Center for Diseases Control, 1990.

DELGADO, G.C. Projeto fome zero: a política da previdência rural. In: TAKAGI, M.; SILVA, J.G. da; BELIK, W. Combate à fome e à pobreza rural. São Paulo: Instituto da Cidadania, 2002. p.179-197.

DREWNOWSKI, A.; POPKIN, B.M. The nutrition transition: new trends in the global diet. Nutrition Reviews, v.55, n.2, p.31-43, Feb. 1991.

DUTRA-DE-OLIVEIRA, J.E.; MARCHINI, J.S. Macrominerais. Ciências nutricionais. São Paulo: Sarvier, 1998. cap.8, p.133-139.

DWYER, J. Dietary fiber and colorectal cancer risk. Nutrition Reviews, v.51, n.5, p.147-155, May 1993.

FACULDADE DE CIÊNCIAS FARMACÊUTICAS. Tabela brasileira de composição de alimentos: projeto integrado de composição de alimentos. http:/www.fcf.usp.br/tabela/tbcamenu.php (10 jul. 2001) 
FAIRBANKS, V.F. Iron in medicine and nutrition. In: SHILS, M.E.; OLSON, J.A.; SHIKE, M. Modern nutrition in health and disease. 8.ed. Philadelphia: Lea \& Febiger, 1994. v.1, cap.9, p.185-213.

FARFAN, J.A.; DOMENE, S.M.A.; PADOVANI, R.M. Síntese comentada das novas propostas sobre recomendações nutricionais para antioxidantes. Revista de Nutrição, v.14, n.1, p.71-78, 2001.

FELIPE, M.R.; DEOLINDO, J.P.; MAFRA, D. et al. Manipuladores de alimentos portadores de Salmonella spp: implicações na produção de alimentação coletiva. Higiene Alimentar, v.9, n.40, p.18-20, nov./dez. 1995.

FRANCO, G. Tabela de composição química dos alimentos. 9.ed. São Paulo: Atheneu, 1992. 307p.

GALEAZZI, M.A.M.; DOMEME, S.M.A.; SICHIERI, R. Estudo multicêntrico sobre consumo alimentar. Cadernos de Debate, v.7, p.11-67, v.esp., 1997.

GUERRA, A; CAZZUNI, D.H. O comportamento do Programa de Alimentação do Trabalhador no Brasil durante os anos 90. Colaboração para o programa Fome Zero. In: Projeto Fome Zero: uma proposta de política de segurança alimentar para o Brasil. São Paulo: Instituto de Cidadania, Fundação Djalma Guimarães, 2001. 118p.

HOFFMANN, R. A diminuição do consumo de feijão no Brasil. In: REUNIÃO DO CONSÓRCIO DAS INSTITUIÇÕES BRASILEIRAS DE ALIMENTAÇÃO E NUTRIÇÃO, São Paulo, 1995. Anais. São Paulo: CIBRAN, 1995. p.6-15. 
INSTITUTO BRASILEIRO DE GEOGRAFIA E ESTATÍSTICA - IBGE. Estudo nacional das despesas familiares - ENDEF: 1974/1975. Rio de Janeiro,1978.

INSTITUTO BRASILEIRO DE GEOGRAFIA E ESTATÍSTICA - IBGE. Estudo nacional das despesas familiares: tabelas de composição de alimentos. 2.ed. Rio de Janeiro, 1981. 213p.

INSTITUTO BRASILEIRO DE GEOGRAFIA E ESTATíStICA - IBGE. Pesquisa de orçamentos familiares 1987/1988: consumo alimentar domiciliar per capita. Rio de Janeiro, 1992. 3v.

INSTItUTO BRASILEIRO DE GEOGRAFIA E EStATíStICA - IBGE. Pesquisa de orçamentos familiares 1995/1996: consumo alimentar domiciliar per capita. Rio de Janeiro, 1998. 3v.

INSTITUTO BRASILEIRO DE GEOGRAFIA E ESTATÍSTICA - IBGE. Programa nacional por amostra de domicílios 1999. Rio de Janeiro, 1999. v.21. p.1-113.

LERNER, B.R. A alimentação e a anemia carencial em adolescentes. São Paulo, 1994. 90p. Tese (Doutorado) - Faculdade de Saúde Pública, Universidade de São Paulo.

LICHTENSTEIN, A.H.; KENNEDY, E.; BARRIER, P. et. al. Dietary fat consumption and health. Nutrition Reviews, v.56, n.5, p.S3-S28, May 1998.

MARTINS, E. Variações no consumo de alimentos no Brasil de 1974/75 a 1987/88. Piracicaba, 1998. 117p. Dissertação (Mestrado) - Escola Superior de Agricultura “Luiz de Queiroz”, Universidade de São Paulo. 
MENEZES, T.; SILVEIRA, F.G.; MAGALHÃES, L.C.G. et al. Gastos alimentares nas grandes regiões urbanas do Brasil: aplicação do modelo AID aos microdados da POF 1995/1996 IBGE. Brasília: IPEA, jul. 2002. (Textos para discussão, 896)

MOLINA, M.C.B.; GROSS, R.; SCHELL, B. et al. Nutritional status of children of urban low income communities, Brasil (1986). Revista de Saúde Pública, v.23, n.2, p.97-101, 1989.

MONDINI, L.; MONTEIRO, C.A. Mudanças no padrão de alimentação da população urbana brasileira: 1962-1988. Revista de Saúde Pública, v.28, n.6, p.433-439, 1994.

MONDINI, L.; MONTEIRO, C.A. Mudanças no padrão de alimentação. In: MONTEIRO, C.A. (Org.). Velhos e novos males da saúde no Brasil: a evolução do país e suas doenças. São Paulo: HUCITEC, 1995. p.79-89.

MONTEIRO, C.A. Transição democrática e fome no país está no fim, afirma especialista da USP. Folha de São Paulo, São Paulo, 30 out. 2002. p.10C.

MÓRON, C. Opciones y desafíos para a seguridad alimentaria de América Latina y el Caribe. Roma: FAO, 1996. Documento para la Cumbre Mundial de la Alimentacion.

NATIONAL ACADEMY OF SCIENCES. Institute of Medicine. Food and Nutrition Board. Dietary reference intakes of energy, carbohidrates, fiber, fat, protein and amino acids (macronutrientes). Washington: National Academy Press, 2002. 963p. http://www.nap.edu (31 Oct. 2002) 
NATIONAL RESEARCH COUNCIL. National Academy of Sciences. Food and Nutrition Board. Recommended dietary allowances. 10.ed. Washington: National Academy Press, 1989.

NAVARRO, A. Composición de ácidos grasos saturados e insaturados em alimentos de consumo frequente na Argentina. Archivos Latinoamericanos de Nutricion, v.47, n.3, p.276-281, Set.1997.

ORGANIZAÇÃO MUNDIAL DE SAÚDE. Elementos-traço na nutrição e saúde humana. São Paulo: Roca, 1998. 297p.

PHILIPPI, S.T.; SARFARC, S.C.; LATTERZA, A.R. Virtual Nutri. versão 1.0 for Windows (software). São Paulo: Universidade de São Paulo, Faculdade de Saúde Pública, Depto. de Nutrição, 1996.

PHILIPPI, S.T; COLUCCI, A.C. São Paulo. In: FISBERG, M.; WEHBA, J.; COZZOLINO, S.M.F. (Org.). Um, dois, feijão com arroz: a alimentação no Brasil de norte a sul. São Paulo: Atheneu, 2002. cap.9, p.211-229.

POSNER, B.M.; FRANZ, M.; QUATROMONI, P. Nutrition and the global risk for chronic diseases: the interhealth nutrition initiative. Nutrition Reviews, v.52, n.6, p.201-207, June 1994.

POURCHET-CAMPOS, M.A. Fibra dietética. In: DUTRA-DE-OLIVEIRA, J.E.; MARCHINI, J.S. Ciências nutricionais. São Paulo: Sarvier, 1998. cap.12, p.209-215: Fibra dietética.

ROCHA, S. As pesquisas nacionais sobre consumo no Brasil: objetivos e aplicações. In: Consumo alimentar: as grandes bases de informação. São Paulo: Instituto Danone, 1999. p.11-17. 
ROSA, A.L.C da.; FERREIRA, A.R.N.; MARTINS, E. et al. Da terra nua ao prato cheio: produção para consumo familiar nos assentamentos rurais do Estado de São Paulo. São Paulo: Fundação Instituto de Terras do Estado de São Paulo, Diretoria Adjunta de Políticas de Desenvolvimento e Gerência de Desenvolvimento Humano, Grupo de Sócio-Economia, 2001. $81 \mathrm{p}$.

SAMPAIO, M. de .F.A. Análise comparativa do consumo de alimentos: América Latina e União Européia. Campinas, 2001. 74p. Dissertação (Mestrado) Faculdade de Engenharia Agrícola, Universidade Estadual de Campinas.

SANTOS, T.M. Lipídeos. In: DUTRA-DE-OLIVEIRA, J.E.; MARCHINI, J.S. Ciências nutricionais. São Paulo: Sarvier, 1998. cap.5, p.87-97: Lipídeos.

SAS INSTITUTE. The SAS system (software). Version 6. Cary, 1996.

SENAUER, B.; SAHN, D.; ALDERMAN, H. The effect of value of time on food comsuption patterns in developing contries: evidence from Sri Lanka. American Journal of Agricultural Economics, v.68, n.4, p.920-927, 1986.

SILVA, E.N. Pesquisa de orçamentos familiares: características gerais. In: Consumo alimentar: as grandes bases de informação. São Paulo: Instituto Danone, 1999. p.39-45.

SILVA, M.V. Estado nutricional de escolares matriculados em Centros Integrados de Educação Pública - CIEP's. São Paulo, 1996. 103p. Tese (Doutorado) - Faculdade de Saúde Pública, Universidade de São Paulo. 
SILVA, M.V.; STURION, G.L.; OMETTO, A.M.H. et al. Estado nutricional de escolares e seu acesso a programas em dez municípios brasileiros. Nutrire, 2002. /No prelo/

UCHIMURA, T.T. Anemia e desnutrição em escolares ingressantes nas escolas estaduais de Maringá, Paraná. São Paulo, 1994. Dissertação (Mestrado) - Faculdade de Saúde Pública, Universidade de São Paulo.

VANNUCHI, H.; MENEZES, E.W.; CAMPANA, A.O. et al. Aplicações das recomendações nutricionais adaptadas à população brasileira. São Paulo: Sociedade Brasileira de Alimentação e Nutrição, 1990. 115p. 